\title{
Etnobotánica y Percepción del Paisaje en Caspana (Provincia de El Loa, Región de Antofagasta, Chile): ¿Una cuña atacameña en el Loa Superior?*
}

\author{
Carolina Villagrán**, Victoria Castro*** y Gilberto SÁncheZ**** \\ A la memoria de Don Julián Colamar, sabio caspaneño. \\ Un homenaje a sus enseñanzas.
}

\section{RESUMEN}

Los antecedentes de la literatura han destacado a la comunidad de Caspana como un ejemplo de interacción de las tradiciones atacameña y altiplánica, en los Andes de la Región de Antofagasta. En este trabajo nos hemos propuesto evaluar esta hipótesis, sobre la base de la nomenclatura botánica, etnoclasificación y utilización de las plantas que manejan los pobladores de esta comunidad. Específicamente, nuestros objetivos fueron: 1.- Recopilar y analizar los nombres y usos de las especies de plantas andinas de la región, los sistemas de etnoclasificación y la conceptualización del paisaje que tienen los caspaneños; 2.Dilucidar, hasta donde sea posible, las lenguas nativas utilizadas en los nombres vernaculares de plantas y paisajes.

La metodología consistió, en una primera etapa, en una excursión de colecta de la flora y entrevistas con 15 pobladores de Caspana, considerando

\footnotetext{
* $\quad$ Proyecto FONDECYT 1970908

** Laboratorio de Palinología, Departamento de Biología, Facultad de Ciencias, Universidad de Chile, Casilla653, Santiago, Chile.E-mail: cvillagr@uchile.cl Departamento de Antropología, Facultad de Ciencias Sociales, Universidad de Chile, Casilla 10115, Santiago, Chile.E-mail: vcastro@uchile.cl

Departamento de Linguística, Facultad de Filosofía, Universidad de Chile, Santiago, Chile. E-mail: gsanchez@uchile.cl
}

preguntas acerca de los nombres vernaculares y usos de 142 especies de plantas, tanto silvestres como malezas, además de conceptos relacionados con la percepción del paisaje vegetal. En una segunda etapa, se realizó una entrevista más amplia a Don Julián Colamar, profundo conocedor de su entorno y las costumbres de los caspaneños, con preguntas acerca de la naturaleza, cultura y lenguas, además de consultas específicas sobre algunos taxa particularmente significativos.

De las 142 especies consultadas, se registraron nombres vernaculares para 130 de ellas $(91.5 \%)$. Los nombres provienen, básicamente, del español y de los idiomas quichua y aymara. En lo que respecta a la utilización, 115 especies $(81 \%)$ resultaron ser aprovechadas para distintos fines, preferentemente para forraje y medicina. Varios de los nombres registrados corresponden a etnocategorías genéricas, y se refieren a grupos de taxa relacionados, ya sea por "parentesco" morfológico o por compartir formas de crecimiento similares. Este tipo de etnoclasificación, morfofisionómica, no difiere de las descritas para otras regiones del Loa superior, y, en general, para los Andes del norte de Chile.

En lo referente a la percepción de paisajes, los caspaneños reconocen distintas unidades etnoecológicas, de acuerdo a diferentes criterios, como, por ejemplo, posición en la gradiente altitudinal, geomorfología, características fitosociológicas y fisionómicas de la vegetación, hábitat de humedales, etc. (e.g. Hoyadas, Filos, Mesones, Corrales, Chanal, Aguadas, Vegas, 
etc.). Además, tal como en otras comunidades del Loa Superior, integran estas unidades etnoecológicas en tres grandes sectores de paisaje, definidos por su utilización agropastoril: Campo, Cerro y Chakra. Las subunidades paisajísticas del Campo, Campo-Khaner y Campo-Q'ulmor, son conceptualizaciones singulares de los caspaneños, y han sido registradas por primera vez en los Andes chilenos.

Los resultados obtenidos en Caspana permiten concluir que, tanto la nomenclatura botánica, como los sistemas de etnoclasificación, percepción del paisaje y modo de utilización de la flora, son compartidos con otras comunidades del Loa Superior y exhiben, en general, los rasgos lingüísticos descritos para la llamada Tradición Altiplánica. Sin embargo, los nombres de localidades conservados en la memoria de un sabio informante son, probablemente, fonemas kunza y/o de otras de las lenguas originarias de la región, que no son aymara ni quichua. Este registro plantea interrogantes acerca de las posibles relaciones del Loa Superior con la Tradición Atacameña o del Desierto, y/o con otras culturas que dominaron la región surandina en tiempos prehispánicos.

\section{ABSTRACT \\ To the memory of Don Julián Colamar, a caspanian wiseman. A Homage to his teachings.}

When considering bibliographic antecedents, the community of Caspana is conspicuous as an example of interactions between the Atacameñan and altiplano traditions, in the Andes of the Region of Antofagasta. In this paper we propose to evaluate this hypothesis based on the botanical nomenclature, ethnoclassifications and utilization of the plants used by the people of this community. Specifically our objectives were to: 1.- compile and analyze the names of the species of Andean plants of the region, as well as the ethnoclassification and Caspanian conceptualization of landscapes; 2.- derive, to the extent possible, the native languages used in the vernacular names of plants and landscape.

Our first phase of methodology consisted of field work, with plant collections and local interviews of 15 inhabitants from Caspana, using questions that considered the vernacular names and uses of 142 species of wild plants and weeds, as well as the concepts related with how these people perceived the vegetal landscape. In a second phase, we obtained a more general interview with an excellent Caspanian person (Don Julián Colamar), with questions regarding nature, culture and language, as well as utilization techniques of some very important taxa.

Of the 142 species consulted, we obtained 130 vernacular names $(91.5 \%)$. These names come basically from Spanish and from the Quichua and Aymara languages. Regarding uses, 115 species $(81 \%)$ were used in one way or another, preferably for fodder and medicine. Several names recorded correspond with generic ethnocategories, and they refer to groups of systematically related taxa, based on morphological "affinities" or because they share similar growth forms. This type of morphophysionomical ethnoclassification does not differ from others described for the Upper Loa river, and in general, from those of the Andes of northern Chile.

Regarding landscape perceptions, Caspanians recognize different ethnoecological units, based on different criteria, such as for example, position along an altitudinal gradient, geomorphology, phytosociological and physionomical characteristics of the vegetation, swampy habitats, etc. (e.g. Hoyadas, Filos, Mesones, Corrales, Chanal, Aguadas, Vegas, etc.). Like other communities of the Upper Loa, they integrate these ethnoecological units into three large landscape sectors, defined by their agro-pastoral uses and called Campo, Cerro and Chakra although the landscape subunits of Campo: Campo-Khaner and Campo-Q'ulmor, are unique conceptualizations recorded here for the first time in the Andes.

The results obtained in Caspana allow us to conclude that in botanical nomenclature as well as ethnoclassification systems, landscape perceptions, and modes of utilization of the flora are shared with other communities of the Upper Loa, and they exhibit, in general, linguistic features described as the Altiplano Tradition. Nevertheless, the locality names conserved in the memory of a wise informer, are most likely Kunza phonemes or from other languages originating in this region 
that are not Aymara or Quichua. This record sets the ground for other questions regarding the possible relationships of the Upper Loa culture with the Atacameño culture of the desert and/or with other cultures that dominated the south Andean region in prehispanic times.

\section{Introducción}

Caspana es una comunidad precordillerana, situada a 91 km. de la ciudad de Calama, en la Región de Antofagasta, Provincia del El Loa, Subregión del río Salado, principal afluente del río Loa. Está localizada a $3260 \mathrm{msnm}$ y entre las coordenadas $22^{\circ} 20^{\prime} \mathrm{S}$ y $68^{\circ} 18^{\prime} \mathrm{W}$ (Fig. 1). Climáticamente, queda comprendida dentro de la zona de "desierto marginal de altura". En este sector, las precipitaciones permiten la existencia de una vegetación de escasa cobertura pero permanente, estructurada básicamente por semidesiertos arbustivos (Tolar) y estepas de Gramíneas con cojines (Pajonal), además de pequeñas formaciones azonales de Vegas.

A diferencia de las restantes localidades de la Subregión de río Salado, la presencia de indígenas originarios de Lipez parece ser mucho menor en esta comunidad, al menos durante la colonia. Se ha documentado, en cambio, el desplazamiento de caspaneños hacia el altiplano de Lipez, hecho no registrado para Ayquina y los demás asentamientos del Loa Superior. Lingüísticamente, algunos informantes señalan que en Caspana se hablaba fundamentalmente el kunza y no el quichua, rasgo que sugiere también posibles diferencias étnicas entre esta población y las restantes de la Subregión Río Salado (Aldunate \& Castro, 1981). No obstante que sabemos que en esta región se habló el quichua y el aymara, no deja de ser significativo que en Caspana se haya conservado la letra, probablemente en kunza, del kausulor, un canto empleado en la ceremonia de limpia de acequias, situación solo comparable al de otras comunidades del Salar de Atacama, pero más bien única en la cuenca del Salado (Castro, 1997).

La percepción actual de los pobladores de Toconce y Ayquina denota a los caspaneños como diferentes, en varias conductas, pero, particularmente, los nombran como descendientes directos de los gentiles, un término de origen español, usado para referirse a la población prehispánica no bautizada; estos gentiles pertenecen, en el ordenamiento local de las "edades del mundo", a la "generación de Rey Inka" y sus antecesores (Castro \& Martínez, 1996). Estas diferencias, entre Caspana y las restantes comunidades del Loa Superior, parecen ser significativas en varios otros aspectos. Así, por ejemplo, Caspana mantiene, tradicionalmente, una relación bastante hermana con el pueblo de Río Grande, hacia el Salar de Atacama. Pareciera que entre ambas comunidades hubiera nexos de parentesco desde antiguo y estas relaciones podrían llegar a explicar esta especie de "cuña de lengua kunza" en la Subregión de río Salado. Caspana se singularizaría, así, por una forma cultural propia, con elementos de la Tradición del Desierto (Salar de Atacama) y de la Tradición Altiplánica (Subregión río Salado, dentro de la Ecozona de quebradas altas y altiplano de la región del Loa Superior) (Castro \& Martínez, 1996; Castro, 1997).

Con el propósito de contribuir al registro de las singularidades lingüísticas de la comunidad de Caspana, en este trabajo se analiza el conocimiento y utilización de la flora silvestre y advena de los caspaneños, con especial énfasis en las lenguas nativas utilizadas en los nombres vernaculares de plantas y en las etnocategorías de paisajes.

\section{Flora y vegetación, metodologías y resultados}

La herborización de la flora zonal y la descripción de las grandes unidades de vegetación de la región de estudio, fue realizada sobre la base de un transecto altitudinal, cuyo trayecto va desde la Quebrada de Caspana hasta el área del Alto Ojo de Q'aulor y Volcán Tatio (Fig. 1), entre 3100 y $4450 \mathrm{~m}$ de altitud, y entre las latitudes $22^{\circ} 15^{\prime}$ $22^{\circ} 30^{\prime} \mathrm{S}$. Adicionalmente, también se realizaron colecciones de la flora azonal de quebradas y de la flora advena de las chacras, principalmente en la quebrada del río Caspana. La flora azonal de humedales fue muestreada en todas las estaciones encontradas, a lo largo del gradiente altitudinal utilizado en la herborización de la flora zonal, específicamente en las vegas del río Caspana y río Salado (3100 m), en la Vega de Chita (3700 $\mathrm{m})$, en la Vega de Jauna y en la Vega del géiser Tatio (4200 m). En la Fig. 1 se muestra la situa- 


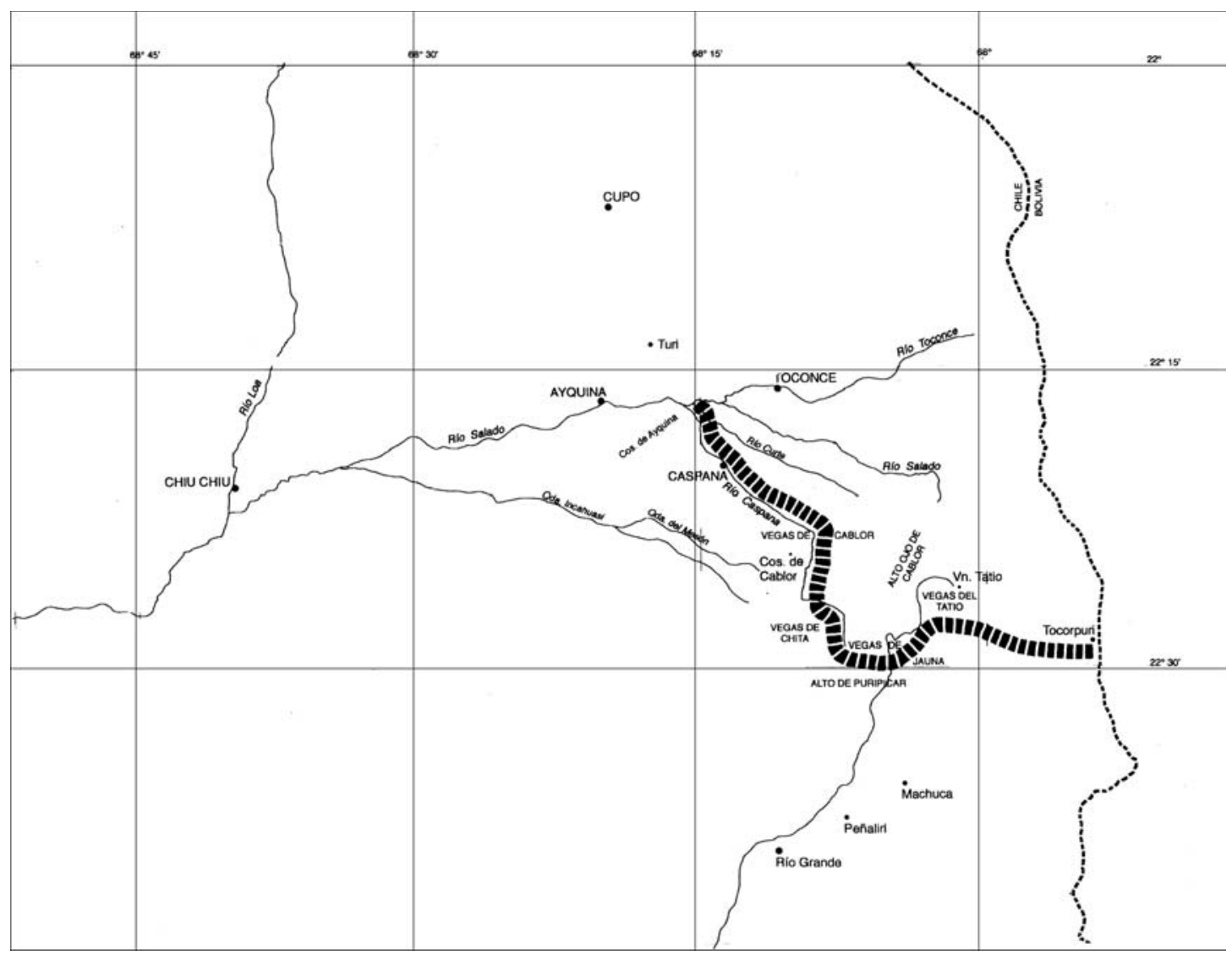

Fig. 1: Región de estudio mostrando la región del Loa Superior, la localidad de Caspana y la trayectoria del transecto (Caspana-Q'aulor-Tatio) para el muestreo altitudinal de la vegetación.

ción geográfica de la localidad de estudio, vegas y quebradas visitadas, y la trayectoria del transecto utilizado para la colección de la flora y el muestreo de la vegetación.

En total, se coleccionaron 142 taxa vegetales, 112 especies nativas y 30 especies advenas, estas últimas malezas de chacras y especies medicinales cultivadas en huertas. En el Anexo 1 se listan, separadamente, las especies silvestres y advenas coleccionadas. Los números de herbario se citan, para cada especie, en el mismo Anexo 1. Los ejemplares quedaron depositados en el Herbario de Carolina Villagrán (Facultad de Ciencias de la Universidad de Chile), con duplicados en el Herbario de la Universidad de Concepción, donde fueron determinadas las especies, con la colaboración de los profesores Clodomiro Marticorena y Oscar Matthei.
Vegetación Zonal: Siguiendo la nomenclatura usada para la definición de los pisos de la vegetación andina del norte de Chile (Villagrán et al., 1981; 1983), se reconocieron en el área de estudio tres escalones altitudinales de vegetación: el piso Puneño o Tolar, semidesierto, caracterizado por la dominancia de arbustos o tolas; el piso Altoandino o Pajonal, con fisionomía esteparia y dominado por Gramíneas en champas y plantas en cojines; el piso Subnival, con coberturas muy ralas de pequeñas hierbas en rosetas y cojines, que se extiende hasta el límite superior de las plantas. Los rangos altitudinales (Tabla 1) y la composición de especies características de cada piso de vegetación, sobre la base del transecto CaspanaQ'aulor, se dan a continuación:

Piso Puneño, 3100-3750 m.: Fabiana ramulosa (tara), Atriplex imbricata (ojála, kachiyuyo), 
Baccharis boliviensis (tola, tolilla) y Fabiana denudata (tolilla).

Piso Altoandino, 3750-4400 m. Tres unidades de vegetación pueden ser distinguidas en este piso, correspondiendo la primera a la transición TolarPajonal, la segunda a una estepa arbustiva baja, y la tercera a la estepa altoandina, con predominancia de pajas, cojines y hierbas perennes. Las especies dominantes de cada unidad son:

3750-3900 m.: Parastrephia lepidophylla (tola amarilla, tola amarga), Baccharis tola ssp. altiplanicola (tolita, chachakoma del burro), Adesmia spinosissima (añawa), Stipa chrysophylla y Anatherostipa venusta.

3900- 4250 m.: Stipa chrysophylla, Baccharis tola ssp. tola (loire, léjia), Parastrephia lepidophylla, $P$. lucida, $P$. quadrangularis (tolas amarillas, tolas amargas), Azorella compacta (yareta), Fabiana squamata (coba) y Pycnophyllum macropetalum (yaretilla)

4250-4400 m.: Stipa chrysophylla, Chaetanthera revoluta, Werneria glaberrima (maransel macho), Perezia ciliosa (maransel hembra), Pycnophyllum macropetalum y $P$. bryoides (yaretillas).

Piso Subnival, sobre $4400 \mathrm{~m}$. dominan especies de Senecio y Festuca chrysophylla (paja brava, iru).

Vegetación Azonal: La flora azonal de quebradas, vegas y bofedales también exhibe diferenciación altitudinal, en la región de estudio. En las quebradas bajas de los ríos Caspana y Salado predominan distintas especies de grandes arbustos de chillka (especies de Baccharis) y Gramíneas perennes, como las enormes matas de cortadera (Cortaderia speciosa) y de paja chillawa (Deyeuxia eminens) y, en el suelo, las especies cespitosas del género Distichlis, llamadas colectivamente gramas. Entre los pastos anuales destacan los sailaos o pastos blancos y las cebadillas, especies de Polypogon y Bromus, y malezas introducidas. La vegetación palustre está principalmente representada por los distintos tipos de junquillo o unquillo, correspondientes a especies de los géneros Juncus y Scirpus; en los cursos de agua, las loromas (especies acuáticas, filamentosas y flotantes, de Chara y Myriophyllum). Por el contrario, en las vegas de mayor altitud, como las de Ch'ita, Jauna y Tatio, predominan los grandes cojines duros del maizal (Oxychloe andina), que proporciona fisionomía de Bofedal a la formación vegetal. Se asocian a estos cojines una variada cantidad de especies diminutas, que conforman también cojines húmedos llamados colectivamente ch'ampas, vegas o pastos de vegas, e incluyen a Scirpus deserticola, S. atacamensis, Hypsela reniformis, Arenaria serpens, varias especies de Werneria, Astragalus bustillosii, Calandrinia occulta, especies de Eleocharis, Triglochin striatum, entre otras. Las lagunitas y esteros, entre los cojines, están cubiertos por pequeñas especies flotantes, tales como la flor de agua (Azolla filiculoides y Lemna aff.). En la Tabla 1 se compara la zonación altitudinal de la vegetación de Caspana con otros transectos andinos del norte de Chile, entre $18^{\circ}$ y $23^{\circ} \mathrm{S}$.

\section{La comunidad de Caspana y las entrevistas etnobotánicas}

"la población llega sólo a 60 habitantes, divididos en 12 familias que llevan los apellidos Saires y Colamares (...), los vecinos más antiguos y notables" (San Román, 1896).

De acuerdo a la documentación colonial, y junto con Ayquina, una de las comunidades vecinas, Caspana existe como pueblo, al menos, desde el siglo XVII. En el área, hay gran cantidad de sitios prehispánicos de los períodos tardíos (ca. 800 al 1550 d.C.). El poblado, que alberga a unos 300 habitantes de economía agropastoril, se organiza en torno al río homónimo y está compuesto por tres sectores, reconocidos por los lugareños como: el "pueblo", la "banda" y la "quebrada" (Délano, 1982; cf. Barón, 1979; Miranda 1998). Los caspaneños poseen aproximadamente 50 has cultivables en andenerías, de las que se obtienen frutales, cereales, maíz y flores. Las actividades de pastoreo se realizan en diferentes unidades ecológicas: las riberas de los ríos, en el campo (tolar) y en las vegas altoandinas de su entorno. Como en todos los pueblos andinos, el calendario anual está marcado por festividades y conmemoraciones tradicionales. En estas ocasiones, el ganado es mantenido en el corral, básicamente ali- 
Tabla 1: Comparación de los rangos altitudinales (msnm) de los Pisos y Formaciones vegetales zonales de los Andes del norte de Chile y Argentina, de acuerdo a 5 transectos (1-5) realizados entre $18^{\circ}$ y $24^{\circ} 30^{\prime} S$, desde el borde desértico hasta el límite superior de la vegetación (1: Villagrán, Kalin \& Armesto 1982;

Villagrán 1988, manuscrito; 3: Villagrán, Armesto \& Kalin 1981; este trabajo; 5: Ruthsatz 1977)

\begin{tabular}{|c|c|c|c|c|c|c|}
\hline $\begin{array}{l}\text { PISOS DE } \\
\text { ALTITUD }\end{array}$ & $\begin{array}{l}\text { FORMACION } \\
\text { VEGETAL }\end{array}$ & \begin{tabular}{l}
\multicolumn{1}{c}{1} \\
ARICA \\
18-19 $^{\circ}$
\end{tabular} & $\begin{array}{l}\quad 2 \\
\text { IQUIQUE } \\
19-20^{\circ}\end{array}$ & $\begin{array}{c}3 \\
\text { TOCONCE } \\
22^{\circ}-22^{\circ} 15\end{array}$ & $\begin{array}{l}\quad 4 \\
\text { CASPANA } \\
22^{\circ} 15^{\prime}- \\
22^{\circ} 30^{\prime}\end{array}$ & \begin{tabular}{l}
\multicolumn{1}{c}{5} \\
NW \\
ARGENTINA \\
$22^{\circ}-24^{\circ} 30^{\prime}$
\end{tabular} \\
\hline SUBNIVAL & $\begin{array}{l}\text { Semidesier- } \\
\text { tos de altura } \\
\text { (cojines y } \\
\text { rosetas) }\end{array}$ & $>4900$ & $>4700$ & $>4250$ & $>4400$ & $>4900$ \\
\hline $\begin{array}{l}\text { ALTO- } \\
\text { ANDINO }\end{array}$ & 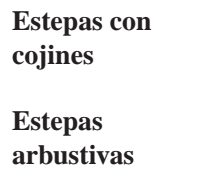 & $\begin{array}{r}4500-4900 \\
4000-4500\end{array}$ & $\begin{array}{r}4500-4700 \\
4100-4500\end{array}$ & $\begin{array}{r}4150-4250 \\
3900-4150\end{array}$ & $\begin{array}{r}4250-4400 \\
3900-4250\end{array}$ & $\begin{array}{l}4500-4900 \\
4100-4500\end{array}$ \\
\hline $\begin{array}{l}\text { INTERFASE } \\
\text { ALTOANDINO/ } \\
\text { PUNEÑO }\end{array}$ & $\begin{array}{l}\text { Transición } \\
\text { Estepa/ } \\
\text { Matorral }\end{array}$ & $3650-4000$ & $3600-4100$ & $3600-3900$ & $3750-3900$ & - \\
\hline PUNEÑO & Matorral & $3100-3650$ & $3100-3600$ & $3200-3600$ & $3100-3750$ & $3200-4100$ \\
\hline PREPUNEÑO & $\begin{array}{l}\text { Semidesier- } \\
\text { tos con } \\
\text { Cactáceas }\end{array}$ & $1540-3100$ & $2530-3100$ & $2700-3200$ & $2700-3100$ & 2000-3200 \\
\hline $\begin{array}{l}\text { PLANICIE } \\
\text { DESERTICA }\end{array}$ & sin vegetación & $<1540$ & $<2530$ & $<2700$ & $<2700$ & \begin{tabular}{|l}
$<2000$ \\
Bosque \\
Tucumano
\end{tabular} \\
\hline
\end{tabular}

mentado con alfalfa y unkillo. Los territorios de pastoreo son comunales y, si están alejados del pueblo, cada familia tiene estancias, paraderos y lugares de refugio (Délano, 1982; Miranda 1998). Estancias importantes para los caspaneños son las establecidas en Kabi, Ch'ita, Minta y Tite. Comparten también, con los comuneros de Río Grande, las vegas del volcán Tatio pero, en este último caso, usando lados diferentes de las faldas del volcán y no mezclando sus animales (Castro y Martínez, 1996).

Con duplicados de las 142 especies coleccionadas en el área de estudio, se preparó un cuaderno de referencia que fue usado para la primera serie de entrevistas etnobotánicas, realizadas durante 1995. En este año fueron entrevistadas 15 personas residentes en Caspana (5 mujeres y 9 hombres), la mayoría dedicadas a actividades agropastoriles. Los nombres científicos de la flora consultada, números de herbario y de referencia en las entrevistas, nombres vernaculares recopilados, usos, procedencia lingüística y los significados de los nombres registrados durante esta primera etapa, se documentan en los Anexos 1 y 2. La segunda etapa consistió en dos entrevistas a Don Julián Colamar (realizadas en 1995 y en 1998), sabio caspaneño, con preguntas acerca de las grandes unidades de paisaje, lenguas nativas, naturaleza y cultura. Con el fin de dejar claramente mos- 


\section{Nombres vernaculares de Caspana, $\mathrm{N}=214$}

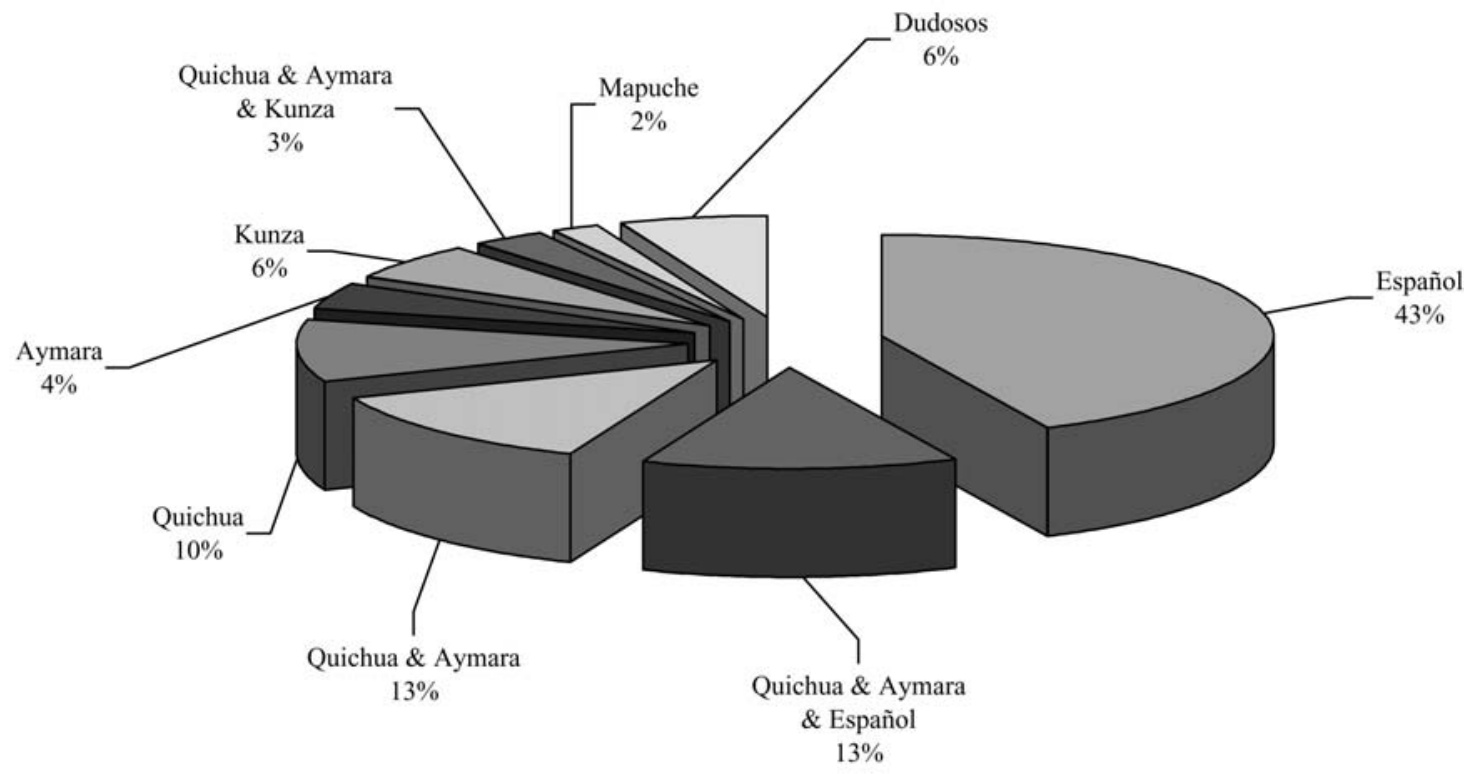

Fig. 2: Las proporciones de las distintas lenguas de los nombres vernaculares, registrados para la flora de Caspana, Loa Superior, Región de Antofagasta, Chile.

trado el sentido de este conocimiento, en los Anexos 3 y 4 se reproduce, textualmente, la comprensión del paisaje expuesta por Don Julián, respetando su pronunciación, y las preguntas realizadas por los autores de este trabajo. En las conversaciones con Don Julián se empleó una metodología mixta, combinando la estructura de entrevista dirigida, con el espacio y tiempo necesario para sus propias reflexiones y preguntas, lo que enriqueció notablemente los resultados esperados. En la Figura 3 se reproduce un dibujo, originalmente realizado por Don Julián, en el que destacan algunos de los topónimos que le parecieron más significativos, en relación al paisaje y territorio de Caspana.

\section{Resultados etnobotánicos}

\subsection{Nomenclatura botánica}

De las 142 especies consultadas, 130 (92\%) fueron reconocidas con nombres vernaculares, en tanto que sólo a 12 especies no se les asignaron nombres (ver Anexo 1). Muchas especies tienen más de un nombre vernacular. En total, para las 142 especies consultadas, se registraron 214 vernáculos (ver Anexo 2). En la Figura 2 se muestran las proporciones de nombres correspondientes a distintas lenguas. El componente principal es el castellano: 93 nombres de plantas son netamente españoles (42\%), mientras que 27 (13\%) son nombres mixtos, que combinan palabras quichua o aymara con el castellano. Los nombres restantes son indígenas, principalmente provenientes de los idiomas quichua y aymara (alrededor de 60 nombres, $27 \%$ del total registrado).

Aproximadamente 27 nombres (13\%) resultaron difíciles de adjudicar, separadamente, a los idiomas quichua o aymara. Estos nombres se grafican en la Fig. 2 con el rótulo quichua \& aymara. Algunos ejemplos de estos nombres, que aparecen perteneciendo a estos dos idiomas, son: Ch'ampa, Chachakoma, Chillawa, Chillka, Chukikandio o Chukikandia, Iru, Lampaya, Motokoro, Pingopingo, Tola y Wailla. Otros nombres son, probablemente, aymara, aunque no se puede des- 


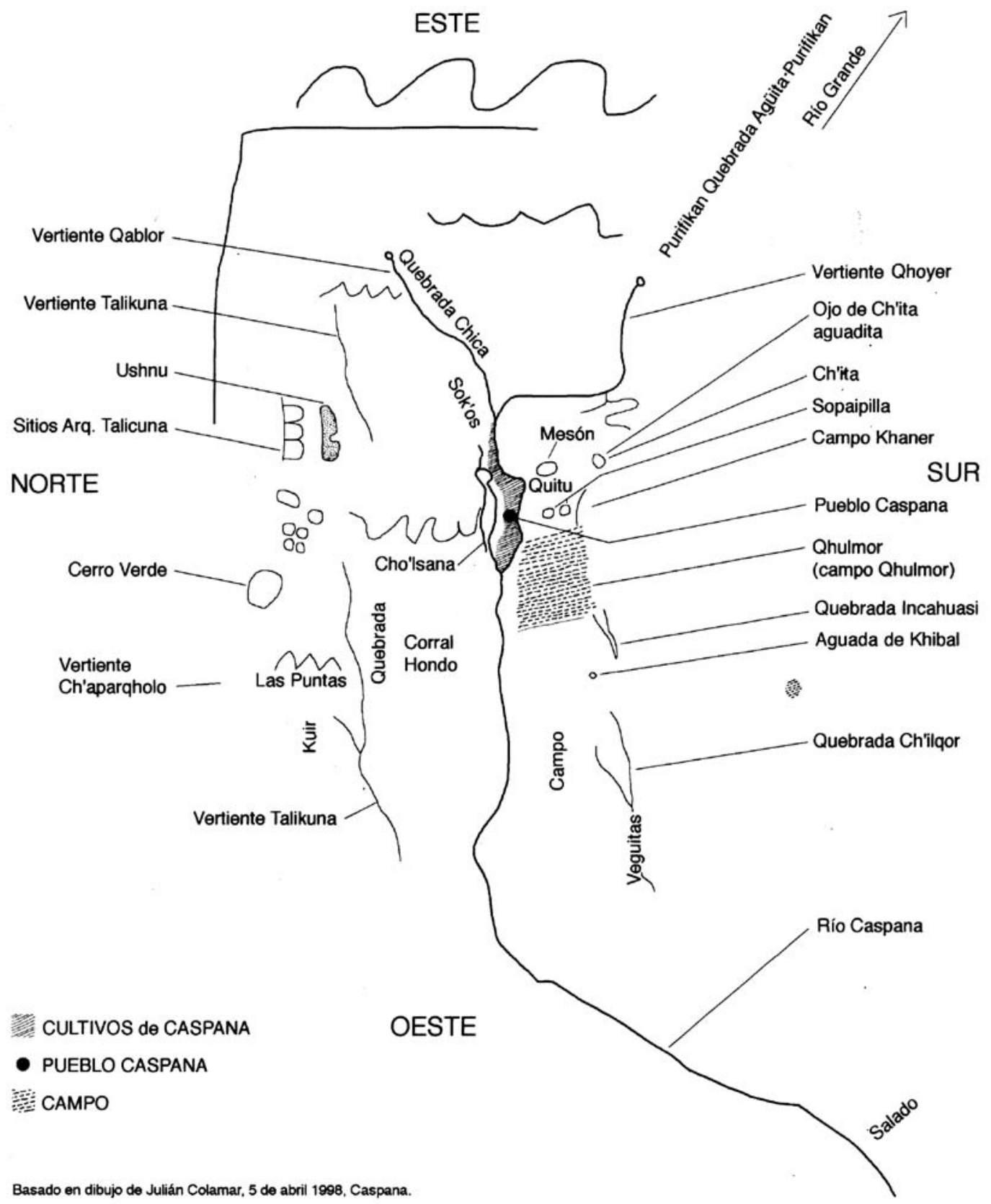

Fig. 3: Bosquejo de la percepción del paisaje en Caspana, mostrando los sectores de Campo-Q'ulmor,

Campo Khaner, Cerros (Filos), Chakras, Quebradas, Vegas, Vertientes y Aguadas. De acuerdo al dibujo proporcionado por Don Julián Colamar. 
cartar su pertenencia al quichua, por ejemplo, T'ume o T'umi; Chutchuka o Chukchuka, Chuklla, Chuko o Chuku y K'iri o K'eri. Viceversa, otros nombres, probablemente, sean quichuas, como K'asawi y Koa, Koba, Qoba o Q'oba. Nombres netamente quichuas (21 nombres, 10\%) serían, por ejemplo, Kachiyuyo, Kaiba, Kuchucho, Maransel, Molle oMuelle, Pupusa, Quisco, Suncho, Tara, Walchawalcha, Wirakucha, Wirawira y Yuyo. Nombres propiamente aymara (4\%) serían, por ejemplo, Añawa, Ch'ana, Chikachika, Illakowa, Muiña y Yareta.

Alrededor de 14 vernáculos (7\%) podrían ser kunza. Algunos de ellos son, con más probabilidad, kunza, ya que corresponden a nombres ampliamente usados en las comunidades del Salar de Atacama para las mismas especies de plantas, como Kolti, Kontokonto o Kontukontu; Sailao; Q'ome o Q'omer; Qore o Qori (sin embargo, los dos últimos nombres pueden ser también quichuas). Otros nombres son usados, exclusivamente, en el Loa Superior y su pertenencia al kunza estaría por comprobar, como, por ejemplo: Loire o Loye; Psómor; y Tamor, Tamur o T'amur. Adicionalmente, se registraron dos nombres, de amplio uso en los Andes del norte de Chile, pertenecientes tanto al kunza, como al quichua y al ymará. Ellos son: Kopa, Kopakopa, Qopa, o Qopaqopa; y Lakolako o Laqulaqu.

Finalmente, existen 13 nombres cuyos idiomas originarios son dudosos. Por ejemplo, los nombres Waje o Waji, Loroma y Pasakana, podrían ser quichua o aymara; el nombre Salkarai, Salqarai o Palkarai podría ser aymara; los nombres Esporal y Vinovino podrían provenir del español. Más enigmáticos aún son los nombres Rikarika y Ojála, que pueden ser tanto indígenas como españoles.

\subsection{Etnoclasificación caspaneña}

Se registraron varios nombres colectivos, correspondientes a agrupaciones de especies que comparten alguna característica en común, ya sea la forma de crecimiento (etnocategorías de formas de vida) o el parecido morfológico general (etnocategorías "taxonómicas"). En la Tabla 2 se muestran los vernáculos colectivos correspondientes a las distintas formas de vida de la flora. Los arbustos, igual que en otras comunidades andinas, son denominados tolas. Las especies, dentro de esta agrupación, pueden ser distinguidas por propiedades como el color (tola amarilla), el sabor (tola amarga), el hábitat (tola de la cordillera), el tamaño (tolillas o tolitas), etc. Las Gramíneas en champas, características del pajonal, son llamadas colectivamente pajas o pajitas. Algunas especies de Gramíneas anuales, a veces introducidas y creciendo en quebradas o huertas, son llamadas colectivamente cebadillas y sailaos. Los cojines del seco son denominados colectivamente yareta o yaretillas, mientras que los de húmedo, en Vegas y Bofedales, se denominan ch'ampas, vegas o pastos de vegas. Las especies acuáticas filamentosas son llamadas loromas; las diminutas especies flotantes, flor de agua.

También se han registrado agrupaciones realizadas sobre la base del parecido morfológico general de los taxa, de manera similar a como se construyen las agrupaciones taxonómicas en botánica. Por ejemplo, se denominan con la palabra tamor, y derivadas, las especies de Adesmia que son resinosas y sin espinas; en contraste, las especies espinosas del género son denominadas añawa. En la Tabla 3 se proporcionan otros ejemplos de este tipo de agrupaciones.

Finalmente, hemos registrado también un caso de denominación basada en la referencia a una planta importante. Se trata de dos especies de árboles ornamentales, plantados en el pueblo de Caspana, que fueron llamados pino (un ciprés, Cupressus, y un tamarindo, Tamarix), probablemente por su parecido a las especies de pinos (Pinus), tan comunes en nuestro país.

\subsection{Percepción del ecosistema andino}

En forma análoga a las distinciones de unidades de paisaje, descritas por los toconceños (Aldunate et al., 1981), los caspaneños integran el paisaje en tres grandes etnocategorías, de acuerdo a la forma de utilización económico-social del entorno, chacra, campo y cerro. En la Tabla 4 se comparan distintos gradientes altitudinales de los Andes de Chile, indicando las equivalencias de estas tres principales etnocategorías del paisaje con las grandes unidades geomorfológicas de los Andes, los pisos altitudinales de vegetación y las formaciones vegetales correspondientes. 


$\begin{array}{lll}\text { ARBUSTOS } & \text { Tolilla } & 24,27,37,39,40,41,76 \\ \text { tola, leña } & \text { Tola } & 27,30,37,39,40,41,77 \\ & \text { Tola amarilla } & 27,39,40,41 \\ \text { Tolita } & 29,32 \\ \text { Leña del Cerro } & 39,40,41 \\ \text { Tola amarga } & 39,40,41 \\ \text { Tola de la Cordillera } & 39,40,41\end{array}$

\section{PASTOS}

$\begin{array}{lll}\text { Paja, cebadilla, } & \text { Cebadilla } & 93,94,106 \\ \text { pasto blanco, } & \text { Paja } & 93,95,97,98,99,102,104 \\ \text { sailao } & \text { Pasto blanco } & 94,122 \\ & \text { Sailao } & 94,141\end{array}$

\section{COJINES}

$\begin{array}{lll}\begin{array}{l}\text { Yareta, } \\ \text { ch'ampa o vega }\end{array} & \text { Yaretilla } & 17,18,52 \\ & \text { Ch'ampa, Vega, Pastos de vega } & 1,4,15,16,50,65,70,89,92,110, \\ 111\end{array}$

\section{ACUATICAS}

$\begin{array}{lll}\text { Loroma } & \text { Loroma } & 2,53 \\ \text { Flor del agua } & \text { Flor del agua } & 4,111\end{array}$

En la misma Tabla 4 se muestran, dentro de cada una de las grandes etnocategorías de paisaje, las subunidades reconocidas en Caspana, de acuerdo a las conceptualizaciones de Don Julián Colamar (Anexos 3 y 4). Se observa que ellas no corresponden a aquellas definidas en el cercano poblado de Toconce, ni tampoco se correlacionan con otras distinciones andinas. Así, por ejemplo, en el Campo, se definieron para Caspana dos subunidades singulares, Campo-Q'úlmor y Campo-Kháner, correspondiendo la primera al piso puneño de Tolar, dominado por arbustos, y la segunda a la transición entre los pisos puneño y altoandino, con mezcla de arbustos y pajas (Tabla 4). Dentro del Campo-Kháner, fueron distinguidos distintos accidentes geográficos y unidades geomorfológicas. Así, por ejemplo, los sustratos aplanados, de calizas intemperizadas, son denominados Sopaipilla; Corral, las quebradas; Mesón, las mesetas y planicies; Hoyadas, las depresiones entre cerros (pasos); lugares con rocas (Khatu); lugares con aguas frías o heladas (Purifik'an). Ciertas plantas, también definen asociaciones vegetales, como por ejemplo el $C h$ 'anal, o agrupaciones de Ch'ana (Chuquiraga spinosa); el nombre de Quebrada Aysert'ume, alude a la presencia del T'ume (Ephedra breana).

En la Figura 3 se presenta el esquema del paisaje del área de estudio, elaborado por Don Julián Colamar, mostrando los sectores de Chakra, el Campo Q'ulmor, el Campo Khaner y las vertientes, quebradas y aguadas del área estudiada. A continuación, se citan textualmente algunos frag- 
Tabla 3: Etnocategorías correspondientes a agrupaciones "taxonómicas"

Etnocategoría

Género

$\mathbf{N}^{\circ}$ s especies en Anexo 1

$\begin{array}{lll}\text { Añawa } & \text { Adesmia (con espinas) } & 62,63 \\ \text { Tamor } & \text { Adesmia (sin espinas) } & 60,61 \\ \text { Tamorcillo } & \text { Adesmia } & 60,61 \\ \text { Tamur } & \text { Adesmia } & 60,61 \\ \text { T'amur } & \text { Adesmia } & 60,61 \\ \text { Tamurquillo } & \text { Adesmia } & 60,61 \\ \text { Garbanzo } & \text { Astragalus/Lupinus } & 63,67 \\ \text { Chillka } & \text { Baccharis } & 24,28 \\ \text { Grama } & \text { Distichlis } & 100,101 \\ \text { Unquillo liso } & \text { Juncus/Scirpus } & 90,107 \\ \text { Junquillo } & \text { Juncus/Scirpus } & 90,91,107 \\ \text { Trébol } & \text { Melilotus/Medicago } & 131,132 \\ \text { Cucharón } & \text { Ranunculus } & 71,72 \\ \text { Pupusa } & \text { Werneria/Perezia } & 45,46,47\end{array}$

Tabla 4: Comparación de los pisos altitudinales y las formaciones vegetales zonales y azonales de los Andes del norte de Chile con las unidades de paisaje y etnocategorías botánicas obtenidas en cuatro estudios realizados entre 18 y 2230'S (1-4): 1: Castro, Villagrán \& Kalin 1982; 2: Gundermann 1984; 3: Aldunate, Armesto, Castro \& Villagrán 1981; 4: este trabajo.

\begin{tabular}{|c|c|c|c|c|c|c|}
\hline $\begin{array}{l}\text { PISOS DE } \\
\text { ALTITUD }\end{array}$ & $\begin{array}{l}\text { VEGETACION } \\
\text { ZONAL }\end{array}$ & \begin{tabular}{|l} 
GEOMORFOLO- \\
GIA, UNIDADES \\
DE PAISAJE Y \\
VEGET. AZONAL
\end{tabular} & $\begin{array}{c}\text { ARICA } \\
1\end{array}$ & $\begin{array}{c}\text { IQUIQUE } \\
2\end{array}$ & $\begin{array}{c}\text { TOCONCE } \\
3\end{array}$ & $\begin{array}{c}\text { CASPANA } \\
4\end{array}$ \\
\hline SUBNIVAL & $\begin{array}{l}\text { Semidesierto } \\
\text { de altura }\end{array}$ & \multirow{2}{*}{$\begin{array}{c}\text { CORDILLERA } \\
\text { OCCIDENTAL } \\
\text { O PRINCIPAL } \\
\text { 'CERRO' } \\
\text { 'HOK'O' O } \\
\text { BOFEDAL }\end{array}$} & $\begin{array}{l}\text { pata- } \\
\text { q'ollo }\end{array}$ & palle & paniso & filo alto \\
\hline ALTOANDINO & \begin{tabular}{|l|}
$\begin{array}{l}\text { Estepas con } \\
\text { cojines }\end{array}$ \\
Estepas \\
arbustivas
\end{tabular} & & $\begin{array}{l}\text { wichu- } \\
\text { irana } \\
\text { pampa } \\
\text { q'ollo }\end{array}$ & $\begin{array}{l}\text { zuni } \\
\text { waña }\end{array}$ & pajonal & pajonal \\
\hline $\begin{array}{l}\text { INTERFASE } \\
\text { ALTOANDI- } \\
\text { NO/PUNEÑO }\end{array}$ & $\begin{array}{l}\text { Transición } \\
\text { estepa/ } \\
\text { matorral }\end{array}$ & \multirow{4}{*}{\begin{tabular}{|} 
PRE- \\
CORDILLERA \\
'CAMPO' \\
'VEGASY \\
QUEBRADAS' \\
'CHACRA'
\end{tabular}} & \multirow{3}{*}{ tolar } & \multirow{3}{*}{ 'costa' } & \multirow{3}{*}{$\begin{array}{l}\text { tolar } \\
\text { pampa }\end{array}$} & \multirow{3}{*}{$\begin{array}{l}\text { campo- } \\
\text { khaner } \\
\\
\text { campo } \\
\text { q'ulmor }\end{array}$} \\
\hline PUNEÑO & Matorral & & & & & \\
\hline PREPUNEÑO & $\begin{array}{l}\text { Semidesierto } \\
\text { con Cactáceas }\end{array}$ & & & & & \\
\hline $\begin{array}{l}\text { PLANICIE } \\
\text { DESERTICA }\end{array}$ & Sin vegetación & & & & & \\
\hline
\end{tabular}


mentos de la conversación sostenida con Don Julián y que, a nuestro juicio, ejemplifican su concepción del paisaje (más detalles en los Anexos 3 y 4).

\section{Campo:}

"Bueno, empecemos por la parte baja de Ch'ita, de Caspana hacia el sur. Entre Caspana e Inkawasi, se llama Campo. Todo en general se llama Campo-Q'úlmor. En estos lugares hay de todos montes, por ejemplo la añawa, el t'ume, la rikarika, el k’iri, el loire, el ojála, la tikára, el t'amor, iluka, todo eso. Por eso el ganado vivía allí anteriormente. Especialmente cuando llueve, se hace muy pastoso y está ahí el ganado. Entonces todos decimos 'Vamos al campo de Q'úlmor, ahi dejamos el ganado'. Y, por otra parte, encima, encima del paisaje de la meseta de Ayquina, eso se llama Campo-Kháner, todo de aquí de la punta hasta Inkawasi también, hasta la Quebrada de Inkawasi que sube hasta Ch'ita. Eso se llama Campo-Kháner. De ahí también hay otros lugares que antes decía Ud. Hay una parte que se llama Sopaipilla, es que habían piedras bien planas, grandes, con hoyos. Como nosotros siempre hacemos la sopaipilla, por eso los antiguos nombraron Sopaipilla al lugar. Dentro de esa Sopaipilla también hay el Mesón; después está Corral Alto. Dentro del CampoKháner está todo eso. Eso es esa parte. De ahi para arriba, p'a Q'aulor yendo, ya tenemos el Corral Largo, la Quebrada Corral Largo, abajo. Arriba se llama la Quebrada Mulurojte. Y después, pasamos eso y tenemos otra parte de esa quebrada que está en subida para la de Q'áulor, que se llama Quebrada Honda o Quebrada de Aysert'ume. De ahí con eso estamos llegando a lugares donde hay la Ch'ana, le dicen Ch'anal, donde hay montes grandes de Ch'ana. Donde hay montes grandes del cerro, un buen trecho, se llama a ese lugar Ch'anal." (Julián Colamar, Anexo 3).

En el Cerro, tal como en Toconce, la formación dominada por pajas es llamada Pajonal. Por el contrario, las cumbres cordilleranas son denominadas Filos ${ }^{1}$, a diferencia de Toconce, en donde se les llama Paniso. Se distinguieron Filos altos y Filos chicos. Ambas unidades pertenecen a los pisos altitudinales superiores, tanto altoandino como subnival" (Tabla 4):

Cerro:

" $Y$ donde hay pajas grandes, pajas altas, pura paja, Pajonal. Donde hay una parte pareja se llama Hoyada, hoyadas. Eso, Filo, Hoyada, Loma, esos son los nombres. Ahí hay Pajonal, Ch'anal, Tolar, donde hay harta tola. Así respetamos nosotros los nombres que tienen esos lugares. Hay también Peñaujero, también esa es palabra colla. Ya no pasa, esa es peña alta. Peñaaujero. Así decimos: de Peñaujero para allá, Pajonal; de Peñaujero para este lado...'; así nombramos nosotros los lugares; para entendernos nosotros con los lugares". (Pregunta: ¿Cómo se llaman los paisajes altos, los altos cerros?). "Filo, el Filo Alto decimos nosotros, por ejemplo, a todo ese cordón de Tatio para acá (para Caspana). Más abajo también tenemos Filo Chico, de Q'aulor para abajo, más abajito" (Julián Colamar, Anexo 3). "Esos son los filos, por eso son el filo chico, el filo alto, son esos cerros que están allá arriba del alto del Ojo de Q'aublor, de Qhoyer, ese siempre es el filo alto. Se decía, se denominaba el filo alto, 'fuimos a la yareta, fuimos a encontrarnos en el filo alto'. En el filo chico es este. Porque p'a este lado no hay, este no hay. Para acá hay lomas, aquí loma alto, aquí también esta pa'l lado de Qhoyer, de Qhoyer este pa'allá es loma alto. Y por aquí está más o menos, Purifik'an" (Julián Colamar, Anexo 4).

También son reconocidas unidades azonales, de humedales, con los nombres de Aguadas y Vegas, cada una distinguida con su nombre geográfico propio.

\footnotetext{
La palabra "filo" también es usada por las poblaciones quichua parlantes del sur andino (Cusihuamán, 1976), en el mismo sentido, y también por los mapuches. Probablemente, esta palabra castellana debió ser comúnmente usada por los españoles en la época colonial.
} 


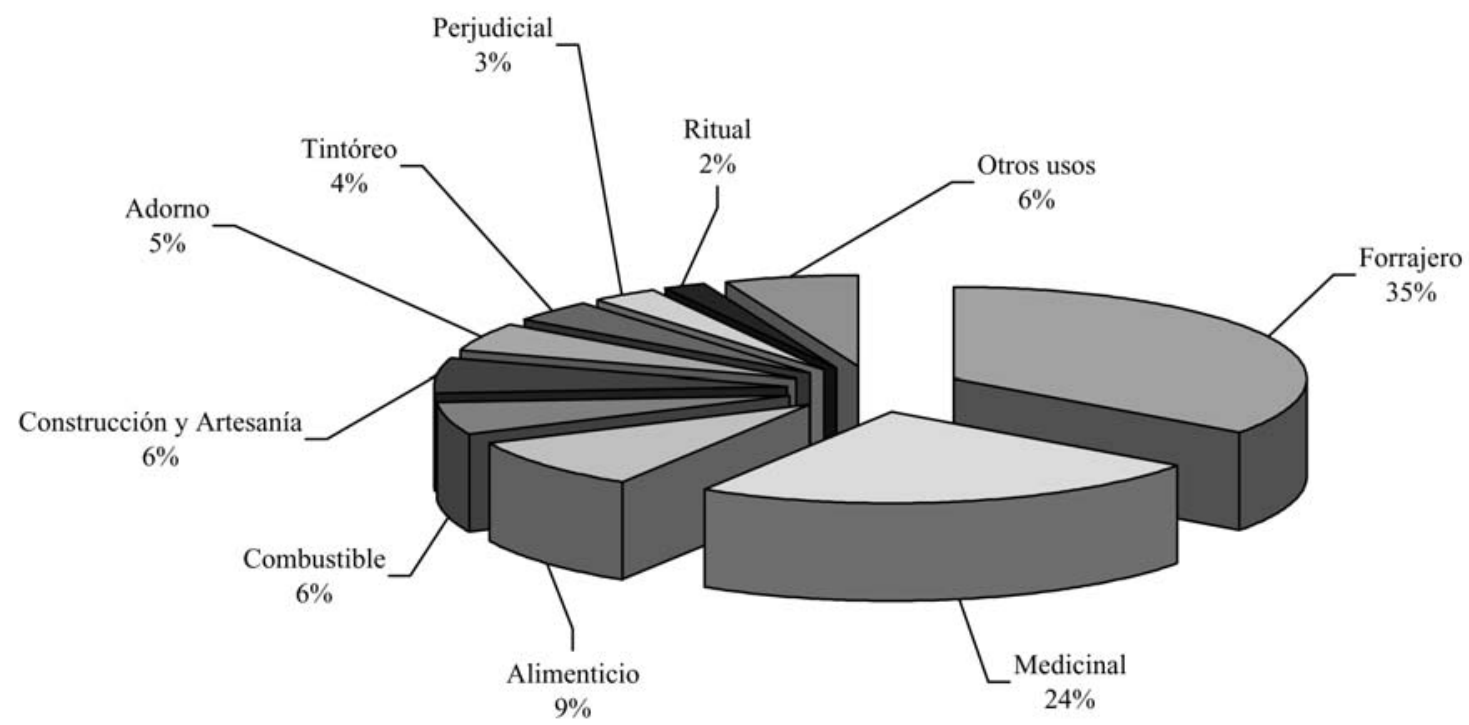

Fig. 4: Distribución de los distintos tipos de usos de las plantas de Caspana, Loa Superior, Región de Antofagasta, Chile.

Vegas, aguadas:

"También hay Aguadas, Aguada de Manantial, Aguada de Tatio, Aguada de Talikuna... La Aguada es para nosotros más chica, más chiquita, donde no hay vegas. Así no más. Si ya tienen veguitas ya decimos la Vega de Tatio, la Vega Q'aulor, la Vega de Qhoyer; son vegas que tiene más, ahí ya se entretiene más el ganado. En la aguada solo se va a tomar agua" (Julián Colamar, Anexo 3).

Asimismo, sectores de la Chakra, como los Tablones, y los nombres propios de los Terrenos (predios) fueron mencionados:

\section{Chakras:}

"Se llaman Chakras, ahora último le dicen Terraza, pero Chakra era el nombre, chakra. Después de acuerdo a cómo van los regadios al lado y el canal al medio, esa parte escalonada, se llama Tablón. Así se dice 'el Tablón del lado bajo, el Tablón de más arriba'. Significa toda una acera, hasta adonde a uno le pertenece”. (Julián
Colamar, Anexo 3). “... los nombres de los terrenos, de los predios que se dice actualmente, pero antes se decía terreno. Ya te dije Soqhor, te dije Ch'olsana y ahora te voy a decir este. Q'ilbar. Ahí tiene usted, Q'ilbar, lo otro, T'oqo... La otra es Khakharte... Claro, todos son (nombres) de las chakras. Cada lugar tenía su nombre. Claro, tenía su nombre... Siloqhitor, ya más o menos lo sé, Siloqhitu. Ahora el otro parte es S'ulte... S'ulti o S'ultin algunos dicen... Y ahora lo otro es Ch'uruta... Fiq'am, ya estamos encontrando más... Lajten, Lajtin, Tamto...Ya, a ver, la otra Qholaire, Qholaire... aire parece que algo es sonido de agua, en kunza, es sonido del agua, parece, no estoy seguro. Ustedes, lo van a ver... Banerqhollo, Banerqhollo... Ninas... Thono... Tamser... otra es Puriq'olay. Eso sería en cuanto a los nombres de los terrenos, no tengo más..." (Julián Colamar, Anexo 4). 


\subsection{Toponimia, naturaleza y cultura}

Como parte de la integración de la naturaleza y la cultura, en la percepción del paisaje y en su vinculación con la reproducción de la vida, dos cerros tienen especial significación para los caspaneños, en su decir, porque son la "cabecera de Caspana", desde donde nacen las aguas del río Caspana. Uno redondo y otro más aguzado, que representan a la mujer y al hombre. De esta unión nace el agua que fertiliza la tierra. Se nombran como Qhoyer y Q'aulor, diciendo explícitamente que sus nombres antiguos (preinka) son los de Sipitare y Sipaqa. Justamente en el kausulor, cantado en la Limpia de Canales, se nombra a "mama Sipaqa" (Délano 1982). De acuerdo a Don Julián Colamar, el cerro de Ch'ita es Sipitare tata y el cerro de Q'aulor es Sipitare mama y, al mismo tiempo, Sipaqa mama (ver Fig. 3 y Anexo 4). Esta dualidad está presente en diferentes esferas de la realidad descritas por los pobladores andinos y también es manifiesta en la clasificación de la flora.

\begin{abstract}
"Donde dices, mama Sipaka le decían a la mujer. El cerro que es de Q'aulor, ese es mama Sipaka. Entonces, ahí, en quechua dentra ¿no es cierto? Diciendo señora, señorita, Sipa, señorita, mama Sipaka. Bueno, el otro se decía siempre, anteriormente, le decían Tata Sipitare. Decían: Sipitare tata, Sipitare mama. O sea que Sipitare Tata significa Sipitare hombre, o cerro hombre. Sipitari mama significa el cerro mujer...El Ch'ita es Sipitari"

(Julián Colamar, Anexo 4).
\end{abstract}

Los cerros no sólo son un elemento visible del paisaje. Son también quienes, en definitiva, hacen posible la vida, otorgando el agua para los cultivos y el forraje, constituyéndose, como deidades o mallku, en toda posibilidad de existencia, al tiempo que el mundo de los antepasados míticos actúa como los mediadores entre caspaneños y mallkus. Y tanto estos cerros como los lugares que ocuparon o fundaron estos ancestros, así como los manantiales, son nombrados dentro de un paisaje inmensamente significativo, transitado por categorías ordenadoras que ya hemos mencionado, junto a formas de organizar el espacio y la vida de los propios caspaneños, que residen en mitos mediatizados por ritos. Nos permitimos reforzar esta aseveración, con fragmentos de otros relatos de Don Julián (Miranda, 1998), que enriquecen aún más esta perspectiva:

“...por ejemplo, la súplica de la lluvia (...).Para hacer la súplica tenemos que traer agua de mar y aquí hay que preparar un huaqui, en la tarde, que son ofrendas para la Pachamama en primer lugar, para los abuelos y para las almas(...) hay que ofrendarles a ellos primero para que ellos sean los intercesores ante el Señor por nosotros (...). Después al otro día, vamos al lugar de la súplica en el cerro de Q'aulor(...). Allá se hace un huaqui pero no se hace ya para las almas y abuelos, sino que se ofrenda más que nada al lugar, al mallku(...). También se usa el incienso, se usa la koba, la virakoba, se usan flores, el agua (...). El agua es la lluvia y las flores son el amor, decimos nosotros.(...). Se hace en Q'aulor porque ahí lo hacían los antiguos, pero se ha cambiado el lugar. Primero se hacía en el cerro de Ch'ita (...) porque (...) hay demostraciones que los antiguos lo hacían ahí, un peñasco que naturalmente tiene hoyos (...). Se hace en un cerro porque los cerros, mallku, tienen poder. Sipitare Tata mallku, Sipitare Mama Mallku (...). Ellos tiene poder(...). El Q'aulor por ejemplo aparenta una mujer, entonces en sus faldas mantiene el ganado. Ahí está el monte que come el ganado y con eso mantiene. El mallku protege al ganado, le da la alimentación. Se respeta(...). El mallku es parte de la Pachamama, porque la Pachamama es todo y el mallku está sentado sobre la Pachamama podemos decir porque la piedra está sobre la tierra (...). Las vertientes de Qhoyer y Q'aulor entren en la quebrada de Caspana y de ahí nosotros las tomamos con canales para el regadio (...). Nosotros en nuestro territorio tenemos el Tatio, con aguas termales que son buenas para la salud, para el reumatismo. Los antiguos contaban que las aguas tienen su Sereno y verdaderamente es así. Al tiempo que van a hacer la fiesta se sienten los cantos o el instrumento que toca, se siente.(...). Está en todas partes 
donde hay aguas, pero todo depende de las personas, que sean del pueblo y entiendan su música. Por ejemplo nosotros estamos aquí y vamos a buscarlo, entonces vamos pensando que el sereno de Q'aulor o de Qhoyer va a tener que entregarnos la música para la banda (...). A veces sucede que uno llega de repente a un ojo de agua, a una vertiente y se pone a tomar agua, entonces se enferma uno, entonces es que el agua, la vertiente se asusta. Hay que pegar un grito antes. Por ejemplo cuando uno va a Talikuna, en el alto, ahí grita, porque en la quebrada los abuelos están durmiendo, entonces con eso despiertan y ya lo están viendo a uno y no le pasa nada. Igual en las vertientes (...). Ahí la vertiente sabe que viene alguien, porque todo está vivo dicen pues, la Pachamama está viva, todo, todo. Por eso dicen los antiguos que hablaban con la piedra y hablaban con el agua".

En la Tabla 5, además de los nombres de formaciones vegetales y topográficas, ya comentadas y mostradas en la Fig. 3, se listan los topónimos para distintos lugares geográficos (quebradas, vegas, cerros, chacras, etc.) registrados en los Anexos 3 y 4. Varios de ellos corresponden a palabras del español, quichua y aymara, pero, la mayor parte, probablemente, sea de origen kunza. Algunos significados de topónimos se indican en la Tabla 5, pero la mayoría de los significados originales de estas palabras, aparentemente, se han perdido. Estos nombres geográficos son cruciales para el cotidiano vivir de los caspaneños. En este sentido, el valor descriptivo de la toponimia está inserto en un sistema cultural en donde es esencial la relación entre los seres humanos y los espacios que transita y habita. Se trata de una interacción estructural entre cultura y naturaleza, en donde la primera le otorga un rol ordenador a la segunda, haciendo posible la existencia de una sociedad, en todas las esferas de su realidad: en sus planos económico, social e ideológico. Por tanto, es un sistema cultural definido el que le otorga existencia y sentido a la naturaleza, pensando y construyendo su paisaje en un tiempo y un espacio, que, no obstante su dinámica, termina siendo socialmente sancionado y, por ende, constitutivamente propio de un grupo cultural, otorgándole su espe- cificidad, aun cuando este sistema pueda compartir principios estructuradores de una o más tradiciones culturales, ancladas en su macroidentidad. Este paisaje singular es registrado y apropiado por quienes lo viven, creando un sistema de comunicación colectivo, de gran eficiencia en la vida de quienes lo comprenden, lo transitan y lo viven. Es su mundo de dominio inmediato y en él la palabra lo identifica, lo representa y lo hace susceptible de comunicación. No obstante la dinámica de cambio cultural que ha afectado a los descendientes de los pueblos originarios, un análisis de la toponimia contiene un potencial informativo y comprehensivo insospechado, que no ha sido suficientemente considerado. Por ejemplo, en el siguiente párrafo, este valor es claramente perceptible: "Así decimos. De Peñaujero para allá, Pajonal; de Peñaujero para este lado, lo otro, así nombramos nosotros los lugares; para entendernos nosotros con los lugares" (Anexo 3).

\subsection{Utilización de la flora}

De las 141 especies consultadas, 114 tenían uno o más usos reconocidos, mientras que 27 no lo tenían. Para las plantas utilizadas se distinguieron 162 usos, los cuales fueron clasificados en: Forrajero (57 especies); Medicinal (50 especies); Combustible (19 especies); Artesanía y Construcción (7 especies); Alimenticio (5 especies) y Ritual (3 especies). Para 14 especies se describieron varios otros modos de utilización, mientras que 7 especies fueron consideradas perjudiciales para la agricultura, generalmente malezas dañinas, o para el consumo del ganado. En la Fig. 4 se muestra la distribución porcentual de los diferentes tipos de usos registrados. En el Anexo 1 se detallan los usos registrados en Caspana, para cada especie; en el Anexo 4 se proporcionan detalles adicionales, acerca del uso ceremonial de distintos materiales botánicos, incluyendo también materiales zoológicos y de otras índoles.

\section{Discusión}

Dentro de la Subregión de Río Salado, como se destacó en la introducción, los caspaneños son percibidos como "diferentes", por toconceños y ayquineños, porque "descienden de los gentiles". Aunque estos pueblos tienen afinidades parentales y sociales entre sí, cada uno tiende a marcar la 
Tabla 5: Nombres de lugares, formaciones vegetales y geomorfológicas, accidentes geográficos y terrenos (chakras) registrados en el Anexo 4 ( $a=$ aymara; $e=e s p a n ̃ o l ; ~ k=k u n z a ; ~ q=q u i c h u a ;$

$$
\text { ¿? =desconocido) }
$$

\begin{tabular}{|c|c|c|}
\hline pila & $i ?$ & \\
\hline banerqhollo & $\mathrm{a}$ & \\
\hline ch'anal & $\mathrm{a}$ & \\
\hline aguada & $\mathrm{e}$ & \\
\hline campo & $\mathrm{e}$ & \\
\hline corral & $\mathrm{e}$ & \\
\hline filo & $\mathrm{e}$ & \\
\hline hoyada & $\mathrm{e}$ & \\
\hline loma & $\mathrm{e}$ & \\
\hline mesón & $\mathrm{e}$ & \\
\hline pajonal & $\mathrm{e}$ & \\
\hline peñaujero & $\mathrm{e}$ & \\
\hline plan tunikula & $\mathrm{e}$ & \\
\hline sopaipilla & $\mathrm{e}$ & \\
\hline tablón & $\mathrm{e}$ & \\
\hline vega & $\mathrm{e}$ & \\
\hline mulurujte, mulorujte & $\mathrm{e} ?, \mathrm{k}$ ? & \\
\hline aiserthume & $\mathrm{k}$ ? & quebrada honda \\
\hline ayquina (aikina) & $\mathrm{k}$ ? & \\
\hline caspana (k'aspana) & $\mathrm{k}$ ? & \\
\hline ch'aparqholo & $\mathrm{k}$ ? & \\
\hline ch'apolqholor & $\mathrm{k}$ ? & \\
\hline ch'ilqor, chilqor & $\mathrm{k}$ ? & \\
\hline ch'iltau & $\mathrm{k}$ ? & \\
\hline ch'ita & $\mathrm{k}$ ? & \\
\hline ch'olsana & $\mathrm{k}$ ? & \\
\hline ch'uruta & $\mathrm{k}$ ? & \\
\hline khakharte & $\mathrm{k}$ ? & \\
\hline khaner & $\mathrm{k}$ ? & \\
\hline khatu & $\mathrm{k}$ ? & lugar con rocas \\
\hline khibal & $\mathrm{k}$ ? & \\
\hline khurte & $\mathrm{k}$ ? & \\
\hline ninas & $\mathrm{k}$ ? & nombre terreno \\
\hline purifik'an & $\mathrm{k}$ ? & fik'an=helado \\
\hline puritama & $\mathrm{k}$ ? & tama=caliente \\
\hline q'aulor & $\mathrm{k}$ ? & \\
\hline qhaina? & $\mathrm{k}$ ? & \\
\hline qharqha & $\mathrm{a}, \mathrm{q}, \mathrm{k} ?$ & filo chico \\
\hline qhito & $\mathrm{q}, \mathrm{k} ?$ & más alto \\
\hline qhitu & $\mathrm{q}, \mathrm{k} ?$ & \\
\hline qholaire & $\mathrm{k}$ ? & aire $=$ sonido agua \\
\hline qhoyer & $\mathrm{q}, \mathrm{k} ?$ & \\
\hline q'ilbar & $\mathrm{k}$ ? & nombre terreno \\
\hline q'ulmor & $\mathrm{k}$ ? & \\
\hline siloqhitu & $\mathrm{q}, \mathrm{k} ?$ & nombre terreno \\
\hline socaire & $\mathrm{k}$ ? & \\
\hline soqhor & $\mathrm{k}$ ? & \\
\hline sulki & $\mathrm{k}$ ? & \\
\hline sulti, sultin & $\mathrm{k}$ ? & \\
\hline tamser & $\mathrm{k}$ ? & nombre terreno \\
\hline thono & $\mathrm{k}$ ? & \\
\hline thono & $\mathrm{k}$ ? & nombre terreno \\
\hline toconce (tokonse) & $\mathrm{a}, \mathrm{k}$ ? & \\
\hline t'oqo & $\mathrm{a}, \mathrm{k} ?$ & nombre terreno \\
\hline chakra & $\mathrm{q}$ & \\
\hline inkawasi & $\mathrm{q}$ & \\
\hline sipaqa & $\mathrm{q}$ & \\
\hline sipitare & $\mathrm{q}$ & \\
\hline tolar & $\mathrm{q}, \mathrm{a}$ & \\
\hline tikara & $\mathrm{q}, \mathrm{k}$ ? & \\
\hline tatio & q? & \\
\hline talikuna & $\mathrm{q} ?, \mathrm{k} ?$ & \\
\hline
\end{tabular}


diferencia con los otros. Así, por ejemplo, es la gente de Ayquina la que, preferentemente, hace el distingo con los caspaneños; en contraste, se refiere a la gente de Toconce, Ayquina y Cupo como "somos todos uno"; esta percepción está comprobada históricamente (Gómez, 1981; Aldunate \& Castro, 1981; Martínez, 1985). Lo cierto es que la arqueología y la etnografía, de algún modo, denotan múltiples interdigitaciones en la región. Por otra parte, Caspana es la única comunidad del Loa Superior que usa la lengua kunza -aparentemente sin conocer el significado en el presente- para sus ceremonias de Limpia de acequias; además, es la comunidad que mantiene nexos más estrechos con el área norte del Salar de Atacama, específicamente con el poblado de Río Grande. Estos rasgos han llevado a considerar a Caspana como un ejemplo de interacción entre las tradiciones de oasis circumpuneños y las de tierras altas en el sur andino (Castro \& Martínez 1996; Castro, 1997).

Por otra parte, estudios arqueológicos realizados en la Provincia de El Loa (Aldunate et al., 1986) han permitido dilucidar que, entre los años 800 a 1000 d.C., existían, al menos, dos tradiciones culturales en la región: una “del Desierto" y otra “Altiplánica”. La primera puede ser identificada con los grupos originarios de la región del Salar de Atacama; se trataría de la etnia atacameña, con una lengua de por sí que no sería ni aymara ni quichua. El término kunza (Ckunsa, sensu Vaisse et al., 1896), para denotar el idioma hablado por los naturales del sector meridional de los Andes de Antofagasta, aparentemente es acuñado sólo en el siglo XIX; no conocemos hasta ahora ninguna mención previa a ese nombre. La segunda tradición está presente en la Subregión del Río Salado, Loa Superior, y es de clara raigambre Altiplánica. La primera impresión es que podría tratarse de una etnia aymara parlante, con elementos de influencia quichua parlantes, puesto que la actual población de Toconce, Ayquina y Cupo tiene apellidos aymaras y, además, abundan los topónimos y nombres de flora y fauna en esa lengua, además de los en quichua.

Los resultados etnobotánicos obtenidos en Caspana son concordantes con la distinción de estas dos tradiciones culturales distintas, en los Andes de la Región de Antofagasta. En efecto, nuestro estudio muestra resultados muy similares a los obtenidos en otras localidades, estudiadas etnobotánicamente, en el Loa Superior (Aldunate et al., 1981; Villagrán \& Castro, 1999; Romo, 1998), tanto en lo que se refiere a la nomenclatura botánica como a los sistemas de etnoclasificación y al modo de utilización de la flora. En efecto, en Caspana, y en las restantes comunidades del Loa Superior ya estudiadas, los nombres indígenas de plantas provienen, básicamente, de los idiomas quichua y aymara, o corresponden a una combinación de estos idiomas con el español. Así, la nomenclatura de plantas es compartida por las comunidades del Loa Superior, y la región exhibe, en general, los rasgos lingüísticos descritos para la Tradición Altiplánica. En contraste, en las comunidades en torno al Salar de Atacama, aunque se conocen también los nombres aymara y quichua, aún se conservan los nombres indígenas de plantas con la configuración fonética del idioma kunza. Adicionalmente, los criterios de clasificación de la flora, y los modos de utilización de la misma, exhiben también rasgos singulares. Estas evidencias son consistentes con la adjudicación de estas comunidades a la denominada Tradición del Desierto (Villagrán et al., 1999). Por otro lado, tanto en la región del Loa Superior, como el Salar de Atacama, la nomenclatura botánica revela una fuerte influencia hispánica y heterogeneidad en lo referente a las lenguas de las cuales provienen los nombres de plantas, rasgo que denota las múltiples influencias culturales que han afectado a la región andina de Antofagasta. Así, en toda la región, predominan ampliamente los nombres de plantas en idioma español, característica compartida por todas las comunidades estudiadas hasta la fecha (Aldunate et al. 1981; Villagrán \& Castro 1999; Villagrán et al. 1999). Específicamente en Caspana, a pesar de sus relaciones etnobotánicas débiles con las comunidades atacameñas, destacan unos pocos nombres de plantas que provienen, probablemente, del kunza. Por ejemplo, dos nombres, hasta la fecha, registrados exclusivamente en Caspana, podrían ser kunza: Loire o Loye, Baccharis tola sp. tola, (Lejía o léjia en otras regiones andinas); y Psómor, una Cactácea no identificada y llamada Cardón chico en otras regiones; otros nombres, posiblemente kunza, solamente registrados para Caspana dentro del área del Loa Superior, pero ampliamente usados en las comunidades del Salar de Atacama, 
son: Kolti, Kontokonto o Kontukontu, para Lupinus oreophilus, y Q'ome o Q'omer, para Opuntia camachoi (el último nombre también podría ser quechua). Otros nombres registrados en Caspana, adscritos al kunsa por Vaisse, y ampliamente usados en el Loa Superior o en el Altiplano de más al norte, son: Sailao, Lako, Kopakopa, Tamor o T'amur. De estos, Sailao y T'amur podrían ser kunza, en tanto que Lako y Kopa también se registran en el léxico aymara de Bertonio.

En lo que se refiere a la etnoclasificación de las plantas, en Caspana tampoco se registraron diferencias con los sistemas ya descritos para otras comunidades del Loa Superior, tanto para la flora zonal (Aldunate et al. 1981) como azonal de vegas y bofedales (Villagrán \& Castro, 1999). Así, en toda la región, las agrupaciones de especies se realizan sobre la base de criterios morfofisionómicos, reconociéndose, básicamente, dos clases de etnocategorías: 1) Formas de vida (como, por ejemplo, tolas; yaretas y yaretillas; pajas y cebadillas; ch'ampas; loromas; flor de agua, etc.) y 2) Etnocategorías Morfológicas o "taxonómicas" (e.g. chillka, grama, junquillo, añawa, tamor, ortega, etc.). La distinción de especies, dentro de estas etnocategorías genéricas, se realiza sobre la base del contraste de distintas propiedades, como el color (e.g. awawa blanca, añawa colorada, añawa verde); el hábitat (e.g. flor del agua, flor del campo, etc.), rasgos también ya documentados en la literatura etnobotánica citada. Principios estructuradores, ampliamente descritos para el mundo andino, como aquellos de dualismo y opuestos complementarios (Grebe \& Hidalgo, 1988; Castro et al., 1982), son evidentes tanto en la distinción de especies (e.g. maransel macho, maransel hembra) como en relación a rasgos esenciales del paisaje, particularmente los cerros (e.g. Sipitare mama, Sipitare tata). Esta homogeneidad en los criterios y principios de clasificación de las plantas, constatada en, prácticamente, todas las comunidades andinas del norte de Chile que hemos estudiado, contrasta con la singular situación de las comunidades atacameñas, en donde los criterios de agrupación y distinción de especies son más diversos (Villagrán et al., 1999). Estos resultados también sustentan la distinción de dos tradiciones culturales distintas en los Andes de Antofagasta.
En lo referente al uso de la flora en Caspana, los grandes rubros de utilización registrados privilegian a las especies forrajeras y medicinales, rasgo ya documentado para todas las floras andinas, estudiadas etnobotánicamente, en el norte de Chile. En contraste, la singularidad de las comunidades del Salar de Atacama, en lo que se refiere a utilización de las plantas, se expresa en: 1) La diversificada forma de uso y elaboración de algunos recursos importantes (e.g. algarrobo, chañar); 2) El uso intensivo de los recursos vegetales, expresado en el uso múltiple de numerosas especies; 3) La importancia de la recolección de especies alimenticias y textiles; 4) La incorporación de usos, alimenticio y medicinal, para la flora de malezas y huertas, de reciente introducción. Entre las comunidades atacameñas y las del Loa Superior, también se pueden establecer diferencias referentes a las especies rituales. Así, por ejemplo, la planta ritual más importante de Caspana es la koba, koba Santiago, q'oba, koa, koa Santiago, illakowa, koiye (Fabiana squamata), con los mismos usos ceremoniales ya descritos para k'oa Santiago o k'oa, otra especie del mismo género (Fabiana bryoides), en Toconce (Aldunate et al., 1981). Cabe destacar que, en todas las comunidades del Salar de Atacama, es una especie de la Familia Compuestas, Parastrephia quadrangularis, la llamada koa, coba o chacha, la usada en el mismo ceremonial (para mayores detalles sobre el significado de la koa, ver Villagrán et al., 1999; Castro 1997). Otra planta con un uso ritual, registrada exclusivamente para Caspana, es el Loire o Loye, llamado también Léjia o Lejía en el Loa Superior y en el Salar de Atacama (Baccharis tola subsp. tola). Se nos ha mencionado: "Cuando se hace un floramento, se mueven las chullas solamente con loire" (más detalles en Anexos 1 y 4).

Las grandes etnocategorías de paisaje reconocidas en Caspana-Cerro, Campo y Chakra- son también las descritas para Toconce, en el Loa Superior (Aldunate et al., 1981), e incluso para algunas comunidades de Atacama, como Talabre (Villagrán et al., 1999, en este volumen). Una singularidad de la región de Caspana, muy explícita en las descripciones de Don Julián Colamar, es la detallada conceptualización del micropaisaje y su nomenclatura. Si bien algunas subunidades paisajísticas, reconocidas al interior de las tres 
categorías mencionadas, son comunes con las descritas para Toconce (e.g. Hoyadas, Vegas, Pajonales, Tolares, Mesones), otras son propias de Caspana. Por ejemplo, dentro de la etnocategoría Campo, se individualizan en Caspana dos grandes sectores, Campo Khaner y Campo Q'ulmor, ambas en idioma, probablemente, kunza. Unidades geomorfológicas como cumbres de cerros, quebradas, sustratos especiales, sectores de Chakras, entre otros, se distinguen con nombres específicos en lengua indígena y en castellano. Algunos ejemplos, Filo, Corral, Sopaipilla, Tablón. Es interesante destacar la tendencia al arcaísmo de las palabras castellanas, usadas en tiempos coloniales (e.g. Hoyada, Filo). Esta lengua, como sucede en todas las tierras altas del área andina, es transformada y hecha propia por los actores, tal como lo señalara Arguedas (1968). En algunos casos la palabra será quechuizada o aymarizada; en otros, será derivada y adscrita a una de las lenguas nativas. Por ejemplo, Alabalte ${ }^{2}$ ("Alabalte, decimos que es bienvenido, en kunza"); o Peñaujero 3 ("Hay también Peñaujero, también esa es palabra colla").

Otro resultado, que merece destacarse, es la diversidad de fonemas en los nombres de los lugares, muchos de ellos bastante difíciles de adjudicar a lenguas conocidas. Algunos nombres geográficos responden a fonemas quichuas, como Chakra, Inkawasi. Otros son aymara, como Banerqhollo, Ch'anal y T'oqo o Ttoqo. Sin embargo, un rasgo muy singular de la toponimia de la región del Loa Superior es que, la mayoría de los nombres de los lugares, no parecen ser ni quichua ni aymara sino más bien parte del léxico

Posiblemente, derivado de la palabra castellana Alabar.

\section{Probablemente, agujero de peña.}

Sin embargo, no hay certeza para la procedencia kunza de ambos términos. Por ejemplo, en escritos del siglo XVIII, la localidad de Ayquina aparece con el nombre de Hiquina e Hiquiná. En un mapa, que dataría entre 1758 y 1822, que se encuentra en el Archivo Británico, el lugar recibe el nombre de Yquina (citado en Castro, 1997). En el siglo XIX, se le reconoce bajo los nombres de Aiquiña y Aikena (Alcedo, 1786; Solano Astaburuaga, 1899; citados en Castro, 1997). La palabra completa, más cercana en sonoridad, sería aiquia que, de acuerdo a San Román, significa "aquí", en kunza; Ay, es "maíz" o la proposición "en". kunza y/o alguna otra lengua. Así por ejemplo, los nombres de dos de los poblados principales del Loa Superior, Ayquina y Caspana, aparentemente, podrían ser kunza (Aikina, K'aspana) ${ }^{4}$. También los cerros principales, como Ch'ita y Q'aulor, y accidentes geográficos, como Ayserthume, Ch'aparqholo, Ch'ilqor, Ch'iltau, Khatu, Khibal, Khurte. Tal como en el poblado de Toconce, las chakras también tienen sus nombres propios, pero lo singular para Caspana es que, estos nombres, sean, aparentemente, kunzas. Por ejemplo, Q'ilbar, Tamser, Thono, Soqhor, Ch'olsana, Khakharte, Sulti, Ch'uruta, Lajten, Qholaire.

Esta profusión de topónimos, con una aparente configuración kunza, tanto para localidades de la región del Loa Superior como también para las de la región del Salar de Atacama (e.g. Socaire, Camar, Puritama, Villagrán et al., 1999, en este volumen), nos lleva nuevamente al tema de las relaciones entre ambos territorios. Esto pese a que, como discutimos anteriormente, la nomenclatura botánica y la etnoclasificación registrada para el Loa Superior, incluida la comunidad caspaneña, exhiben los rasgos lingüísticos descritos para la Tradición Altiplánica, mientras que las comunidades atacameñas, los de la Tradición del Desierto. Alternativamente, topónimos de los Andes de la región de Antofagasta pueden corresponder a los remanentes de lenguas nativas, que no serían ni la quechua, ni la aymara, ni la kunza, y que se han conservado en la región, desde tiempos prehispánico; esta hipótesis es plausible porque, en el sur andino, el parentesco y superposición de lenguas es tan complejo que, aunque los avances son significativos, no permiten ser concluyentes en términos de lenguas originarias, máxime cuando se percibe que la gente de estos territorios, en tiempos coloniales y probablemente desde antes, hablaba, en muchos casos, más de una lengua (Torero, 1987; Bouysse Cassagne, 1975). Por ejemplo, algunas fuentes etnohistóricas del siglo XVI hacen referencia a varios grupos étnicos en el altiplano meridional, y al uso de, al menos, cuatro lenguas: aymara, quichua, puqina $\mathbf{y}$ uroquilla (chipaya de Posnasky) (Bouysse Cassagne, 1975; Schiappacasse, Castro \& Niemeyer, 1989; Castro 1997). Un ejemplo de la complejidad lingüística de este problema es una referencia aparecida en un documento acerca del proceso de extirpación 
de idolatrías, que afectó a Atacama La Baja (Subregión de río Salado), durante el siglo XVII. Esta fuente señala que el ídolo de Caspana se llamaba Sintalasna. Los términos que componen este nombre no exhiben cercanía con el quichua ni el aymara, y muy poco con el $\boldsymbol{k u n z a}^{5}$. En contraste, privilegian la lengua puqina $^{6}$ y uroquilla, esta última, de acuerdo a Torero (1987), es la lengua uro chipaya ${ }^{7}$.

Finalmente, queremos destacar que, a pesar del interés linguístico de la toponimia recabada, no podemos concluir nada, sin que se desarrolle una investigación en profundidad de las lenguas involucradas. Aunque los diccionarios para las lenguas nativas del sur andino son deficitarios, con excepción de aquellos aymara y quichua, una de las limitaciones de este trabajo es no haber pesquisado aquellos topónimos de difícil adscripción en los diccionarios puqina y uro chipaya. Sin embargo, creemos que no bastaría con esta investigación. Entender la complejidad cultural de los Andes de Antofagasta requeriría de la integración de evidencias provenientes de muchas disciplinas distintas, las cuales se encuentran en diferentes grados de desarrollo en nuestro país. Por ejemplo, ni siquiera están establecidos los parentescos entre las posibles lenguas originales que podrían corresponder a los topónimos de los Andes del norte de Chile. Torero (1987), sobre la base de estudios lingüísticos del área centro-sur andino, destaca el parentesco entre las lenguas pukina y callawaya (parentesco rechazado por Oblitas, 1978) y postula relaciones entre pueblos y lenguas aymara, puqina y uro chipaya, en tiempos preinka y, además, sugiere la presencia de collas puqina hablantes hasta la costa de Atacama. Estas referencias denotan, con claridad, la complejidad que hemos esbozado.

Agradecimientos Dedicamos este trabajo a la memoria de Don Julián Colamar de Caspana quien fuera, hasta diciembre de 1998, Presidente de la Asociación de Tradiciones y Costumbres de todos los pueblos del interior; Ministro de la Iglesia Católica de Caspana; Presidente del Comité de Ganadería; agricultor y pastor. Junto con agradecerle sus gentilezas y conocimientos, agradecemos también la paciencia y conocimientos de los caspaneños que soportaron nuestras entrevistas etnobotánicas: Sra. Eusebia Paniri Paniri, Don Benicio Paniri, Sr. Colamar, Don Juan de la Cruz Colamar Colamar, Don Luis Alberto Colamar, Don Claro Anza, Don Ascencio Anza Anza, Sra. Juana Colamar Anza, Don Felipe Terán, Don Emilio Ansa, Sra. Elena Ansa, Sra. Marta Panire. Este trabajo ha sido financiado con los proyectos FONDECYT 1940380 (Castro \& Varela) y FONDECYT 1970908 (Castro, Villagrán \& Sánchez).
En kunza la palabra sutalanau es traducida como "la palma de la mano" (Créqui Montfort \& Rivet, 1927; De La Grasserie, 1894, citados en Castro 1997).

Sintal'a es "uno, sólo, único", en el chipaya de Posnasky, y Asna, "ordenar", en lengua pukina, de acuerdo a Torero (1987).

Según Créqui Montfort \& Rivet (1927, citado en Castro 1997) Sintal'a, podría ser también lengua uroquilla. El vocablo Acna está definido originalmente como chipaya del lago Coipasa y chipaya de Posnasky, pero Torero (1987) afirma que es uroquilla. 


\section{BIBLIOGRAFIA}

ALDUNATE, C. y V. CASTRO. Las Chullpa de Toconce y 1981 su relación con el poblamiento altiplánico en el Loa Superior. Periodo Tardío. Ediciones Kultrún Ltda., Santiago.

ALDUNATE, C., J., ARMESTO, V. CASTRO y C. VILLA1981 GRAN. Estudio etnobotánico en una comunidad precordillerana de Antofagasta: Toconce. Boletín del Museo Nacional de Historia Natural 38.

ALDUNATE, C., J. BERENGUER, V. CASTRO, L. CORNE1986 JO, J.L. MARTINEZ y C. SINCLAIRE. Cronología y asentamiento en la región del Loa Superior. Proyecto sistemas de asentamiento en la región del Loa Superior: patrones arqueológicos y etnográficos. Dirección de Investigación y Bibliotecas - Universidad de Chile. Santiago.

ANONIMO Manual trilingüe de aymara que1981 chua y castellano. Editorial Mercurio, Lima.

ARGUEDAS, J.M. Yawar Fiesta. Editorial Universitaria, 1968 Santiago.

BALLON E., R. CERRON-PALOMINO y E. CHAMBI. 1992 Vocabulario razonado de la actividad agraria andina. Centro Bartolomé de las Casas, Cusco, Perú, 301 pp.

BARON, A.M. Excavación de un Cementerio. Sus po1979 tencialidades. Tesis para optar al grado de Licenciado en Arqueología y Prehistoria. Departamento de Ciencias Antropológicas y Arqueología, Universidad de Chile, Santiago.

BERTONIO, L. Vocabulario de la lengua aymara.

[1612] 1984 Primera Parte: español-aymara, 1-474. Segunda Parte: aymara-español: 1-397. Ediciones Ceres, Cochabamba, Bolivia.

BOUYSSE CASSAGNE, TH. La identidad aymara. Edito1987 rial Hisbol, La Paz.

CARDENAS, M. Manual de plantas económicas de 1989 Bolivia. Los Amigos del Libro, La PazCochabamba.

CASTRO, M., VILLAGRAN, C. y M. KALIN-ARROYO. 1982 Estudio etnobotánico en la precordillera y altiplano de los Andes del Norte de Chile $\left(18-19^{\circ} \mathrm{S}\right)$. El Hombre y los Ecosistemas de Montaña, Vol. II. MAB-6, UNESCO, Montevideo.
CASTRO, V. "Todos Santos" en Toconce. MS, 1991 FONDECYT 1940380.

CASTRO, V. Huacca Muchay. Evangelización y 1997 religión andina en Charcas, Atacama la Baja. Tesis para optar al grado de Magister en Historia, Mención Etnohistoria, Universidad de Chile.

CASTRO, V. y V. VARELA Ceremonias de tierra y agua. 1994 Ritos milenarios andinos. Fondart Fundación Andes, Santiago.

CASTRO, V. y J. L. MARTINEZ. Poblaciones indígenas de 1996 la Provincia de El Loa. En: Culturas de Chile. Vol. II Etnografía. Editorial Andrés Bello, Santiago.

COROMINAS, J. Breve diccionario etimológico de la 1973 lengua castellana. Ed. Gredos S.A., Madrid, España, 627 pp.

CUSIHUAMAN, A. Diccionario quechua: Cuzco-Collao. Ministerio de Educación/Instituto de Estudios Peruanos, Lima.

DELANO, P. 1982

Aspectos socioeconómicos de una comunidad del norte grande: Caspana. Tesis para optar al grado de Licenciado en Antropología Social. Facultad de Filosofía, Humanidades y Educación. Departamento de Ciencias Sociológicas y Antropológicas. Universidad de Chile, Santiago.

GIRAULT, L. Kallawaya curanderos itinerantes de 1987 los Andes. Imprenta Quipus, La Paz, Bolivia, $671 \mathrm{pp}$.

GOMEZ, C. La comunidad campesina indígena 1980 del Loa Superior. Tesis de grado para optar al título de Licenciatura en Antropología Social; Facultad de Ciencias Humanas, U. de Chile, Santiago

GONZALEZ-HOLGUIN, D. Vocabulario de la lengua ge[1608] 1952. neral de todo el Perú llamada lengua quichua o del Inca.Libro Primero: quechua-castellano: 1-374. Libro Segundo: castellano-quechua: 375-695. Imprenta Santa María, Lima, Perú.

GREBE, M.E. y B. HIDALGO. Simbolismo atacameño: un 1988 aporte etnológico a la comprensión de significados culturales. Revista Chilena de Antropología 7. Facultad de Ciencias Sociales, Universidad de Chile. 
GUNDERMANN, H. Ganadería Aymara, Ecología y Forra1984 jes: Evaluación regional de una actividad productiva andina. Chungara 12, Universidad de Tarapacá, Arica.

LEHNERT, R. Diccionario Toponimia Kunza. Nor1994 print, Antofagasta, Chile, 81 pp.

LENZ, R. 1910 chilenas derivadas de lenguas indígenas americanas. M. Ferreccio (Ed.). Imprenta Universitaria, Santiago, Chile, $987 \mathrm{pp}$.

LIRA, J. Diccionario Kkechuwa-Español. Uni1945 versidad Nacional de Tucumán. Publicación 369. Instituto de Historia, Linguística y Folklore.

LIRA, J. Medicina andina. Farmacopea y ri1995 tuales. Centro de Estudios Regionales "Bartolomé de las Casas". Cusco.

MARTINEZ, J.L. Adaptación y cambio en los atacame1985 ños. Los inicios del período colonial, siglos XVI y XVII. Andes: 9-25; Santiago.

MERCADO, C., P. RODRIGUEZ y P. MIRANDA. Pa que 1997 coman las almas. FONDART, Ediciones LOM, Santiago.

MIRANDA, P. Julián Colamar Recuerda. Visiones 1998 de Caspana. LOM Ediciones, Santiago.

MÖSBACH E.W. Botánica Indígena de Chile. (C. Aldu1992 nate y C. Villagrán, eds). Editorial Andrés Bello, Santiago, Chile, 140 pp.

MOSTNY, G. Peine, un pueblo Atacameño. Publica1954 ción $\mathbf{N}^{\mathbf{0}} \mathbf{4}$ del Instituto de Geografía de la Facultad de Filosofía de la Universidad de Chile.

MUNIZAGA, C. y H. GUNCKEL. Notas Etnobotánicas del 1958 Pueblo Atacameño de Socaire. Publicaciones del Centro de Estudios Antropológicos 5, Universidad de Chile, Santiago.

OBLITAS, E. Cultura Callawaya. Ediciones Popula1978 res, La Paz, Bolivia.

REAL ACADEMIA ESPAÑOLA. Diccionario de la lengua 1970, 1992 española. Editorial Espasa-Calpe, Madrid.

ROMO, M. 1998
RUTHSATZ, B. Pflanzengesellschaften und ihre Le1977 bensbedingungen in den Andinen Halbwüsten Nordwest Argentiniens. Dissertationes Botanicae 39.

SAIGNES, T. En busca del poblamiento étnico de los 1986 Andes bolivianos, siglos VI y VII. Avances de Investigación 3, La Paz.

SCHIAPPACASSE, V., V. CASTRO y H. NIEMEYER. Los 1989 Desarrollos Regionales en el Norte Grande. En: Culturas de Chile, Prehistoria Tomo I:181-220. Editorial Andrés Bello, Santiago.

TORERO, A. Lenguas y Pueblos Altiplánicos en tor1987 no al siglo XVI. Revista Andina 5 (2), Cusco.

VAISSE, E., F. HOYOS y A. ECHEVERRIA. Glosario de 1896 la Lengua Atacameña. Imprenta Cervantes, Santiago, Chile, 36 pp.

VARELA, V. De Toconce pueblo de Alfareros a Turi, 1992 Pueblo de Gentiles.Tesis para optar al grado de Antropología con mención en Arqueología. Escuela de Antropología, Facultad de Ciencias Sociales. Universidad de Chile.

VILLAGRAN, C., J. J. ARMESTO y M. T. K. ARROYO. 1981 Vegetation in a high Andean transect between Turi and Cerro León in Northern Chile. Vegetatio 48.

VILLAGRAN, C., M.T.K. ARROYO y J. ARMESTO. La 1982 vegetación de un transecto altitudinal en los Andes del Norte de Chile (18-19 $\left.{ }^{\circ} \mathbf{S}\right)$. El Hombre y los Ecosistemas de Montaña, Vol. II. MAB-6, UNESCO, Montevideo

VILLAGRAN, C., M. T. K. ARROYO y C. MARTICORENA. 1983 Efectos de la desertización en la distribución de la flora andina de Chile. Revista Chilena de Historia Natural 56 .

VILLAGRAN, C. y V. CASTRO. Etnobotánica y manejo 1999 ganadero de las vegas, bofedales y quebradas en el Loa Superior, Andes de Antofagasta, Segunda Región, Chile. Ms en prensa. Chungara.

VILLAGRAN, C., V. CASTRO, G. SANCHEZ, M. ROMO, 1999 C. LATORRE y L. F. HINOJOSA. La tradición surandina del desierto: Etnobotánica del área del Salar de Atacama (Provincia de El Loa, Región de Antofagasta, Chile). Estudios Atacameños, este volumen. 


\section{ANEXO 1 \\ CATALOGO DE LAS ESPECIES VEGETALES COLECTADAS EN CASPANA, REGION DE ANTOFAGASTA, CHILE}

Se listan separadamente los taxa nativos y los introducidos. Las especies nativas han sido agrupadas en grandes conjuntos taxonómicos (Criptógamas, Gimnospermas, Angiospermas - Dicotiledóneas y Angiospermas - Monocotiledóneas). Dentro de cada uno de estos grupos, las Familias, Géneros y Especies se ordenaron alfabéticamente. La información de cada especie se ha organizado de la manera siguiente:

1. Nombre científico, autor, familia (la Familia se cita con mayúsculas y abreviada a los seis primeros dígitos). A continuación se proporcionan los números de colección correspondientes al Herbario de C. Villagrán (depositado en la Facultad de Ciencias de la Universidad de Chile, con duplicados en el Herbario de la Universidad de Concepción). Entre paréntesis se cita el número de referencia del cuaderno utilizado en las entrevistas.

2. Nombres vernaculares, en cursivas, con que se conoce a la especie en Caspana. Cuando se registró más de un nombre, éstos se presentan ordenados, comenzando por el nombre que ha sido mencionado por un mayor número de entrevistados.

3. Claves de las clases de usos asignados a la flora de Caspana: Co, Comestible; F, Forrajero; M, Medicinal; L, Leña; C, Construcción y Artesanías; $\mathrm{R}$, ritual; P, Perjudicial; O, Otros usos variados; $\mathrm{S} / \mathrm{U}$, Sin uso reconocido.

4. Comentario en relación a los usos de la planta, de acuerdo a las entrevistas realizadas a los caspaneños. Cuando existe información complementaria, obtenida en Caspana o Toconce por otros investigadores, se proporciona precedida por las siguientes claves: PD, Priscilla Délano 1982; PMB, Pablo Miranda 1998; AACV, Aldunate, Armesto, Castro \& Villagrán 1981; VC, Villagrán \& Castro 1999; VCR, Victoria Castro 1998.

5. Claves de los orígenes de los vernáculos: A, aymara; E, español; K, kunza; $\mathrm{M}$, mapuche; $\mathrm{Q}=$ quechua; ?= desconocido.
6. Comentario respecto al significado de los nombres comunes citados para la especie. Los textos consultados se citan con las siguientes siglas: $\mathrm{B}=$ Bertonio (1612); $\mathrm{Ba}=$ Ballon et al. (1992); JC = J. Corominas (1973); C = Cusihuaman (1976); DT = Diccionario Trilingüe (1981); G = Girault (1987); GH = González Holguín (1952); L = Lenz (1910); LE = Lehnert (1994); Li = Lira (1945, 1995); $\mathrm{M}=$ Mösbach (1992); RAE = Diccionario Real Academia Española (1970); V = Vaisse et al. (1896), de acuerdo a VC = Villagrán \& Castro 1999.

\section{FLORA NATIVA}

\section{CRIPTOGAMAS}

\section{1) Musgo, BRYOPH 8805 (117) \\ Ch'ampa \\ $\mathrm{O}$}

Adorno para el Nacimiento (Pesebre), se guarda y al año siguiente vuelve a reverdecer.

Q, A

De acuerdo a VC, Ch'ampa, quechua, "pedazo de césped con la tierra que se pega entre las raíces; especies de plantas que tienen raíces largas, tupidas y ordenadas" (L:337). "Terrón moldeado y seco que se usa como adobe" (C:42).

\section{2) Chara, CHARAC 8709 (56) \\ Loroma \\ $\mathrm{S} / \mathrm{U}$ \\ ¿A?, ¿Q?}

Loroma, probablemente de Larama, aymara, fino azul (B:242,1).

3) Alga verde filamentosa, CHLORO 8795 (57) Laqulaqu, Lakolako, Lama, Verdelagua $\mathrm{O}$

La gente tiene la experiencia de que cuando hay bastante lakolako encima del agua, va a llover. Cuando está la planta asentada, no va a llover. Q, A, K, E

De acuerdo a VC, Lakho, quechua, correspondería a las algas verdes del género Cladophora (G:96). Laqhu, quechua, "alga comestible que cre- 
ce en los lagos" (BA:168). En el Lago Titicaca, el repliegue del alga significa año con escasa lluvia. Es señal de sequía o lluvia (BA:267). Lako, aymara, "ouas de la Laguna, o yerua verde como estopa, o lana, y suelen comerla en locros" (B:187) Liki-liki, quechua, "es señal de lluvia o sequía (BA:265). Lacko, cunza, "una planta acuática en las lagunas i ríos de la cordillera" (V:24; LE:40). Lama, mapuche moderno, "tejido de lana, generalmente negro, cubierto de flecos largos en toda su extensión" (L:421-422).

4) Azolla filiculoides Lam., AZOLLA 8784 (83) Flor del agua, Ch'ampa

F

Ver $\mathrm{N}^{\mathrm{o}} 1$ para el significado de ch'ampa.

\section{5) Thelypteris argentina (Hieron.) Abbiatti,} THELYP 8841 (132)

\section{Regalís, Regále, Helecho}

$\mathrm{M}$

Remedio para el estómago, es muy fresco

$\mathrm{E}$

Regaliz, palabra del latín y griego, se usa para designar a Orozuz (del árabe), planta. Otras acepciones: Rizomas de esta planta. Trozo seco del rizoma de esta planta. Pasta hecha con el jugo del rizoma de esta planta, que se toma como golosinas (RAE II : 1754). Helecho es una palabra del latín filictum. En una acepción estrictamente botánica, designa a cualquiera de las plantas de las Filicíneas. Entre una variada información, se señala que el rizoma de la planta hembra se ha usado en medicina como antihelmíntico; en cuanto a la planta macho, su rizoma es de sabor algo amargo y olor desagradable, y se emplea en medicina como vermífugo (RAE, II: 1091).

\section{GIMNOSPERMAS}

\section{6) Ephedra breana Phil., EPHEDR 8718 (8) T'ume, T'umi, Pingopingo $\mathrm{M}$}

Mezclada con lampaya (Lampaya medicinalis), se usa hervida como baño contra el reumatismo. Como infusión, mezclada con pelitos de choclo y soiko (Tagetes multiflora), también se usa como remedio para la vejiga, para mal de orines, para los riñones. Eventualmente se comercializa en pequeñas cantidades a Calama.

A, Q
Pinco pinco (sano sano): aymara, "Yerua buena para desecar las flemas" (B(2): 308). Pinco, "el madero largo que corre por toda la cumbre de mojinete a mojinete, donde se juntan las tijeras del tejado" (B,II: 265). Pingopingo: nombre vulgar de un arbusto sin hojas que crece en las cordilleras de todo el país. Ephedra spec. (L: 600). Pingopingo. Chile. Arbusto de la familia de las Efedráceas con flores pequeñas, y por fruto unas nuececitas que así como sus hojas son diuréticas y depurativas (RAE: 1604-1605). De acuerdo a Bertonio, tumi es el cuchillo de los indios, al modo de aquel que usan los zapateros (II:364); en quechua es cuchillo de indios de cobre a manera de segur sin cabo (GH, I:346; R:85).

\section{ANGIOSPERMAS- DICOTILEDONEAS}

7) Carpobrotus aequilaterus (Haw.) N.E.Br., AIZOAC (148)

\section{Bálsamo}

M

Plantada en huertas. El jugo de las hojas carnosas es medicinal.

$\mathrm{E}$

Del latín balsamum. Sustancia aromática que se obtiene de ciertos árboles. Medicamento compuesto de sustancias, comúnmente aromáticas, que se aplica como remedio en las heridas, llagas y otras enfermedades (RAE(1): 256).

\section{8) Schinus molle L.var. areira (L.) DC., ANACAR (96) \\ Muelle, Molle, Pimiento \\ $\mathrm{M}$}

Hay dos formas de la planta, el pimiento blanco y el rojo. Es remedio para el mal aire (dolores de cabeza, de dientes, de los ojos); se hierve un par de minutos y se aplica como cataplasma durante la noche, o para baños, mezclado con cortadera (Cortaderia speciosa) y palqui negro (Cestrum parqui); también para el dolor del estómago.

Q, E

Mulli, quechua. Un árbol y la frutilla (GH,I:249). Molle: Nombre vulgar de un grande i hermoso árbol del Perú y del norte de Chile, cultivado también en el Centro, donde se denomina pimiento (Schinus molle). Molli, (Middendorf 597), quechua, nombre de un árbol de los valles de madera dura; de las pepitas negras de la fruta se prepara una bebida fermentada (Id 604); mulli (molli): 
nombre de un árbol cuya fruta infundida con agua se usa contra los males de la vejiga. (L:510-511). Molle, del quechua molli, árbol de mediano tamaño de la familia de las Anacardiáceas, propio de América Central y Meridional, con hojas fragantes y frutos rojizos; su corteza y resina se estiman como nervina y antiespasmódicas. El mismo nombre se aplica a otro árbol de la misma familia en Bolivia, Ecuador y Perú, cuyos frutos se emplean para fabricar una especie de chicha (RAE: 1391). Molle, voz quechua y vulgar de un hermoso árbol del Perú de la familia de las Anacardiáceas (Schinus molle L.). El Molle de Chile (Central) es (también) otro vegetal, Schinus latifolius (Gill. ex Lindl.) Engler), arbusto o árbol de ramas peludas y hojas enteras, grandes, elíptico-oblongas (M:89). Pimiento es palabra española.

9) Cactaceae, sp. 1, CACTAC (101)

Pasakana, Psómor, Cardón pasakanero

Co

Cactácea voluminosa y globoide algo afín al género Soherensia. El fruto es llamado Pasakana y es comestible.

¿Q?, ¿A?, ¿K?, E

Dos palabras en aymara podrían ser sugerentes en relación al nombre pasakana: Phasa, tierra, o greda que los indios comen con papas, salsa de los indios (B,II:258) y Caana, montón de piedras o de papas (B,II:32). Psomor podría ser palabra kunza. Para significado de Cardón, ver $\mathrm{N}^{\circ} 11$.

\section{0) Cactaceae, sp. 2, CACTAC (101 B) Chikachika \\ $\mathrm{O}$}

Cactus columnar bajo, con varias ramas, que no hemos observado pero que las personas mencionan. Las espinas se usan para palillos.

A

Chica, aymara, juntamente (B, II: 79). En quechua, Chica, tantas veces (R: I, 37).

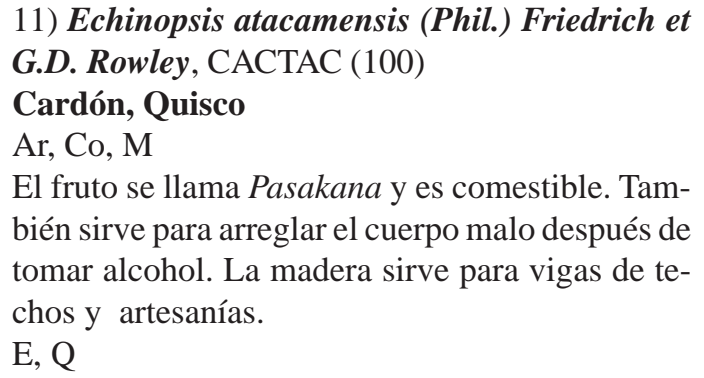

11) Echinopsis atacamensis (Phil.) Friedrich et$$
\text { G.D. Rowley, CACTAC (100) }
$$$$
\text { Cardón, Quisco }
$$$$
\mathrm{Ar}, \mathrm{Co}, \mathrm{M}
$$

El fruto se llama Pasakana y es comestible. También sirve para arreglar el cuerpo malo después de tomar alcohol. La madera sirve para vigas de techos y artesanías.

E, Q

Cardón, del castellano cardo. En Argentina, especie de cacto gigante que sirve para setos espinosos y como planta forrajera (RAE:412). Quisco, derivado del quechua Quichca, espina (GH,I:307). Quisca: espinas grandes de las especies de las Cactáceas, quisca, la espina. (L:675).

12) Opuntia camachoi Espinosa, aff., CACTAC 8794 (98)

Q'ome, Q'omer, Espina, Agujilla

$\mathrm{M}$

Las frutas (tunas) son ácidas como el limón y se prepara una bebida con su pulpa disuelta en agua cocida, colada y sin semillas ni cáscara; esta bebida es remedio para la vejiga, alivia la fiebre y sirve para los dolores de garganta. También sana las heridas. Las espinas indican "que corta" (la enfermedad), tal cual lo hace la cortadera. La flor es buena para el cáncer.

¿K?, E

Corresponde a la misma especie llamada kume en el Salar de Atacama. Ckummi, kunza, planta que parece de la familia de las tunas (V: 21). Ckumi látigo, penca (V: 21). Los nombres de Espina y Agujilla son españoles y aluden a las espinas de la planta.

13) Hoffmannseggia doellii Phil. subsp. doellii, CAESAL (125)

\section{Motokoro}

Co

La papa dulce era consumida como alimento por los antiguos (los abuelos).

Q, A

Mutu, Arborcillo de alcaparras desta tierra (B,2: 228); Buñuelos o tortillas de quinoa a semejanza de un bonete de clérigo (Ibid.). Qurur, quechua, ovillos (GH,I:56). Qura, quechua, broza, mala hierba para los cultivos en general, pero puede ser útil como forraje para el ganado (Ba:128-129).

14) Moschopsis monocephala (Phil.) Reiche, CALYCE 8766 (28)

Waje, Baji

$\mathrm{M}, \mathrm{F}$

Lo come principalmente la vicuña. La raíz se toma en infusión contra el dolor de huesos.

¿A?, ¿Q?

Huakhi, aymara, yerba que trepa como hiedra, y la forma como romaza, y buena contra frialdades (B,2:144). Según Bertonio (B,2:2), la pronuncia- 
ción de KHI, equivale a la $\mathrm{J}$ castellana. Wahi, quechua, cierta enredadera de las montañas, de uso medicinal (Li,1074). Aunque las descripciones parecen corresponder a una especie de la vertiente oriental de los Andes, Lira agrega que también hay wahi de puna. Tiene su servicio $(\mathrm{Li}, 150)$.

\section{5) Hypsela reniformis (Kunth) K.Presl, CAMPAN 8711 (54) \\ Ch'ampa, Vega, Pastos de vega \\ $\mathrm{F}$}

Forraje para el ganado. Para el significado de ch'ampa ver taxa $\mathrm{N}^{\circ} 1$.

$\mathrm{Q}, \mathrm{A}, \mathrm{E}$

Para el significado de ch'ampa ver taxa $\mathrm{N}^{\circ} 1$. Vega, antigua voz común al castellano con el portugués y sardo: Huerta, tierra baja, llana y fértil (JC:599). En Chile, terreno muy húmedo (RAE:1325).

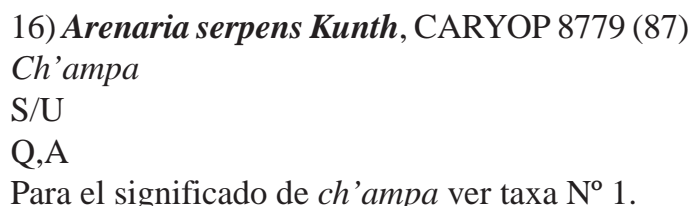

17) Pycnophyllum bryoides (Phil.) Rohrb., CARYOP 8749 (36)

\section{Yaretilla}

M

Buena para el resfriado y como tónico para el pelo. A, E

Nombre asociado al de Yarita, aymara, resina de la puna (B,2: 412), por su similitud con la yareta.

18) Pycnophyllum macropetalum Mattf., CARYOP 8755 (35)

\section{Yaretilla}

M

$\mathrm{Al}$ igual que la especie anterior, se señaló como buena para el resfriado y como tónico para el pelo.

A, E

Ver taxa anterior.

19) Atriplex imbricata (Moq.) D.Dietr., CHENOP 8676 (74)

Ojála, Kachiyuyo

$\mathrm{F}, \mathrm{L}$

Come el ganado, la cabra, la oveja. Es también leña.

¿K?, ¿E?, Q

De acuerdo a VC, Cachiyuyo, quechua, hierba de la sal. Varias especies de Chenopodiáceas (M:76). Kacha yиyu, quechua, "yeruas secadas a mano" (GH:149,1). Kachi yиyo, aymara, corresponde a Chenopodium murale (G:174). De acuerdo a VCR, el vocablo Oja, según Torero, sería voz kallawaya y pukina, que significa "comer".

\section{0) Atriplex sp - Chenopodium sp 2, CHENOP 8832 (140) \\ Yuyo \\ F, O}

Se usa para los animales. Hay dos clases, de campo y de chacra. El de campo es finito; el de hoja más ancha es de chacra. Se usa para hacer ch'ili en Caspana, más suave que la llipta que hacen en Toconce. De acuerdo a PMB, "La coquita también es buena para el dolor de la guatita. Las hojitas ahora se mascan solas, pero antes la gente usaba ch'ile, se hace de una hierba que hay, de yuyo, se saca en su tiempo y al retostarle se corre igual así que la grasa y se hace una planchita y es bastante picante, de ahí se sacaba y con ese comían antes la coca".

Q

Yuyo, "variedad de quinoa" (LE:22); Yuyu, hortaliza (B, 1:341); también, yeruas de comer cozidas (B,1:472) ; Yuyo, kunza, variedad de quinoa, llamada también sacksaholor (V:29); dícese también de otra planta comestible parecida al bledo español (V:36). Yuyu, quechua, hojas y tallo verdes y tiernos del nabo $(\mathrm{C}, 169)$. Үиуи, quechua, bledo, hojas tiernas, comestibles, de la quinua (Ba:121) (R:56). Yиyu, hortaliza, o yerua del campo de comer (R:94). Yuyu, quechua y aymara, hojas y tallo verdes y tiernos del nabo (C.169); (Ba:208). Yuyo: cualquier yerba silvestre, maleza, yerba mala. (L:784); Yuyo, variedad de quinoa (LE:22). Yuyo, quechua, denominación dada a Brassica rapa $L$., maleza comestible (M:80).

Yuyo. En Argentina, Chile y Uruguay, yerbajo, hierba inútil. En Perú hierbas tiernas comestibles (RAE: 2118).

21) Sarcocornia fruticosa (L.) A.J. Scott, CHENOP 8690 (72)

Walkita, Walchawalcha

$\mathrm{F}$

La comen los animales.

Q, E

De acuerdo a VC, Huallcca, quechua, collar o cadena, o sartal de quentas, y todo lo que se pone 
al cuello hombres y mugeres, o bestias, o animales, etc. (GH:173,2). Justamente bajo esta forma es descrita por los lugareños ("parece un collarcito").

\section{2) Ambrosia artemisioides Meyen et Walp., COMPOS 8696 (64) \\ Tikara, Pikara, Cadillo \\ F, M}

Se usa como remedio para el dolor de estómago, la úlcera y resfrío. También forraje para el burro y la cabra.

¿K?, Q; E

Tticka, kunza, señal, flor (V: 33). En quechua, Tica es flor o plumaje (R,1: 83). Tika, flor (Ba:119). Tikaray, florecer (Ba:119). Pikara, posible deformación de la palabra tikara.

Cadillo, del latín catellus, perrillo. Planta umbelífera, muy común en los campos cultivados con fruto elipsoidal erizado de espinas tiesas. También se denomina así a otra planta y a su fruto, de la familia de las Compuestas y con frutos aovados cubiertos de espinas ganchudas (RAE: 353). Nombre dado a las plantas de la familia de las Rosáceas, Acaena trifida, A. pinnatifida y $A$. splendens, con frutitos armados de aguijones derechos o glochidios que molestan tanto a los seres humanos como a los animales (M:83).

\section{3) Artemisia copa Phil., COMPOS 817 (105) Qopaqopa, Kopakopa, Qopa, Kopa $\mathrm{M}$}

Remedio para los cólicos del estómago y para el aire. Se toma en infusión.

Q, A, K

Copa, aymara, color verde, gusano como luciérnaga (B(2):52) (B,2:322). Ckopa, kunza, puño, mango. Una planta arborescente de la cordillera, "mui abundante; es la primera que se encuentra al salir del llano de Atacama, después de Peine, vía Antofagasta de la Sierra" (V:19). Ccoppa, quechua, azul claro o turquesado (GH,1:68). Copa, quechua, piedra turquesa (R:25). Copa, palabra quechua (Artemisia copa Phil.), arbusto aromático del Norte Grande, envuelto en un tomento blanquizco (M:113); también en Lenz (L:209). Kopa, una planta arborescente de la cordillera (Schuller:34); Mun:17).
24) Baccharis sp 1, COMPOS 8697 (65)

Quinchamale, Tolilla, Chillkca

$\mathrm{L}$

Se usa como leña

M, ¿A?, ¿Q?; Q, A, E; Q, A

Kinchamali, como voz aymara y Chinchamali como voz quechua, otra especie de uso medicinal en Bolivia (G, 162). Quinchamale, también podría derivarse del vocablo mapuche quinchamalí, que en mapuche alude a una yerba medicinal (L:668). Tolilla, derivado de Tola. En aymara, Ttola lahua, leña para quemar "de que hay grandes llanadas" (B,2:185). Tola, América Meridional. Nombre de diferentes especies de arbustos de la familia de las Compuestas que crecen en las laderas de las Cordilleras (RAE:1273). Ttola, planta sudamericana (JC:571). Ttola, quechua, "árboles que se llaman tola, que sirven de leña y todo el año está verde". (G:484). Tola, voz quechua, se refiere según el Dr. Reiche (Geografía Botánica) al hábito, más que a caracteres sistemáticos, de un grupo de arbustos xerófitos del extremo norte (M:105). En aymara, Chillca, hiel o cólera (B,2:82). Cchillca, una mata espinosa (B,2:85). En quechua, Chillca, mata de hojas amargas $(\mathrm{R} ; 36)$. De acuerdo a Middendorf, Chillca, plantas de unas hojas de un sabor mui amargo se emplean machacadas en cataplasmas sobre articulaciones hinchadas; también se usan para teñir de verde (VC). Chilca, voz quechua pero de uso corriente entre los mapuches, que reúne ejemplares de hojas delgadas, en su mayoría estrechas y lineares aplicada a diversa especies (M:109-110). En Colombia y Guatemala, nombre que se da a un arbusto resinoso de la familia de las Compuestas que crece en las faldas de las montañas de todo el continente americano (RAE: 645 ).

\section{5) Baccharis sp 2, COMPOS 8811 (114) \\ Chuchuka, Chukchuka, Chutchuka \\ $\mathrm{F}$ \\ Forraje para animales. Crece a orillas de ríos y en chacras.}

$\mathrm{A}, i \mathrm{Q}$ ?

Chhukhchu, temblor de todo el cuerpo, enfermedad que da en los yungas (B:(2):91). Chucchu, quechua, frío de calentura (R:38).

26) Baccharis alnifolia Meyen et Walp., COMPOS 8700, 8796 (67)

Chillka blanca 
L, M, O

Se usa principalmente como leña. También es remedio. Como parche, se usa para el estómago. También se utiliza como escoba para limpiar el horno cuando está caliente. La especie no fue distinguida de la $\mathrm{N}^{\circ} 28$.

Q, A, E

Ver $\mathrm{N}^{\circ} 24$.

27) Baccharis boliviensis (Wedd.) Cabrera, COMPOS 8722 (1)

Tola, Tolilla, Tola amarilla, Tola de salud

$\mathrm{L}$

Se usa solamente para hacer fuego.

Q, A, E

Ver $\mathrm{N}^{\circ} 24$.

28) Baccharis scandens (Ruiz et Pavón) Pers., COMPOS 8677, 8797 (68-69)

Chillka, Suncho

L, M, O

Se usa principalmente como leña. También es remedio. Se utiliza como escoba para limpiar el horno cuando está caliente. Como parche se usa para el estómago.

$\mathrm{Q}, \mathrm{A} ; \mathrm{Q}$

Ver $\mathrm{N}^{\circ}$ 24. Sunchu, quechua, muturu, hongo que se presenta en las hojas de la quínoa en forma de áreas amarillentas onduladas, adquiriendo un aspecto encrespado (Ba: 135); Suntchir, kunza, amargo (V: 30).

Suncho. Del latín cingulum. Abrazadera, zuncho. En Bolivia, planta herbácea de la familia de las Compuestas, parecida a la margarita, con flores amarillas. En Argentina, chilca, arbolito (RAE:1919).

29) Baccharis tola Phil. subsp. altiplanicola F.H. Hellwig, COMPOS 8768 (34)

Tolita, Chachakoma del burro

$\mathrm{F}$

La comen el burro y la llama, pero en poca cantidad.

Q, A, E; Q, A, E

Ver $\mathrm{N}^{\circ} 24$ para tolita. Chachakoma, aymara (B2:68): hombre pobre; Chachacuma, quichua, árbol de esta tierra (R,1:33). Chachakuma, quechua, Chachacomo: árbol pequeño de altura. Arbusto medicinal (C:34); Chachacoma, "nombre vulgar de una planta de la alta cordillera de
Coquimbo i Atacama" (Senecio eriophyton) usada en la medicina casera, balsámica, excitante, estomacal, contra la puna, etc. Uso medicinal contra la puna (Murillo 117). Chachakuma, quechua, de acuerdo a Middendorf, nombre de un árbol de 20 a 30 pies de alto, de madera mui pesada i de color morado, que tiene muchos usos en la carpintería, i no puede ser la misma planta (L:237). Chachacoma, en Chile planta de la cordillera andina, de flores amarillas y de uso en la medicina casera. (RAE:632). Chachacoma, voz quechua, según el Dr. Lenz, significa hombre pobre. Nombre de Senecio eriophyton y S. hirtus, indicados para el estómago, el mal de puna y la presión alta de la sangre (M: 113).

30) Baccharis tola Phil. subsp. tola, COMPOS 8719 (15)

Loire, Loye, Léjia, Lejía, Tola

L, R, M

$\mathrm{Su}$ tronco es un combustible más duradero que otros montes. Sirve también para la salud del ganado y es remedio para empachos. "Cuando se hace un floramento, se mueven las chullas solamente con loire". La chulla se prepara con la sicha molida del loire o tola amarilla de K'ablor y Ko'iller. Es probable que estas chullas se confeccionen con la harina de la sicha (Ombrophyton subterraneum) que produce el loire. Frente a enfermedades producidas por el rayo, es preciso "chullarla" (acto de purificación) a la persona. De acuerdo a PMB, "Chullar" se dice. "Hay una planta que produce un producto, que llamamos sicha, esas semillas finitas tienen que molerse bien molidas y eso es la chulla".

K?; E; Q, A

Probablemente, loire (y su derivado loye) sean palabras kunzas. Lejía. Del latín. Agua en que se han disuelto álcalis o sus carbonatos. La que se obtiene cociendo ceniza sirve para la colada (RAE: 1241).

31) Chaetanthera revoluta (Phil.) Cabrera, COMPOS $8762(29,30)$

$\mathrm{S} / \mathrm{U}$

Se destacó su parecido con la flor de la puna, otra especie del género (Chaetanthera sphaeoroidalis), que crece en el piso subnival de los Andes del Norte Grande de Chile. 
32) Chersodoma, aff., COMPOS 8792 (88)

Tolita

$\mathrm{S} / \mathrm{U}$

$\mathrm{Q}, \mathrm{A}, \mathrm{E}$

Ver $\mathrm{N}^{\circ} 24$

33) Chuquiraga atacamensis Kuntze, COMPOS 8726 (10)

K'iri, K'eri, Candela, Lengua de gallina

$\mathrm{M}, \mathrm{L}, \mathrm{O}, \mathrm{F}$

Se usa como abortivo, mezclado con otras hierbas.

También como leña, especialmente para el horno, para hacer pan amasado. Los animales lo comen.

A, ¿Q?; E

En aymara, Queri queeri, el fogón para guisar (B,2:290), lo que hace sentido con las excelentes propiedades combustibles de esta planta; Kero, madera, palos, o vigas, y cosas semejantes (B,2:196).

34) Chuquiraga spinosa Less. subsp. rotundifolia (Wedd.) C. Ezcurra, COMPOS 8735 (22)

Ch'ana

$\mathrm{L}, \mathrm{Ar}, \mathrm{M}$

Muy durable como combustible. Se usa también como ramadón en las estancias, se cubre el techo y encima se coloca la paja. Las flores son remedio para el corazón.

A

En aymara, Chana, el hijo nacido a la postre; Chhana, una temporada en que suele haber algo (B,2:70); Ccana, luz (B,2:41).

35) Coreopsis suaveolens Sherff, COMPOS 8843 (130)

\section{Flor amarilla}

$\mathrm{S} / \mathrm{U}$

$\mathrm{E}$

36) Cotula mexicana (DC.) Cabrera, COMPOS 8801 (120)

$\mathrm{S} / \mathrm{U}$

37) Diplostephium meyenii Wedd., COMPOS 8703 (71)

Tola, Tola de alma, Tolilla, Leña quebrolla, Quebraolla

$\mathrm{M}$

A, Q, E

Ver $\mathrm{N}^{\circ} 24$ para tola y derivados. Quebraolla, de quiebra y olla, vocablos españoles.
38) Haplopappus rigidus Phil., COMPOS 8733

(12)

Bailawen, Bailabien

M, O

Remedio para el resfrío, para el dolor de estómago, cuando cae mal la comida, y contra empachos. Se usa también como afrodisíaco.

$\mathrm{M}$

Failahuén, baylahuén, vailahuén, nombre mapuche significa fermento (Haplopappus baylahuen Remy), subarbusto de la zona marítima del norte. Contiene una resina medicinal, usada en aplicaciones externas para curación de heridas, e ingerida como estimulante, digestivo y sudorífico (M:110).

39) Parastrephia lepidophylla (Wedd.) Cabrera, COMPOS 8747 (43)

Tola amarilla, Tola amarga, Tola, Tolilla, Tola de la Cordillera, Leña del Cerro

$\mathrm{L}$

Es durable como combustible. Esta especie no fue distinguida de las dos siguientes por ninguno de los entrevistados.

A, Q, E

Ver $\mathrm{N}^{\circ} 24$ para el significado de tola y palabras derivadas.

40) Parastrephia lucida (Meyen) Cabrera, COMPOS 8770 (42)

Tola amarilla, Tola amarga, Tola, Tolilla, Tola de la Cordillera, Leña del Cerro

$\mathrm{L}$

Es durable como combustible. Ver $\mathrm{N}^{\mathrm{o}} 37$ para el significado de tola.

A, Q, E

Ver $\mathrm{N}^{\circ} 24$ para el significado de tola y palabras derivadas.

41) Parastrephia quadrangularis (Meyen) Cabrera, COMPOS $8771(40,41)$

Tola amarilla, Tola amarga, Tola, Tolilla, Tola de la Cordillera, Leña del Cerro

$\mathrm{L}$

Es durable como combustible. Ver $\mathrm{N}^{\mathrm{o}} 37$ para el significado de tola.

A, Q, E

Ver $\mathrm{N}^{\circ} 24$ para el significado de tola y palabras derivadas. 
42) Perezia ciliosa (Phil.) Reiche, COMPOS 8756

Maransel hembra

$\mathrm{S} / \mathrm{U}$

Q

Maranséra, planta lobelia de la familia de las Campanuláceas, que se usa a manera de especia (LI:630). Lira da el nombre de maranséra a una planta a la que atribuye el hecho de que al molerla, es muy gomosa y pestífera. Al batán "lo enreda con su gomosidad, y al que muele lo asfixia con el olor" (Li:90).

43) Pluchea absinthioides (Hook. et Arn.) H. Rob. et Cuatrec., COMPOS 8840 (127)

\section{Brea, Brella}

F

Es forraje

E

Brea. Del castellano, brear. Arbusto de Chile, de la familia de las Compuestas del cual se extraía una resina que se usaba en lugar de brea (RAE: 323).

\section{4) Polyachirus sp, COMPOS (154)}

\section{Hediondilla}

$\mathrm{F}$

$\mathrm{E}$

El nombre castellano Hediondilla es otorgado a otra especie en Bolivia (G:388), por su olor.

\section{5) Senecio sp, COMPOS 8758 (33)}

Pariente de la chachakoma, Chachakoma, Chachakoma macho, Pupusa

$\mathrm{M}$

A veces se le toma como chachacoma con algún resultado. Remedio para el resfrío.

Q, A, E; Q

Ver $\mathrm{N}^{\circ} 29$ para chachakoma. Pupusa, quechua, según Girault (G:452), corresponde a Werneria poposa. De acuerdo Yacoleff y Herrera (1935), se trataría de $\boldsymbol{W}$. digitata.

46) Senecio pappii Ric. et Martic., COMPOS 8748 (16)

Pupusa

M, F

Remedio para el resfrío. También forraje.

Q

Ver $\mathrm{N}^{\circ} 45$ para pupusa.
47) Senecio rosmarinus Phil., COMPOS 8739 (18)

Pupusa?, Wirawira, Viravira

F, M

El burro le come solamente cuando está seco. Es remedio para el dolor de garganta.

Q

Ver $\mathrm{N}^{\circ} 45$ para pupusa. Viravira, origen quechua: huira huira, nombre vulgar de una yerba lanuda, medicinal. Por ser famosa vulneraria i febrífuga se llama también yerba de la vida (L:769). Vira vira, expresión peruana (Gnaphalium viravira $\boldsymbol{M o l}$.), además llamado bálsamo del campo y yerba de la vida, planta envuelta enteramente en un vello blanquizco-lanudo. Tiene propiedades medicinales curativas de las heridas e interiormente en tisanas expectorantes, sudoríficas y febrífugas (M:11).

48) Tagetes minuta L., COMPOS (153)

Soiko casero

$\mathrm{M}$

$\mathrm{A}, \mathrm{Q} \mathrm{Q}$ ?

Soico, siuica, aymara, Yerba, cortadera (B,2: 321). Soiko, quechua según Girault y corresponde a esta misma especie en Bolivia.

49) Werneria glaberrima Phil., COMPOS 8761

\section{Maransel macho}

$\mathrm{M}$

Remedio para el dolor de abertura de carne y también para las quebraduras, como la Tolilla (Fabiana denudata). En infusión, también es remedio para el riñón.

Q

Ver $\mathrm{N}^{\circ} 42$ para maransel.

50) Werneria, aff., COMPOS 8781 (86)

Ch'ampa

$\mathrm{S} / \mathrm{U}$

Para el significado de ch'ampa ver $\mathrm{N}^{\mathrm{o}} 1$.

51)Descurainia perkinsiana Muschler, CRUCIF 8737 (27)

K'asawi

$\mathrm{F}$

Muy bueno para engordar los animales, la llama, la cabra, la oveja. El burro lo come seco.

$\mathrm{Q}$, ¿A?

Qasawi, quechua, casahui, enfermedad que consiste en la aparición de manchas oscuras en forma 
redondeada en la parte aérea, especialmente en las hojas, de las plantas de papa y haba. Es causada por un hongo (Ba:136).

\section{2) Frankenia triandra J. Remy, FRANKE 8760}

Yaretilla

$\mathrm{F}$

Comida para la vicuña

A, E

Ver $\mathrm{N}^{\mathrm{o}} 17$ para yaretilla.

53) Myriophyllum aquaticum (Vell.) Verdc., aff., HALORA 8717, $8812(53,115)$

Loroma

$\mathrm{F}$

Cuando está verde es buen alimento para el burro. La cabra y la oveja la comen cuando está seca.

¿Q?, ¿A?

Probablemente, del aymara, 'fino, azul' (B (1): 242).

54) Phacelia setigera Phil.; P. pinnatifida Griseb. ex Wedd., HYDROP 8744 (152)

Sobaco negro

$\mathrm{S} / \mathrm{U}$

$\mathrm{E}$

55) Satureja parvifolia (Phil.) Epling, LABIAT 8842 (131)

Muiña, Muina, Miuña

$\mathrm{M}$

Es buena para el dolor de estómago.

A

Muña, poleo de la Tierra (GH,1:249); también en Girault, para la especie que él denomina Satureja boliviana. Según Cárdenas, en Bolivia se designa genéricamente como Muñas a las plantas impregnadas a olor a menta y que son arbustos propios de la cordillera andina (1989: 295).

56) Caiophora sp, LOASAC (158)

\section{Ortega blanca}

M

E

Derivado de Ortiga. Del latín urtica. Planta herbácea de la familia de las Urticáceas, con hojas cubiertas de pelos que segregan un líquido urente, muy común en España (RAE: 1490).
57) Caiophora superba Phil., LOASAC 8701 (70) Ortega, Ortiga

$\mathrm{M}, \mathrm{O}$

Considerada remedio contra las alergias, el resfrío, la vejiga y los gusanos estomacales (lombrices). También sirve para lavarse el pelo, para que no se caiga. Lo come la cabra.

$\mathrm{E}$

Ver número anterior.

58) Tarasa tenella (Cav.) Krap., aff., MALVAC 8809 (112)

Malva

$\mathrm{S} / \mathrm{U}$

Maleza

E

Del latín malva. Planta muy abundante, de la familia de la Malváceas con flores moradas, es usada en medicina por el mucílago que contiene las hojas y las flores (RAE: 1300).

59) Prosopis chilensis (Molina) Stuntz var. chilensis, MIMOSA 8838 (133)

Algarrobo

$\mathrm{S} / \mathrm{U}$

$\mathrm{E}$

Derivado del castellano algarroba. Arbol de la familia de las Papilionáceas, originario de Oriente, cuyo fruto denominado algarroba es una vaina azucarada y comestible, de color castaño por fuera y amarillento por dentro, con semillas muy duras, y la cual se da como alimento al ganado de labor. En América se da este nombre a varios árboles y plantas, como el curbaril o cenízaro (RAE: 98).

60) Adesmia atacamensis Phil., PAPILI 8724 (6) Tamor, T'amur, Tamur, Tamorcillo, Tamurquillo F, L, M

Lo come el ganado, sobre todo el burro. También se usa como leña. Es remedio para la úlcera. Esta especie no fue distinguida de la que sigue.

¿K?; ¿K?, E

En kunza, Ttama, caliente (V:32).

61) Adesmia rhameri Phil., aff., PAPILI 8732 (5) Tamor, T'amur, Tamur, Tamorcillo, Tamurquillo F, L, M

Lo come el ganado, sobre todo el burro. También se usa como leña. Es remedio para la úlcera.

$\mathrm{K}$ ?; ¿K?, E

En kunza, Ttama, caliente (V:32). 
62) Adesmia erinacea Phil., PAPILI 8723 (7)

Añawa blanca, Espina blanca

$\mathrm{M}, \mathrm{F}$

Se usaba antiguamente como remedio para las punas. La come el ganado.

A; A, E

Añahuaya lahua, mata espinosa. (B(2):21). Lahua, leña para quemar (B:185,2), en sentido genérico.

\section{3) Adesmia spinosissima Meyen, PAPILI 8721}

Añawa, Añawa verde, Añawa colorado

$\mathrm{L}, \mathrm{F}$

Para leña y para alimentación del ganado, especialmente la oveja, corderos, la cabra y la llama.

A; A, E

Ver $\mathrm{N}^{\circ}$ anterior.

\section{4) Astragalus arequipensis Vogel, PAPILI 8741} (19)

\section{Garbanzo, Garbancillo}

P

Muy abundante en tiempo de lluvias y dañino para el animal que lo come cuando está seco: lo engorda y enloquece (llamos, burros, cabras, ovejas)

E

Español, de origen incierto. Planta herbácea de la familia de las Papilionáceas, con tallo de cuarenta o cincuenta centímetros de altura, duro y ramoso; hojas compuestas de hojuelas elípticas y aserradas por el margen; flores blancas, axilares y pedunculadas, y fruto en vaina inflada, pelosa, con una o dos semillas amarillentas, de un centímetro aproximadamente de diámetro, gibosa, y con un ápice encorvado (RAE: 1022).

65) Astragalus bustillosii Clos, PAPILI 8786 (81) Ch'ampa

$\mathrm{S} / \mathrm{U}$

Para el significado de ch'ampa ver taxa $\mathrm{N}^{\circ} 1$.

66) Lupinus oreophilus Phil., PAPILI 8746 (17) Kontokonto, Kontukontu, Konte, ¿Kontikonto?, Salkarai, Salqarai, Flor del campo

F, L, O

Los lugareños aprecian como adorno sus hermosas flores moradas, blancas y amarillas. Lo come también el ganado pero poco. Una persona lo calificó de dañino para el ganado. Se usa también como leña. A mediados del siglo XX en Socaire, oasis alto del Salar de Atacama, el nombre conte alude también a Lupinus oreophilus y se la connota como la más bella flor silvestre. El cantal, nombre kunsa del purikamani, usa esta flor como ornamento en las ceremonias de culto a los cerros con ocasión de la limpia de acequias (Mostny, 1954:75 y Munizaga y Günckel, 1958:31). De acuerdo a AACV, en la cuenca del río Salado, nuestra región de estudio, los pobladores de Toconce y Aiquina denominan a esta misma especie como flores del campo. Es muy apreciada por la belleza de sus flores y se usa como "adorno" en los hogares de Toconce. De acuerdo a VCR, son notables tres aspectos en esta variante: su calidad de especie silvestre, la denotación de su belleza y colorido por los lugareños y su carácter sagrado al ser utilizada en el contexto de la adoración a los cerros.

¿K?; ¿A?; E

Conti, según San Román, significa "gente", en cunza (VC). Ckonti, ckonte, es muy usado en cunza,según Vaisse, y significa Gente (V:19). Sallca en aymara, significa vicuñas y guanacos y animales salvajes como estos, sin dueño (B,2: 306). En quechua, Sallca es Sierra, o tierra de secano y temporal donde llueve, o puna $(\mathrm{GH}, \mathrm{I}$ : 32).

67) Lupinus subinflatus C.P.Sm., PAPILI 8736

\section{Garbanzo}

$\mathrm{P}$

Lo come también el ganado pero poco. Parece ser perjudicial para el ganado.

$\mathrm{E}$

Ver $\mathrm{N}^{\mathrm{o}} 64$ para garbanzo.

68) Plantago tubulosa Dcne., aff., PLANTA 8800 (121)

$\mathrm{S} / \mathrm{U}$

69) Gilia glutinosa Phil.; G. crassifolia Benth., POLEMO 8725 (11)

\section{Alhucema, Pasto del campo, Pasto de lluvia}

F

Lo come el ganado en la época de lluvias.

E

Alhucema, del árabe aljuzema, espliego.

70) Calandrinia occulta Phil., aff., PORTUL 8782

(85)

Ch'ampa

$\mathrm{S} / \mathrm{U}$

Para el significado de ch'ampa ver taxa $\mathrm{N}^{\mathrm{o}} 1$. 
71) Ranunculus cymbalaria Pursh f. cymbalaria, RANUNC 8707 (58)

\section{Cucharón}

$\mathrm{F}$

Forraje.

$\mathrm{E}$

La palabra alude a la forma de la hoja de la planta.

72) Ranunculus uniflorus Phil. ex Reiche f. uniflorus, RANUNC 8716 (55)

\section{Cucharón}

$\mathrm{F}$

Forraje.

E

La palabra alude a la forma de la hoja de la planta.

73) Calceolaria stellariifolia Phil., SCROPH 8745 (26)

\section{Zapatilla}

$\mathrm{M}$

Remedio para la vejiga.

E

La palabra alude a la forma de las flores de la planta. En Bolivia, el mismo nombre se usa para designar a otras especies de Calceolaria (G: 403).

74) Mimulus glabratus Kunth, SCROPH 8802, $8789(92,123)$

\section{Berro}

\section{Co F M}

Se come en ensaladas y es remedio para el hígado.

E

Berro, español, "Crucífera de lugares aguanosos que se come en ensaladas" (JC:94).

75) Cestrum parqui L'Hérit., SOLANA 8839 (124)

Palki

M

Remedio

M

Nombre vulgar de un arbusto o arbolillo mui común i de mal olor; es de mucho uso en la medicina casera como diaforético, excelente sudorífico. Etimología mapuche (L: 547). De origen araucano. Arbusto americano de la familia de las Solanáceas de olor fétido. Su cocimiento se emplea en Chile contra la tiña, y como sudorífico, y la planta para hacer jabón (RAE: 1512).
76) Fabiana denudata Miers, SOLANA 8751 (2) Tolilla

M, R

Remedio muy bueno para quebraduras de huesos de la gente y de los animales. Se usa molida, a modo de pasta mezclada con excremento de guaichu, y con otros ingredientes (claras de huevo) para enyesar. La tolilla se muele bien y se mezcla con orines hasta que queda como una pomada y ahí se le agregan el resto de los ingredientes También es buena para el estómago y dolores internos. Se usa tradicionalmente en las fiestas cuando fallece un pariente, para hacer sahumerio. De acuerdo a PMB, los yerbateros traen un polvo de Bolivia, llamado "soldac- soldac", que se mezcla con el guano de guaicho. ("Esta pomada se pone calientito donde está la fractura, se pone encima un trapo y se aprieta bien fuerte y se deja sin mover hasta que pasa todo el dolor").

Q, A

De acuerdo a VC, Tola, se usa en América meridional. Nombre de diferentes especies de arbustos de la familia de las Compuestas que crecen en las laderas de las Cordilleras (RAE:1273). Derivado del aymara Ttola, planta sudamericana (JC:571). Ttola, quechua, "árboles que se llaman tola, que sirven de leña y todo el año está verde". (G:484). V \& C.

77) Fabiana ramulosa (Wedd.) Hunz. et Barboza, SOLANA 8698 (66)

Tola, Tara

F, L, M

Muy abundante. Se usa como leña y algo la come el ganado. Se emplea para impedir la caída del cabello

Q, A; Q

Ver $\mathrm{N}^{\circ} 76$ para el significado de tola. Ttara, es nombre quechua según Girault y designa entre los kallawaya a la especie Caesalpinia tinctoria (G:252). Tara. Perú, arbusto con hojas pinadas, flores amarillas, y legumbres oblongas y esponjosas (RAE: 1944). Ttara, kunza, blanco: duro, firme: dícese de un terreno con eflorescencias salitrosas que a la vez que blanco, lo hacen firme i duro (V: 33). Tara, quechua, psispalla, ispata; Formación no típica de dos yemas separadas que presentan los tubérculos de papas y ocas; se considera que es el espíritu de las plantas tubíferas (Ba:178). Tara (Coulteria tinctoria H.B. Kth.), árbol del norte; usado en medicina por sus propie- 
dades astringentes y en tintorería para teñir de negro.

78) Fabiana squamata Phil., SOLANA 8769 (44) Qoba, Q'oba, Koba, Koba Santiago, Koa, Koa Santiago, Illakowa, Koille

$\mathrm{L}, \mathrm{R}$

Se usa para el sahumerio del ganado, para la suerte. Es una costumbre. Durante el floramento del ganado en verano y para el rodeo del ganado (junio), se la quema con incienso (resina de llareta, Azorella compacta) y con wirakoba (especie proveniente de Bolivia) ${ }^{8}$. Se nos informó, textualmente: "Con la koba Santiago pedimos a Dios nuestro Señor, a San Santiago. La wirakoba se pone para la Pachamama, para la Santa Tierra. El incienso va con la oración. Se ponen los tres y con ese compuesto dentro de un cobero (vasija de greda de uso ceremonial), la señora se hinca y suplica al Señor por su ganado, por lo que tiene, por lo que va a hacer, especialmente como estímulo para el floramento". También se usa para la salud de las personas: "la ponemos en el nacimiento". Se puede usar como leña. La virakoba se trae de Bolivia y también otra clase de incienso.

De acuerdo a PD, la ceremonia de floramiento se realiza dentro del corral. En la puerta se ponen ramas de $k^{\prime} \circ a$, dirigidas hacia afuera para que señalen el camino a los animales; los dueños del ganado recorren varias veces el corral tirando chicha de maíz, coca y alcohol a la tierra, pachamama, dentro y fuera del recinto, sobre las flores que aún no han sido colocadas y sobre los animales. Mientras el hombre va haciendo las ofrendas la mujer lleva un plato con ramas de k'oa humeando, que no debe prender llamas (sahumerio). Según PMB, es usual que en la época del carnaval, después de floramentos estivales y antes de Semana Santa, el día martes de carnaval, la gente challe (bendiga) sus vehículos y "entonces los dueños ponen el vino, la hoja de coca, la koba, la virakoba". "Los pagos a Santiago son en primer lugar con koba Santiago, la virakoba, la grasa y junto con eso van las chullas, la chicha cocida,

De acuerdo a Cárdenas (1989), en Bolivia la koa más común es llamada huira-koa. Corresponde a una especie de Diplostephium que crece en el norte de Chile o en la frontera con Bolivia. De acuerdo a Castro, Villagrán \& Kalin (1982), la koa en los Andes de Arica es Diplostephium cinereum. guantada, la harina blanca y la harina culle. En Toconce la koa o koa Santiago es Fabiana bryoides y se la usa en todos los pagos, quemándola como incienso en un cobero, un sahumador de cerámica o piedra volcánica confeccionado exclusivamente para este propósito (AACV). En Socaire, Munizaga y Gunckel (1958) atribuyen usos similares a la especie Parastrephia quadrangularis que se nombra allá como coba o koa.

$\mathrm{Q}$, ¿A?

Wira-quya, quechua, hierba silvestre, hierba para sahumar los cultivos. Planta de manchas blancas en los tallos y las hojas que crece en las punas y se la utiliza en los ritos y ceremonias para proteger los cultivos. (Ba: 179). Koa, (ver Huayccha). Orégano de acá de esta tierra (B (2):56). Illakowa es palabra aymara.

79) Lycium humile Phil., SOLANA 8798 (73)

Ch'ampita

F, P

La come el animal. Para la siembra es mala hierba.

Para el significado de ch'ampa ver taxa $\mathrm{N}^{\circ} 1$.

80) Azorella compacta Phil., UMBELL 8767 (39) Yareta

M, L

Remedio para la tos, se toma como mate. Medicina para la diabetes. La llareta es reconocida como el mejor combustible.

A

Según VC, Yareta, yaretilla, voces americanas de procedencia discutida (M:98). Yarita, aymara, 'resina de la puna' (B:412,2).

81) Lilaeopsis macloviana (Gand.) A.W. Hill, UMBELL $8708(52,77)$

$\mathrm{S} / \mathrm{U}$

82) Mulinum crassifolium Phil., UMBELL 8757 (20)

\section{Chukikandi, Chukikandia, Chuchikandia}

$\mathrm{M}$

Remedio para el resfriado, para la tos, para los pulmones y también para la diabetes. Se le toma en mate reposado, con azúcar quemada, leche y unas gotitas de vino.

Q, A 
Chuki, voz aymara para designar a la planta Pragmitis communis, especie silvestre que crece en los yungas de Coroico (G: 118). Chuqui es lanza en aymara (B: 93). Chuqui, lanza, en quechua (R: 38).

83) Acantholippia deserticola (Phil. Ex F. Phil) Moldenke, VERBEN 8730 (3)

Qore, Qori, Rikarika

$\mathrm{M}, \mathrm{L}$

Se utiliza para el dolor de estómago, cuando cae mal la comida y para el hielo (gripe). Se prepara en mate el tallo o la semilla; también se preparan los tallos tostados y cocidos en infusión. Se usa como leña principalmente la raíz, cuando está seca. De acuerdo a PMB, "Para el dolor de estómago es bueno la rica rica, nosotros le decimos el k'ore, la muina. Se prepara un agüita".

¿K?; ¿Q?, ¿E?

La palabra es probablemente kunza y denomina la misma especie conocida en el salar de Atacama como kore o kori. En cunza, Ckori es gordo (V:20). Pierna de cori o rica-rica, dícese como apodo al que tiene la pierna velluda (V:20). En quechua, Cori, oro, metal (R:25).

84) Junellia seriphioides (Gillies et Hook.) Moldenke, VERBEN 8720 (14)

Comida de llamo (a), Rosa, Rosas, Vinovino

$\mathrm{F}$

Todas las personas entrevistadas destacan su hermosura y su olor fragante cuando florece rosado. Lo come sobre todo la llama cuando está verde; el burro lo come cuando está seco.

$\mathrm{E} ; i \mathrm{E}$ ?

85) Lampaya medicinalis Phil., VERBEN (157) Lampaya

$\mathrm{M}$

$\mathrm{Q}, \mathrm{A}$

Nombre vulgar de un arbustito medicinal de la cordillera de Atacama, Verbenácea, Lampaya medicinalis Ph. (L:422). Lampaya voz aymara (Lampaya medicinalis Phil.), arbusto bajo de gruesas hojas ovales, preconizado como antirreumático, sudorífico e indicado contra los resfriados. Crece en la cordillera de Tarapacá (M:103).

86) Pitraea cuneato-ovata (Cav.) Caro, VERBEN 8828 (143)

\section{Papa blanca}

$\mathrm{P}$

Maleza perjudicial para los sembrados.

Q, E

Papa, quechua, rayzes de comer que sirven de pan como turmas de tierra (GH, I :279).

87) Urbania pappigera Phil., VERBEN 8765 (37) $\mathrm{S} / \mathrm{U}$

88) Verbena bonariensis L., VERBEN 8836 (136) Verbena

$\mathrm{M}$

Remedio para heridas internas.

De acuerdo a PMB, "La verbena era buena para el lastimado, para el golpe, se toma, también se machucan y se pone en el machucón".

$\mathrm{E}$

Del latín verbena, herbácea anual de la familia de la Verbenáceas, muy común en España (RAE: 2076).

\section{ANGIOSPERMAS MONOCOTILEDONEAS}

89) Eleocharis sp, CYPERA 8775 (78)

Ch'ampa, Vega, Pastos de vega

$\mathrm{S} / \mathrm{U}$

Para el significado de ch'ampa ver taxa $\mathrm{N}^{\circ} 1$.

90) Scirpus sp 1, CYPERA 8679 (61)

Unquillo liso, Junquillo

Ar, F, O

Sirve para amarrar las flores y las verduras; también para el trenzado, para artesanías, para canastos. Es forraje para el ganado. Tiene los mismos usos que Juncus arcticus.

E

Español, de junco (del latín Juncus) (RAE:775). Junquillar, español, nombre dado a varias especies del género Juncus (M: 67).

91) Scirpus sp 2, CYPERA 8694 (62)

Unquillo cuadrado, Junquillo

F

Sirve solo para el ganado.

$\mathrm{E}$

Ver taxa anterior.

92) Scirpus deserticola Phil.; S. atacamensis (Phil.) Boeck., CYPERA 8778, 8803, (75, 119) Ch'ampa, Vega, Pastos de vega 
F

Para el significado de ch'ampa ver taxa $\mathrm{N}^{\circ} 1$. Q, A; E

93) Anatherostipa venusta (Phil.) Peñail., GRAMIN 8752 (25)

\section{Paja, Cebadilla}

$\mathrm{O}, \mathrm{F}$

Anuncia el tiempo no muy bueno; cuando florece decimos "este año no va a llover". También la come el animal, la llama, el burro.

$\mathrm{E}$

Paja, del latín palea. Caña de trigo, cebada, centeno y otras Gramíneas, después de seca y separada del grano (RAE: 1501). Cebadilla, español, identifica una especie de cebada que crece espontáneamente (RAE:383).

\section{4) Bromus catharticus Vahl, GRAMIN 8806} (110)

\section{Sailao, Pasto blanco, Cebadilla}

$\mathrm{F}$

¿K?; E

Para cebadilla, ver taxa $\mathrm{N}^{\circ}$ 93. Sailao, se conserva como topónimo de un predio agrícola en Calama (LE:58), luego podría ser un vocablo kunza o derivado de otra lengua indígena. En Atacama sailau, fue un nombre usado como apellido indígena en 1612 (V:29). De acuerdo a VC, Sailla, quechua, Festuca dolichophylla (G:117).

95) Deyeuxia eminens J. Presl, aff., GRAMIN 8773, $8706(80,60)$

Paja, Chillawa, Paja Chillawa, wailla

Ar, F

Para los techos en las estancias. Se pone abajo y encima otras pajas o montes. También se usa a veces para techar la cocina. La come el burro, la llama.

E; Q, A

Para paja ver $\mathrm{N}^{\circ} 93$. De acuerdo a VC, Cchillihua, aymara, 'hicho gordo y liso como la caña del trigo de que hazen petacas, y otras muchas cosas' (B:130 y 264, 2). Huaylla, aymara, 'hicho largo y blando con que cubren las casas' (B:156, 1; 130,2). Huaylla, quechua, 'el prado verde no agostado, o el buen pasto (GH: 192,2). 'Pastizal, prado' (C:163).

96) Cortaderia speciosa (Nees et Meyen) Stapf, GRAMIN 8704 (59)

Cortadera, Cola de zorro, Kuchucho (flor)
Ar, M, O

La raíz tierna, hervida y con azúcar tostada, es remedio para el resfrío y la fiebre. Las raíces y las hojas se usan también como baños, para los resfríos; la flor, para el enfriamiento. Es buena para hacer el aparejo para el burro y el tallo de la cortadera también se usa para techumbres de casas, poniendolo bajo la paja. La flor (inflorescencia) se usa para adorno y se llama Kuchucho. De acuerdo a PD, la primera corrida del techo es de cortadera, traída de la quebrada, se va colocando en capas una hacia arriba y otra hacia abajo. Sobre ella se pone la paja brava (traída de los cerros a mayor distancia), en montones que han sido untados previamente con barro arcilloso en la base. El techamiento solamente puede hacerse durante los meses de septiembre a marzo, por una parte, debido a que el barro que se usa es muy helado, lo cual dificulta su manipulación en invierno, y, por otra, porque la cortadera y la paja están más tiernas y se pueden trabajar mejor; seca produce cortaduras en las manos. Un techo de paja puede durar entre 15 y 20 años.

E, Q

De acuerdo a VC, Cortadera, español, de cortar. En Argentina, mata de Gramineae propia de terrenos llanos y húmedos de hojas angostas de color verde-azulado, y flores en panículas fusiformes, grisácea con reflejos plateados (RAE:369). Kuchucho es una palabra quichua (LI:539).

\section{7) Deyeuxia sp 1, GRAMIN 8790 (90)}

Chuku, Paja, Chuklla

$\mathrm{F}$

Lo comen las llamas, las vicuñas.

$\mathrm{A}$, ¿Q?; E

Para paja ver $\mathrm{N}^{\circ}$ 93. De acuerdo a VC, Cchukhu, aymara, "espinoso hablando de la leña" (B:228,1). Сhиси, quechua, "bonetes o sombreros antiguos" (GH:118,2). Chhukhlla, aymara, "pajita" (B:343,1). $\mathrm{V} \& \mathrm{C}$

98) Deyeuxia sp 2, GRAMIN 8791 (91)

Paja

$\mathrm{F}$

E

Para paja ver $\mathrm{N}^{\circ} 93$.

99) Deyeuxia sp 3, GRAMIN 8787 (93)

Paja

F

E

Para paja ver $\mathrm{N}^{\circ} 93$. 
100) Distichlis scoparia (Kunth) Arechav., GRAMIN 8695 (49)

\section{Grama}

$\mathrm{F}$

Lo comen los animales.

$\mathrm{E}$

De acuerdo a VC, Grama, español, del latín Gramen (RAE:674).

101) Distichlis sp, GRAMIN 8713 (50)

\section{Grama}

$\mathrm{F}$

E

Para el significado del nombre ver la especie anterior.

102) Festuca chrysophylla Phil., GRAMIN 8738 (23)

\section{Paja brava, Iru, Paja}

Ar, F

Se usa para los techos de las casas, antes de la floración. También para la alimentación del llamo y del burro. De acuerdo a PD, el techamiento es un trabajo colectivo. Mientras las mujeres se dividen en dos grupos: unas en la cocina ayudando en la preparación de las comidas y otras "chancando" la paja brava, es decir golpeando la parte de la raíz para dejarla limpia, los hombres van haciendo montones con la paja, untándolos con el barro y acarreándolos hasta la casa, donde otros que están sobre el techo los van colocando.

E; Q, A

Para paja ver $\mathrm{N}^{\circ} 93$. De acuerdo a VC, del quechua Ichhu, paja del cerro (C:59). Del aymara Hichu, "yerba como esparto (retama) cuyas especies es bien saberla que son éstas: Orco sicuya, Cachu sicuya, Huaylla, Cchillihua, Phurqhue, Iru” (B:130,2).

103) Puccinellia frigida (Phil.) I.M. Johnst., GRAMIN 8693, 8715 (48)

$\mathrm{F}$

Sin nombre, se la llamó pasto de las orillas no mas.

104) Pennisetum chilense (E. Desv.) B.D. Jackson ex R.E. Fries, GRAMIN 8731 (4)

Qhaiwa, Qhaiba, Qaiba, Kaiba, Paja, Esporal, Paja blanca
F, O

Forraje. Las cañas más largas se usan para tostar. Es considerada mala hierba porque crece entre las siembras y si no se desmaleza, no deja madurar los cultivos.

Q; E; ¿E?

De acuerdo a VC, Kaiwa, quechua, corresponde a Cyclanthera sp, especie cultivada de las Yungas (G:421).

105) Jarava frigida (Phil.) F. Rojas, aff., GRAMIN 8743 (24)

Paja fina, Paja vizcachera

$\mathrm{F}$

Le come sobre todo la vizcacha, las llamas poco. Una persona informa que esta paja sirve para espantar espíritus malos.

E; E, Q

Para paja ver $\mathrm{N}^{\circ} 93$.

106) Nasella nardoides (Phil.) Barlworth, GRAMIN 8759 (45)

Chuko, Paja, Pajita, Cebadilla

$\mathrm{F}$

La come mucho el ganado, la llama.

$\mathrm{A}, i \mathrm{Q}$; E

Para paja ver $\mathrm{N}^{\circ}$ 93. Para cebadilla ver $\mathrm{N}^{\circ} 93$; Para chuko ver $\mathrm{N}^{\circ} 97$.

107) Juncus arcticus Willd., JUNCAC 8705,8813 $(63,116)$

Unquillo liso, Unquillo duro, Junquillo

Ar, F, O

El unquillo liso sirve como cordel para amarrar la verdura, las flores. También para prensados, para artesanía, canastos. Es forraje.

$\mathrm{E}$

Para unquillo ver $\mathrm{N}^{\circ} 90$

108) Juncus sp, JUNCAC 8804 (118)

109) Oxychloe andina Phil., JUNCAC 8785 (82) Maizal

$\mathrm{S} / \mathrm{U}$

$\mathrm{E}$

Palabra derivada de mahiz, vocablo posiblemente haitiano (L: 465).

110) Triglochin striatum Ruiz et Pavon, JUNCAG 8692, $8692(51,79)$

Ch'ampa, Vega, Pastos de vega

$\mathrm{F}$

Para el significado de ch'ampa ver taxa $\mathrm{N}^{\mathrm{o}} 1$. 
111) Lemna valdiviana Phil. (¿L. minuta Kunth?), LEMNAC 8783 (84)

Flor del agua, $C h$ 'ampa

F

Para el significado de ch'ampa ver taxa $\mathrm{N}^{\mathrm{o}} 1$.

112) Ruppia filifolia (Phil.) Skottsb./ Potamogeton, RUPPIA 8799 (122)

Agua sana

$\mathrm{F}$

E

De acuerdo a VC, Agua sana, de las mismas palabras en español (JC:365).

\section{ESPECIES PLANTADAS Y MALEZAS}

113) Cupressus sp, CUPRES 8824 (151)

Pino

$\mathrm{S} / \mathrm{U}$

Arbol plantado en el poblado de Caspana.

E

114) Senna bicapsularis (L.) Roxb. / S. septentrionalis, aff., CAESAL 8837 (134)

\section{$\mathrm{S} / \mathrm{U}$}

Arbolito sin nombre y plantado en el pueblo de Caspana.

115) Artemisia abrotanum L., COMPOS 8824

Eter

M

En huertas. Para el dolor de estómago. Compone el cuerpo cuando está malo por embriaguez.

E

116) Bidens laevis (L.) Britton, Sterns et Poggenb., COMPOS 8823 (145)

Té

$\mathrm{S} / \mathrm{U}$

Maleza.

E

117) Matricaria chamonilla L., aff., COMPOS (156)

\section{Manzanilla}

M

Plantado en huertas como hierba medicinal.

E

118) Sonchus asper (L.) J.Hill, COMPOS 8835 (135)
Werakucha, Wirakucha, Verakucha, Wirakocha $\mathrm{M}$

Maleza medicinal. Se usa para aliviar el resfrío de las guaguas, haciendo un matecito.

Q

Wira-q'uya, quechua, hierba silvestre, hierba para sahumar los cultivos (Ba: 179).

119) Taraxacum officinale Weber, COMPOS $8808(109,139)$

Lengua de león, Achicoria

F, M

Maleza de reciente incorporación en la zona y usada como forraje y medicina.

E

120) Xanthium spinosum L., COMPOS 8830 (126)

Cepacaballo

$\mathrm{S} / \mathrm{U}$

Maleza. Pasto.

E

Cepa Caballo, Ajonjera (RAE: 459). Ajonjera: Planta perenne de la familia de las Compuestas, de treinta a cuarenta centímetros de altura, con raíz fusiforme, hojas puntiagudas y espinosas y flores amarillentas (RAE: 76).

121) Convolvulus arvensis L., CONVOL 8818 (104)

Corriwela, Correwela, Corrihuela, Correhuela, Corrijuela, Correvuela, Verdelaga

$\mathrm{F}, \mathrm{M}$

Maleza. Reemplaza a la alfalfa para alimentar conejos. Medicina para el estómago y vejiga.

E

Correhuela. Derivado del castellano. Mata de la familia de las Convolvuláceas, de tallos largos y rastreros que se enroscan en los objetos que se encuentran. Se emplea como vulneraria (RAE: 579).

Verdolaga, en castellano, del mozárabe berdolaca, planta herbácea anual, de la familia de las Portulacáceas, con tallos tendidos, gruesos, jugosos. Es planta hortense y se usa como verdura. Por extensión, cualquier verdura.

122) Capsella bursa-pastoris (L.) Medik., CRUCIF 8820 (102)

Triangular, Pasto blanco

$\mathrm{P}$

Maleza dañina

E 
123) Lepidium sp 1, CRUCIF 8825 (129)

$\mathrm{P}$

Hierba mala, maleza.

124) Lepidium sp 2, CRUCIF 8815 (107)

$\mathrm{P}$

Maleza. Hierba mala.

125) Erodium cicutarium (L.) L'Hér. ex Aiton, GERANI 8814 (108) Agujilla, Alfilerillo, Alfileres, Tachuela

$\mathrm{F}$

Maleza. Forraje para conejos.

E

Alusión a la forma de los frutos.

126) Marrubium vulgare L., LABIAT (97)

Toronjil cuyano, Paiko cuyano, Ajenko

M

Plantada en huertas como medicina. Es bueno para bajar la presión, mejor que el matico (Buddleja globosa). También para el dolor de estómago y para hacer fricciones.

E; Q; E

Toronjil. Del árabe turunyan, turunyin, hierba abejera. Planta herbácea anual, de la familia de las Labiadas, sus hojas se usan como remedio tónico y antiespasmódico (RAE: 1999). Cuyano. Natural de la región de Cuyo, Argentina. En Chile, dícese de los naturales de la República Argentina (RAE: 631).

Payco, quechua, hierba medicinal (R: 69). Paico, del quechua, payqu. En América Meridional, planta herbácea de la familia de las Quenopodiáceas, usada como antihelmíntico en la medicina popular (RAE: 1500). Paico, quechua, comprende la sección Ambrina del género Chenopodium (Ch. ambrosioides, Ch. pinnatisectum, Ch. andicola $y$ Ch. chilense), planta muy aromática, su infusión es eficaz para afecciones estomacales y digestivas (M: 75). Ajenko, derivado del castellano ajenjo. Planta perenne de la familia de las Compuestas de hojas blanquecinas; es medicinal, muy amarga y algo aromática. También se confeccionan con ella algunas bebidas alcohólicas. (RAE: 74)]

127) Mentha piperita L., LABIAT 8822 (146)

\section{Yerba buena}

M

Plantada en huertas como medicina.

E
De las palabras castellanas hierba y buena. Planta herbácea de la familia de las Labiadas, se cultiva mucho en las huertas y se la utiliza como condimento. El mismo nombre se da a otras plantas Labiadas parecidas a la anterior como el mastrazo, el sándalo y el poleo (RAE: 1105).

128) Mentha citrata Ehrh., LABIAT 8821 (147) Menta

M

Plantada en huertas como medicina.

$\mathrm{E}$

Del latín, menta. Hierbabuena (RAE: 1356).

129) Origanum marjorana L., LABIAT 8807

Orégano

Co

Plantada en huertas como aliño.

$\mathrm{E}$

130) Medicago sativa L., PAPILI 8729 (95)

Alfalfa, Alfa

$\mathrm{F}$

El forraje más importante en la región. La alfalfa se cultiva como forraje complementario, para el corral.

$\mathrm{E}$

Del árabe, al-fasfasa. Melga común que se cultiva para forraje. También se denomina así a un arbusto siempreverde de la familia de las Papilionáceas. Es originario de Italia y se cultiva como planta de adorno y para forraje (RAE: 95).

131) Melilotus indicus (L.) All., PAPILI 8728 (94) Trigól, Trébol, Treból

F

Pasto para el ganado, ovejas, burros. Es veneno para los conejos.

E

Del catalán trébol y este del griego. Planta herbácea anual, de la familia de las Papilionáceas, es espontánea en España . (RAE: 2020).

132) Melilotus/Medicago, aff., PAPILI 8810 (113) Trébol

F

E

Ver $\mathrm{N}^{\mathrm{o}}$ anterior. 
133) Plantago major L., PLANTA 8816 (106)

\section{Llantén}

$\mathrm{M}$

Maleza. Remedio para el cáncer, heridas. Se toma mezclada con toronjil cuyano.

$\mathrm{E}$

Del latín plantago, inis. Planta herbácea, de la familia de las Plantagináceas, muy común en los sitios húmedos; el cocimiento de las hoja se usa en medicina (RAE: 1280).

134) Polygonum aviculare L, aff., POLYGO 8831

$\mathrm{S} / \mathrm{U}$

Maleza

135) Rumex crispus L., aff., POLYGO 8829 (142)

\section{Lanteja}

F

Maleza usada como forraje.

$\mathrm{E}$

\section{6) Ruta chalepensis L., RUTACE (149)}

\section{Ruda}

$\mathrm{M}$

Plantada en huertas como medicina.

Según PMB, "Para apurar la guagua era la ruda, porque eso como que le abriga al cuerpo y apura el parto. Otros dicen el hinojo. Si toma ruda por ejemplo, para tener el primero, con eso tiene que seguir y tener todos sus críos, no cambiar.' E

Del latín ruta. Planta perenne de la familia de las Rutáceas, de olor fuerte y desagradable, usada en medicina (RAE, 1816).

\section{7) Tamarix gallica, TAMARI (150)}

\section{Pino}

$\mathrm{S} / \mathrm{U}$

Arbol plantado en el pueblo de Caspana.

E

138) Foeniculum vulgare Mill., UMBELL (155)

\section{Hinojo}

M

Medicinal.

E

Del bajo latín foeniculum. Planta herbácea de la familia de las Umbelíferas; toda la planta es aromática, de sabor dulce, y se usa en medicina y como condimento (RAE: 1110).
139) Avena sativa L., GRAMIN 8833 (138)

Cizaña

$\mathrm{S} / \mathrm{U}$

$\mathrm{E}$

140) Hordeum vulgare L., aff., GRAMIN 8834

(137)

$\mathrm{S} / \mathrm{U}$

141) Polypogon interruptus Kunth, GRAMIN 8678 (46)

Sailáo, Sáilao

$\mathrm{F}$

Maleza de los sembrados.

¿K?

Ver $\mathrm{N}^{\circ} 94$.

142) Polypogon monspeliensis (L.) Desf., GRAMIN 8714 (47)

Sailáo, Sáilao

F

Maleza de los sembrados.

¿K?

Ver $\mathrm{N}^{\circ} 94$.

Otras especies mencionadas por Don Julián Colamar y no coleccionadas por nosotros:

143) Krameria lappacea (Dombey) Burdet et B.B. Simpson, KRAMER

Tikara, Chakachaka

Q, ¿K?; Q

Tikara [ti'kare], 31, 76, Q, ¿K? Tticka, kunza, “señal, flor" (V:33). Técara, kunza, "nueve" (SR:9). En quechua, Tica. Flor o plumaje (R(1):83). T'ika, "flor" (Ba:119). T'ikaray, florecer (Ba:119). En aymara, "Ttica", escudilla "de hicho de que usan en los caminos porque no se quiebra; es también una caxuela redonda de hicho[paja] en que los hechiceros guardan cosas para sus embustes" (B(2):354). "Tica". Adobe de barro (B(2):353); la misma grafía y significado en quechua ( $\mathrm{R}(2): 83)$. Ch'aka, quechua: afónico, ronco, que sufre ronquera, que no tiene voz, sin sonido (LI:153).

144) Ombrophyton subterraneum (Aspl.) Hansen, BALANO

Sicha, Ank'añoca

No hemos visto la especie en Caspana. Las sichas son tuberosidades radicales que corresponden a la planta parásita Ombrophyton subterraneum. 
Son muy apetecidas como alimento y también tienen uso ceremonial. El nombre sicha ha sido registrado, para esta especie, en el Loa Superior (AACV).
¿?; Q

Hank'a, quechua, rosetas de grano tostado (LI:215); ñocca, yo (GH(1):23 y 263). 
ANEXO 2

NOMBRES ASIGNADOS LOCALMENTE A LAS ESPECIES DE CASPANA, ORDENADOS ALFABETICAMENTE Y SUS POSIBLES LENGUAS

( A, aymara; E, español; K, kunza; M, mapuche; Q= quechua; ?= desconocido. Los números al lado de cada nombre se refieren al orden de las especies en el Anexo 1).

\begin{tabular}{|c|c|c|}
\hline Achicoria & $\mathrm{E}$ & 119 \\
\hline Aguasana & $\mathrm{E}$ & 112 \\
\hline Agujilla & $\mathrm{E}$ & 12,125 \\
\hline Ajenko & $\mathrm{E}$ & 126 \\
\hline Alfa & $\mathrm{E}$ & 130 \\
\hline Alfalfa & $\mathrm{E}$ & 130 \\
\hline Alfileres & $\mathrm{E}$ & 125 \\
\hline Alfilerillo & $\mathrm{E}$ & 125 \\
\hline Algarrobo & $\mathrm{E}$ & 59 \\
\hline Alucema & $\mathrm{E}$ & 69 \\
\hline Añawa & A & 63 \\
\hline Añawa blanca & $\mathrm{A}, \mathrm{E}$ & 62 \\
\hline Añawa colorado & $\bar{A}, \mathrm{E}$ & 63 \\
\hline Añawa verde & $\mathrm{A}, \mathrm{E}$ & 63 \\
\hline Bailabien & M & 38 \\
\hline Bailawen & $\bar{M}$ & 38 \\
\hline Baji & ¿A?, ¿Q? & 14 \\
\hline Bálsamo & $\mathrm{E}$ & 7 \\
\hline Berro & $\mathrm{E}$ & 74 \\
\hline Brea & $\mathrm{E}$ & 43 \\
\hline Breya & $\mathrm{E}$ & 43 \\
\hline Cadillo & $\mathrm{E}$ & 22 \\
\hline Candela & $\mathrm{E}$ & 33 \\
\hline Cardón & $\mathrm{E}$ & 11 \\
\hline Cardón pasakanero & $\mathrm{E}$, ¿Q?,A? & 9 \\
\hline Cebadilla & $\mathrm{E}$ & $93,94,106$ \\
\hline Cepacaballo & $\mathrm{E}$ & 120 \\
\hline Ch'ampa & $\bar{Q}, \mathrm{~A}$ & $\begin{array}{c}1,4,15,16, \\
50,65,70, \\
89,92,110, \\
111\end{array}$ \\
\hline Ch'ampita & $\mathrm{Q}, \mathrm{A}, \mathrm{E}$ & 79 \\
\hline Ch'ana & A & 34 \\
\hline Chachakoma & $\mathrm{Q}, \mathrm{A}$ & 45 \\
\hline Chachakoma del burro & $\mathrm{Q}, \mathrm{A}, \mathrm{E}$ & 29 \\
\hline Chachakoma macho & $\mathrm{Q}, \mathrm{A}, \mathrm{E}$ & 45 \\
\hline Chikachika & A & 10 \\
\hline Chillawa & $\overline{\mathrm{Q}, \mathrm{A}}$ & 95 \\
\hline Chillka & $\mathrm{Q}, \mathrm{A}$ & 24,28 \\
\hline Chillka blanca & $\mathrm{Q}, \mathrm{A}, \mathrm{E}$ & 26 \\
\hline Chuchikandia & $\mathrm{Q}$, ¿A? & 82 \\
\hline Chuchuka & $\mathrm{A}, \iota \mathrm{Q} ?$ & 25 \\
\hline
\end{tabular}

\begin{tabular}{|c|c|c|}
\hline Chukchuka & $\mathrm{A}, i \mathrm{Q} ?$ & 25 \\
\hline Chukikandi & $\mathrm{Q}, \mathrm{A}$ & 82 \\
\hline Chukikandia & $\mathrm{Q}, \mathrm{A}$ & 82 \\
\hline Chuklla & $\mathrm{A}, i \mathrm{Q} ?$ & 97 \\
\hline Chuko & $\mathrm{A}, i \mathrm{Q} ?$ & 106 \\
\hline Chuku & $\mathrm{A}, \iota \mathrm{Q} ?$ & 97 \\
\hline Chutchuka & $\mathrm{A}, i \mathrm{Q} ?$ & 25 \\
\hline Cizaña & $\mathrm{E}$ & 139 \\
\hline Cola de zorro & $\mathrm{E}$ & 96 \\
\hline Comida de llamo (a) & $\mathrm{E}$ & 84 \\
\hline Correhuela & $\mathrm{E}$ & 121 \\
\hline Correvuela & $\mathrm{E}$ & 121 \\
\hline Corrihuela & $\mathrm{E}$ & 121 \\
\hline Corrijuela & $\mathrm{E}$ & 121 \\
\hline Cortadera & $\mathrm{E}$ & 96 \\
\hline Cucharón & $\mathrm{E}$ & 71,72 \\
\hline Espina & $\mathrm{E}$ & 12 \\
\hline Espina blanca & $\mathrm{E}$ & 62 \\
\hline Esporal & ¿E? & 104 \\
\hline Éter & $\mathrm{E}$ & 115 \\
\hline Flor amarilla & $\mathrm{E}$ & 35 \\
\hline Flor del agua & $\mathrm{E}$ & 4,111 \\
\hline Flor del campo & $\mathrm{E}$ & 66 \\
\hline Garbancillo & $\mathrm{E}$ & 63 \\
\hline Garbanzo & $\mathrm{E}$ & 63,67 \\
\hline Grama & $\mathrm{E}$ & 100,101 \\
\hline Hediondilla & $\mathrm{E}$ & 44 \\
\hline Helecho & $\mathrm{E}$ & 5 \\
\hline Hinojo & $\mathrm{E}$ & 138 \\
\hline Illakowa & A & \\
\hline Iru & $\mathrm{Q}, \mathrm{A}$ & 102 \\
\hline Junquillo & $\mathrm{E}$ & $90,91,107$ \\
\hline K'asawi & $\mathrm{Q}, i \mathrm{~A} ?$ & 51 \\
\hline K'iri & $\mathrm{A}, \measuredangle \mathrm{Q} ?$ & 33 \\
\hline Kachiyuyo & Q & 19 \\
\hline Kaiba & Q & 104 \\
\hline K'eri & 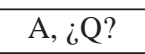 & 33 \\
\hline Koa & $\mathrm{Q}$, ¿A? & 78 \\
\hline Koa Santiago & $\mathrm{Q}$, ¿A? , E & 78 \\
\hline Koba & $\mathrm{Q}$, ¿A? & 78 \\
\hline Koba Santiago & $\mathrm{Q}$, ¿A?, E & 78 \\
\hline Kolti & ¿K? & 66 \\
\hline
\end{tabular}




\begin{tabular}{|c|c|c|}
\hline Kontokonto & ¿K? & 66 \\
\hline Kontukontu & ¿K? & 66 \\
\hline Kopa & $\mathrm{Q}, \mathrm{A}, \mathrm{K}$ & 23 \\
\hline Kopakopa & $\mathrm{Q}, \mathrm{A}, \mathrm{K}$ & 23 \\
\hline Kuchucho (flor) & Q & 96 \\
\hline Lakolako & $\mathrm{Q}, \mathrm{A}, \mathrm{K}$ & 3 \\
\hline Lama & $\mathrm{E}$ & 3 \\
\hline Lampaya & $\overline{\mathrm{Q}, \mathrm{A}}$ & 85 \\
\hline Lanteja & $\mathrm{E}$ & 135 \\
\hline Laqulaqu & $\mathrm{Q}, \mathrm{A}, \mathrm{K}$ & 3 \\
\hline Lejía & $\mathrm{E}$ & 30 \\
\hline Léjia & $\mathrm{E}$ & 30 \\
\hline Lengua de gallina & $\mathrm{E}$ & 33 \\
\hline Lengua de león & $\mathrm{E}$ & 119 \\
\hline Leña del cerro & $\mathrm{E}$ & $39,40,41$ \\
\hline Leña quebrolla & $\mathrm{E}$ & 37 \\
\hline Llantén & $\mathrm{E}$ & 133 \\
\hline Loire & ¿K? & 30 \\
\hline Loroma & ¿Q?, ¿A? & 2,53 \\
\hline Loye & ¿K? & 30 \\
\hline Maizal & $\mathrm{E}$ & 109 \\
\hline Malva & $\mathrm{E}$ & 58 \\
\hline Manzanilla & $\mathrm{E}$ & 117 \\
\hline Maransel hembra & $\mathrm{Q}$ & 42 \\
\hline Maransel macho & Q & 49 \\
\hline Menta & $\mathrm{E}$ & 128 \\
\hline Miuña & A & 55 \\
\hline Molle & Q & 8 \\
\hline Motokoro & $\mathrm{Q}, \mathrm{A}$ & 13 \\
\hline Muelle & Q & 8 \\
\hline Muina & A & 55 \\
\hline Muiña & $\mathrm{A}$ & 55 \\
\hline Ojala & ¿K?, ¿E? & 19 \\
\hline Orégano & $\mathrm{E}$ & 129 \\
\hline Ortega & $\mathrm{E}$ & 57 \\
\hline Ortega blanca & $\mathrm{E}$ & 56 \\
\hline Ortiga & $\mathrm{E}$ & 57 \\
\hline Paiko cuyano & $\mathrm{Q}, \mathrm{E}$ & 126 \\
\hline Paja & $\mathrm{E}$ & $\begin{array}{c}93,95 \\
97,98,99 \\
102,104 \\
106\end{array}$ \\
\hline Paja blanca & $\mathrm{E}$ & 104 \\
\hline Paja brava & $\mathrm{E}$ & 102 \\
\hline Paja chillawa & $\mathrm{E}, \mathrm{Q}, \mathrm{A}$ & 95 \\
\hline Paja fina & $\mathrm{E}$ & 105 \\
\hline Paja vizcachera & $\mathrm{E}, \mathrm{Q}$ & 105 \\
\hline Pajita & $\mathrm{E}$ & 106 \\
\hline Palkarai & ¿A? & 66 \\
\hline
\end{tabular}

\begin{tabular}{|c|c|c|}
\hline Palki & $\mathrm{M}$ & 75 \\
\hline Papa blanca & $\mathrm{E}$ & 86 \\
\hline $\begin{array}{l}\text { Pariente de la } \\
\text { chachakoma }\end{array}$ & $\mathrm{E}, \mathrm{Q}, \mathrm{A}$ & 45 \\
\hline Pasakana & ¿Q?, ¿A? & 9 \\
\hline Pasto blanco & $\mathrm{E}$ & 94,122 \\
\hline Pasto de lluvia & $\mathrm{E}$ & 69 \\
\hline Pasto del campo & $\mathrm{E}$ & 69 \\
\hline Pastos de vega & $\mathrm{E}$ & $\begin{array}{c}15,89,92 \\
110\end{array}$ \\
\hline Pikara & ¿K?, ¿Q? & 22 \\
\hline Pimiento & $\mathrm{E}$ & 8 \\
\hline Pingopingo & $\mathrm{Q}, \mathrm{A}$ & 6 \\
\hline Pino & $\mathrm{E}$ & 113,137 \\
\hline Psómor & ¿K? & 9 \\
\hline Pupusa & Q & $45,46,47$ \\
\hline Qaiba & Q & 104 \\
\hline Qhaiba & Q & 104 \\
\hline Qhaiwa & Q & 104 \\
\hline Qoba & $\mathrm{Q}, i \mathrm{~A} ?$ & 78 \\
\hline Q'oba & $\mathrm{Q}$, ¿A? & 78 \\
\hline Q'ome & ¿K? & 12 \\
\hline Q'omer & ¿K? & 12 \\
\hline Qopa & $\mathrm{Q}, \mathrm{A}, \mathrm{K}$ & 23 \\
\hline Qopaqop & $\mathrm{Q}, \mathrm{A}, \mathrm{K}$ & 23 \\
\hline Qore & ¿K? & 83 \\
\hline Qori & ¿K? & 83 \\
\hline Quebraolla & $\mathrm{E}$ & 37 \\
\hline Quinchamale & $\mathrm{M}$, ¿A?, ¿Q? & 24 \\
\hline Quisco & Q & 11 \\
\hline Regale & $\mathrm{E}$ & 5 \\
\hline Regalís & $\mathrm{E}$ & 5 \\
\hline Rikarika & ¿Q?, ¿E? & 83 \\
\hline Rosa & $\mathrm{E}$ & 84 \\
\hline Rosas & $\mathrm{E}$ & 84 \\
\hline Ruda & $\mathrm{E}$ & 136 \\
\hline Sailao & ¿K? & 94,141 \\
\hline Salkarai & ¿A? & 66 \\
\hline Salqarai & ¿A? & 66 \\
\hline Sobaco negro & $\mathrm{E}$ & 54 \\
\hline Soiko casero & 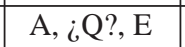 & 48 \\
\hline Suncho & $\mathrm{Q}$ & 28 \\
\hline T'ume & $\mathrm{E}$ & 125 \\
\hline Tamor & ¿K? & 60,61 \\
\hline Tamorcillo & ¿K?, E & 60,61 \\
\hline Tamur & ¿K? & 60,61 \\
\hline T'amur & ¿K? & 60,61 \\
\hline Tamurquillo & ¿K?, E & 60,61 \\
\hline Tara & Q & 77 \\
\hline
\end{tabular}




\begin{tabular}{|c|c|c|}
\hline Té & $\mathrm{E}$ & 116 \\
\hline Tikara & ¿K?, ¿Q? & 22 \\
\hline Tola & $\mathrm{Q}, \mathrm{A}$ & $\begin{array}{c}27,30,37, \\
39,40,41, \\
77\end{array}$ \\
\hline Tola amarga & $\mathrm{Q}, \mathrm{A}, \mathrm{E}$ & $39,40,41$ \\
\hline Tola amarilla & $\mathrm{Q}, \mathrm{A}, \mathrm{E}$ & $27,39,40,41$ \\
\hline Tola de alma & $\mathrm{Q}, \mathrm{A}, \mathrm{E}$ & 37 \\
\hline Tola de la cordillera & $\mathrm{Q}, \mathrm{A}, \mathrm{E}$ & $39,40,41$ \\
\hline Tola de salud & $\mathrm{Q}, \mathrm{A}, \mathrm{E}$ & 27 \\
\hline Tolilla & $\mathrm{Q}, \mathrm{A}, \mathrm{E}$ & $\begin{array}{c}24,27,37, \\
39,40,41, \\
76\end{array}$ \\
\hline Tolita & $\mathrm{Q}, \mathrm{A}, \mathrm{E}$ & 29,32 \\
\hline Toronjil cuyano & $\mathrm{E}$ & 126 \\
\hline Trébol & $\mathrm{E}$ & 131,132 \\
\hline Treból & $\mathrm{E}$ & 131 \\
\hline Triangular & $\mathrm{E}$ & 122 \\
\hline Trigól & $\mathrm{E}$ & 131 \\
\hline T'umi & $\mathrm{A}, \mathrm{Q}$ & 6 \\
\hline Unquillo cuadrado & $\mathrm{E}$ & 91 \\
\hline Unquillo duro & $\mathrm{E}$ & 107 \\
\hline
\end{tabular}

\begin{tabular}{|l|c|c|}
\hline Unquillo liso & $\mathrm{E}$ & 90,107 \\
\hline Vega & $\mathrm{E}$ & $\begin{array}{c}15,89,92, \\
110\end{array}$ \\
\hline Verakucha & $\mathrm{Q}$ & 118 \\
\hline Verbena & $\mathrm{E}$ & 88 \\
\hline Verdelaga & $\mathrm{E}$ & 121 \\
\hline Verdelagua & $\mathrm{E}$ & 3 \\
\hline Vinovino & ¿ $?$ & 84 \\
\hline Viravira & $\mathrm{Q}$ & 47 \\
\hline Wailla & $\mathrm{Q}, \mathrm{A}$ & 95 \\
\hline Waje & ¿A?, ¿Q? & 14 \\
\hline Waji & ¿A?, ¿Q? & 14 \\
\hline Walchawalcha & $\mathrm{Q}$ & 21 \\
\hline Walkita & $\mathrm{Q}, \mathrm{E}$ & 21 \\
\hline Werakucha & $\mathrm{Q}$ & 118 \\
\hline Wirakucha & $\mathrm{Q}$ & 118 \\
\hline Wirawira & $\mathrm{Q}$ & 47 \\
\hline Yareta & $\mathrm{A}$ & 80 \\
\hline Yaretilla & $\mathrm{A}, \mathrm{E}$ & $17,18,52$ \\
\hline Yerba buena & $\mathrm{E}$ & 127 \\
\hline Yuyo & $\mathrm{Q}$ & 20 \\
\hline Zapatilla & & 73 \\
\hline
\end{tabular}




\section{ANEXO 3 \\ ENSEÑANZAS DE DON JULIAN}

\section{Caspana, $1995(\mathrm{JC}=$ Don Julián Colamar; *=entrevistadora)}

* Don Julián, a mí me interesa saber cómo la gente nombra los distintos paisajes de plantas de la zona, paisajes bajos, las alturas ¿Cómo le llaman?

JC. Bueno, empecemos por la parte baja de Ch'ita, de Caspana hacia el sur. Entre Caspana e Inkawasi, se llama Campo. Todo, en general, se llama Campo-Q'ulmor. En estos lugares hay de todos montes, por ejemplo, la añawa, el t'ume, la rika-rika, el k’iri, el loire, el ojála, la tikára, el t'amor, iluka $a^{9}$, todo eso. Por eso el ganado vivía allí, anteriormente. Especialmente cuando llueve, se hace muy pastoso y está ahí el ganado. Entonces todos decimos: "Vamos al Campo de Q'úlmor, ahí dejamos el ganado". Y, por otra parte, encima, encima del paisaje de la meseta de Ayquina, eso se llama Campo-Kháner, todo de aquí, de la punta, hasta Inkawasi también, hasta la Quebrada de Inkawasi, que sube hasta Ch'ita. Eso se llama Campo-Kháner. De ahí también hay otros lugares, que antes decía Ud. Hay una parte que se llama Sopaipilla: es que habían piedras bien planas, grandes, con hoyos. Como nosotros siempre hacemos la sopaipilla, por eso, los antiguos nombraron Sopaipilla al lugar. Dentro de esa Sopaipilla también hay el Mesón; después está Corral Alto. Dentro del Campo-Kháner está todo eso. Eso es esa parte. De ahí para arriba, p'a $Q$ 'aulor yendo, ya tenemos el Corral Largo, la Quebrada Corral Largo, abajo. Arriba, se llama la Quebrada Mulurujte. Y después, pasamos eso, y tenemos otra parte de esa quebrada que está en subida para la de Q'aulor, que se llama Quebrada Honda o Quebrada de Aiserthume. De ahí, con eso, estamos llegando a lugares donde hay la $C h^{\prime}{ }^{\prime}{ } a^{10}$, le dicen Ch'anal, donde hay montes grandes de Ch'ana. Donde hay montes grandes del Cerro, un buen trecho, se llama a ese lugar Ch'anal. Y donde hay pajas grandes, pajas altas, pura paja, Pajonal. Donde hay una parte pareja, se llama Hoyada, hoyadas. Eso, Filo, Hoyada, Loma, esos son los nombres. Ahí hay Pajonal, Ch'anal, Tolar, donde hay harta tola. Así respetamos nosotros los nombres que tienen esos lugares. Hay también Peñaujero, también esa es palabra colla. Ya no pasa, esa es peña alta. Peñaujero. Así decimos: 'De Peñaujero para allá, Pajonal; de Peñaujero para este lado, lo otro', así nombramos nosotros los lugares; para entendernos, nosotros, con los lugares.

* ¿Cómo se llaman los paisajes altos, los altos cerros?

JC. Filo ${ }^{11}$, el Filo Alto decimos nosotros, por ejemplo, a todo ese cordón de Tatio para acá (para Caspana). Más abajo también tenemos Filo Chico, de Q'aulor para abajo, más abajito. También hay Aguadas: Aguada de Manantial, Aguada de Tatio, Aguada de Talikuna.

* ¿Se pueden concebir, como Aguadas, las Vegas, los Bofedales ${ }^{12}$ ?

JC. No. La aguada es para nosotros más chica, más chiquita, donde no hay vegas. Así no más. Si ya tienen veguitas, ya decimos la Vega de Tatio, la Vega Q’aulor, la Vega de Qhoyer; son vegas que tiene más, ahí ya se entretiene más el ganado. En la aguada solo se va a tomar agua.

Respectivos nombres científicos de los taxa citados: Adesmia spinosissima y A. erinacea; Ephedra breana; Acantholippia deserticola; Chuquiraga atacamensis; Baccharis tola ssp. tola; Atriplex imbricata; Ambrosia artemisioides; Adesmia atacamensis y A. bracteata; Krameria lappacea.

10 Ch'ana, Chuquiraga spinosa $\mathrm{ssp}$. rotundifolia.

11 La palabra "filo" también es usada por las poblaciones quichua parlantes del sur andino (Cusihuamán, 1976 ), en el mismo sentido, y también por los mapuches. Probablemente, esta palabra castellana debió ser comúnmente usada por los españoles en la época colonial.

12 Las turberas andinas, de acuerdo a la fisonomía y composición florística, altitud, topografía y sustratos, se clasifican en: a) Vegas, o praderas húmedas formadas por un tapiz herbáceo continuo de especies palustres y cojines planos de diminutas especies arosetadas. Se desarrollan en el ámbito puneño, generalmente en quebradas y orillas de cursos de agua; b) Bofedales, formación vegetal altoandina, dominada por cojines duros de Juncáceas. 
llama Tablón. Así se dice: "el Tablón del lado bajo, el Tablón de más arriba". Significa toda una J.C.: $\quad$ Esas se llaman Chakras, ahora último le dicen Terraza, pero Chakra era el nombre, Chakra. Después, de acuerdo a cómo van los regadíos al lado, y el canal al medio, esa parte escalonada, se acera, hasta adonde a uno le pertenece. Y así la gente conoce. Está bien así. Sí, eso es. Antiguas técnicas. Sí. ${ }^{13}$

\section{ANEXO 4 \\ ENSEÑANZAS DE DON JULIAN}

\section{Caspana, Abril de 1998. (JC= Don Julián Colamar; *=entrevistadores)}

* Esta visita es muy especial Don Julián. Quisimos esta vez traer lo que nosotros habíamos escrito sobre cómo ven el paisaje que los rodea, el conocimiento de las plantas en Caspana, la forma en que lo estamos escribiendo nosotros, para conocer tu opinión y que nos corrijas y comentes lo que te parezca. Y por si fuera poco, consultarte sobre algunos usos de plantas que nos faltaban. También sobre algunos nombres de plantas que anotamos en el Salar y que no habíamos escuchado, porque tú puedes saber.

JC. Ya. Vamos a trabajar juntos.

* Sí, eso queremos. Mira, la tarea que estamos haciendo es larga. Ya estamos escribiendo este trabajo de Caspana, con lo que habíamos estudiado con los caspaneños y contigo de las plantas y del paisaje. Para ir haciéndolo, también buscamos lo que otras personas hayan escrito antes. Por ejemplo, escribimos algo para una parte del trabajo que vamos a llamar percepción del paisaje y que trata de cómo los caspaneños describen su paisaje. Lo traje escrito y lo someto a tu juicio para que nos digas qué te parece: "Dos cerros tiene especial significación para los caspaneños, en su decir, porque son la cabecera de Caspana, desde donde nacen las aguas del río Caspana; uno redondo

Los significados de las palabras Cerro, Campo, Chakra, Hoyada, Pajonal, Tolar, Tola, Vega y Bofedal se describen en otros trabajos etnobotánicos publicados para el Loa Superior (Aldunate et al. 1981; Villagrán \& Castro 1999). y otro más aguzado que representan a la mujer y al hombre. De esta unión nace el agua que fertiliza la tierra; se nombran como Qhoyller y Kablor diciendo explícitamente que sus nombres antiguos" (y yo creo que esos nombres son de antes del inka) "son los de Sipitare y Sipaka. Justamente en el kausulor cantado en la Limpia de Canales se nombra a mama Sipaka". Bueno Don Julián, queremos saber si al escribirlo así, está el sentir de verdad de los caspaneños. Quiero que nos digas como lo encuentras, si algo no está bien. El trabajo también queremos mandarlo a la comunidad, va a venirte para ti.

JC. Sí. Está bien. Pero hay una parte que te explico. Donde dices, mama Sipaqa le decían a la mujer. El cerro que es de Q'aulor, ese es mama Sipaqa. Entonces, ahí, en quechua dentra ¿no es cierto? Diciendo señora, señorita, Sipa, señorita, mama Sipaqa. Bueno, el otro se decía siempre, anteriormente le decían Tata Sipitare. Decían: Sipitare tata, Sipitare mama. O sea que Sipitare Tata significa Sipitare hombre, o cerro hombre. Sipitari mama significa el cerro mujer.

* Y el mismo es las dos cosas.

JC. Eso.

* ¿Eso podría ser cunsa?

JC. Podría ser cunsa Sipitari. Sipitare. Yo conocía el nombre Sipitare, siempre los antiguos decían Sipitare.

* Cerro macho, ¿algo así sería?

JC. Cerro macho, cerro hombre. Como hombre y siempre se respeta así. 
* ¿Pero solamente el Chita se llama Sipitare o cualquier cerro se llama Sipitare?

JC. El Ch'ita, el Ch'ita es Sipitari.

* Qué bueno que nos enseñes. Porque habíamos leído que Koller era Sipitare. Y no. Es Chita.

JC. El Ch'ita es Sipitare. El Q'aulor es Sipitare mama.

*. Ya. El Káblor es mama.

JC. Es bueno así corregirlo juntos, porque yo mismo puedo equivocarme de repente

* Chita es Sipitare.

JC. Sí.

* Y Káblor es Sipitare mama. Ya. ¿Y el Qoiller es Sipaka, o es otro?

JC. No, el mismo. El Sipitare mama es mama Sipaqa, le decían a ese mismo.

* Perfecto. Quiere decir que el mismo Kablor tiene hartos nombres. Alguien escribió antes y no estaba bien pues.

JC. A lo mejor ellos se confundieron. No me hicieron entender bien [no me entendieron bien]. Antes yo tenía también esa manera de ser, un poco más mezquino, para no darle... . No les conocía mucho, mientras que ahora yo a ustedes, ya les conozco años ya.

* La pronunciación exacta es entonces: Ch'ita.

JC. Ch'ita. Ahí yo no sé qué significado tiene que darle usted a esa salida. Si está en cunsa, está en quichua, en aymara. No sé.

* Le encuentro cara de aymara, pero no estoy seguro en este momento. Ahora, ¿K'aulor?

JC. Q'aulor. Q'aulor.

* Es la otra. Eso a mí me parece que podría ser kunsa. Y la otra pronunciación es Q'oiller.

JC. Qhoyer, Qhoyer.

* Fíjate que él sabe cuando tú pronuncias K'a, k'o o qué sé yo. Sabe si se podría escribir con la letra K o con Q. Así lo vamos a poder escribir bien.

* Entonces la última es K'oller.

* Ahí estamos. Queremos corregir y que quede bueno este trabajo para todos. Después leímos que en el kausulor cantaban la Limpia de Canales en nombre de mama Sipaka.

JC. Claro. Porque hay un verso que dice... . Ya se me olvidó. Cantando me acuerdo.

* ¡Cántalo!

JC. Wa ñusta mama sipaqa iyayvayay, Chirinchoron, Khalten khalten Wa ñusta mama sipaqa iyayvayay
Chirinchoron, Khalten khalten

Aloskita, mendosita

Unuta mama sipaqa ayayvayay. Eso. Así dentra.

* ¡Qué lindo! ¡Qué hermosura!

* Sí. Bueno. Hay palabras quechua.

JC. Sí.

* Pero entremedio pareciera haber una que no tiene terminación quechua. De todas maneras si ha quedado aquí bien, pues después lo reescucho ¿no?

* Es muy lindo. No te había escuchado. He escuchado al abuelito Víctor cuando cantaba...

* Y entremedio dice mendocita también.

* Había escuchado al abuelito Víctor ese canto de la vicuñita, "Yo no soy...

JC. Vicuñita para tener asta yo soy taruquita...”. Claro, él sabía más quichua.

* Sí. El cantaba en quechua. Pero no había escuchado la que cantaste tan linda. Es precioso, suavecito así, lindo....

JC. Ese es el canto para la Limpia del Canal aquí, habría que completarla.

* ¿LLo que cantaste es todo?

JC. No es[está]completo y más, hay harto. Entonces[Fue porque] tú me dijiste que salía alguna [palabra], en el canto, entonces yo te di ese tema de Wañusta mama sipaqa. Ese te decía yo, sale ahí. Ese es el[kablor], entonces le llaman Mama Sipak'a no más, no ya ñusta. La Ñusta significa ya la muerte pues. ¿No es cierto? Que la mamá se estaba muriendo y traiga agua y...

* Y que la joven traiga agua...

JC. No. La joven también estaba ahí y después le pide unuta mama sipaqa. A él le pide agua, ¿no es cierto? Porque primero se dice wañusta mama sipaqa. Entonces la señora tendría que cuidarle porque está muriéndose ya ella. Entonces unuta mama sipaqa. Entonces ya ahí tendría que llevarle agüita.
* Unuta.
* Así está pidiendo a los cerros por el agua...

JC. No, ese es un canto que ya, en otra parte, pero al cerro también se le llama ahí, mama sipaqa.

* ¿Cómo sigue después la traducción en castellano de lo que cantó?

JC. No, no lo tenemos en castellano, nada, solamente ahí no más. Será en kunsa, será en quechua, no sé en qué estará. Pero nosotros en castellano no lo tenemos nada claro. 
* Claro que si tú quieres que Gilberto trate de entenderlo más, tendrás que cantarle más para que tuviera más frases.

\section{* Darme la idea ¿no?}

JC. Mejor le hago yo el canto completo

* A ver.

JC. Pero en otro momento.

* Está bien, así lo vamos haciendo al pasito.

JC. Es que yo tendría que repasarlo un poquito.

\section{* Entonces ¿mañana?}

JC. Mañana o el lunes en la noche puede ser, porque en el día estoy ocupadito. Si no, tendría que ser esta noche y yo tendría que irme a la casa y repasarme algo[acordarse].

* Esa podría ser una solución ¿no?

* Mira, si tú quieres así, está bien. Porque yo igual vengo en junio y de repente Gilberto puede venir este otro año. Por otro lado esta oportunidad es con poquita gente y parece mejor para hacerlo. Entonces, si quieres venir a comer esta noche y ahí te has recordado, estaría bueno. Pero antes quiero preguntarte otras cosas ¿ya? ¿Puede ser?

JC. Ahora seguimos pues.

* Te quiero leer cómo se va escribiendo este trabajo que estará listo en unos tres años más, porque se demora. Y así tú vas corrigiéndonos y comentando, qué te parece. Así está quedando: "Análogo a las categorías del paisaje descritas por los toconceños, los habitantes de Caspana tienen su propia forma de nombrar y reconocer su paisaje. Una excelente descripción nos entrega Don Julián Colamar, sabio caspaneño; reproducimos su comprensión del paisaje y las preguntas realizadas por nosotros, con el fin de dejar claramente demostrado la claridad y sentido de este conocimiento". La idea de este párrafo es destacar el valor de la ciencia indígena al lado de la ciencia universitaria. Demostrar que ustedes son los que conocen con más detalle. Y traje para eso las preguntas que te hizo Carolina y tus respuestas, para que lo revises y lo amplíes. En fin, nos comentes y nos corrijas si quieres. Además, Gilberto al escucharte sabrá cómo escribir las palabras.

* Primero, hablando sobre el paisaje de Caspana, sobre los lugares que ustedes nombran. Por ejemplo, la palabra Aisertume ¿qué significará?
JC. Ayserthume. Ayserthume, no sé lo que quiere decir. Thume decimos nosotros, por ejemplo, al pingo pingo; le decimos thume.

* "Con eso estamos llegando a lugares donde hay chana", decías en la primera conversación. ¿Le dicen Chanal, donde hay montes grande de chana? ¿Se llama ese lugar chanado?".

JC. Ch'anado, Ch'anal, Ch'ana es el monte.

* Como preferimos que lo que tú nos has enseñado salga bien preciso, te pediría que nos hagas un dibujo y ahí, ir marcando los nombres que nos has dado.

JC. Ya. Bueno ${ }^{14}$.

* Empecemos por la parte baja de Chita, de Caspana hacia el sur, entre Caspana e Inkahuasi, ¿se llama campo?

JC. Aquí entonces ponemos Ch'ita, esta parte es el cerro, este lugar, toda esta meseta, se llama Campo Khaner. Este es el cerro Ch'ita. Entonces abajo es ya la aguadita de $C h$ 'ita, de ahí sale esta quebrada, baja por Inkawasi. Entonces de ahí que, todo este es el Campo Khaner. Eso es lo que quiero que te quede a usted claro.

* ¿Y ese nombre Khaner ¿querrá decir algo? JC. Posiblemente, yo no lo sé. Inkawasi. Y este es el Campo de Khaner, este que está aquí. Yo le puse Caspana ahí, pero, como ser éste, todo este campo se llama Khaner.

* Ya. ¿Está bien cómo quedó indicado en el dibujo?

JC. Ahí está bien. Entonces este que baja por acá, de ahí empieza Caspana, ahí está el sembrío ¿ve? Ahora este es el campo Qhulmor, esos son, hasta aquí. Este es el Khaner. De ahí bajan Las Puntas que son estas las mesetas. De ahí para acá, pa' abajo, es el campo Qhulmor. Sí, todo este Campo. Me esperan para seguir, vuelvo en un ratito.

* Ya volviste pues. Entonces ahora seguimos. ¿Otro campito es éste?

JC. Ese sí, es Campo Qhulmor. Te muestro Q'aulor, de ahí vienen las aguas que estamos tomando todos. Q'aulor. Y este es Talikuna. Y acá es Cerro Verde. Esta es la parte de arqueología en la que estaban los tambos, todo eso.

* ¿ ¿Y ese es el sitio de Talikuna?

JC. Sí. Talikuna. Y acá, éste es el usnu ${ }^{15}$, que está arribita.

14 Ver dibujo de Don Julián que acompaña este escrito. 15 “Usnu. Tribunal de juez de una piedra hincada" sensu G. Holguín, I: 359; “Altar antiguo”, Ibid.: II: 403. 
JC. Sí, de Cerro Verde, este es usno, donde llegaba el rey.

* El Inka.

JC. El Inka ahí, ese se llama usnu. Y acá está Ch'ilqor, éste es un río, una quebrada y ahí sale agüita pa' acá, y viene a juntarse aquí con Caspana, Ch'ilqor. Y acá, ese es el río Caspana, claro. Aquí está Khibal.

* ¿Eso es el nombre del lugar?

JC. Sí, de una aguadita ahí, es Khibal. Y acá es Ch'apolqholor. Ch'aparlqholor. Se llama la quebrada de Ch'aparqholo. Yo le hablo para que vuelva el recuerdo. Porque me acuerdo de esas palabras. El significado, qué significa, yo quiero saber.

JC. Sé una canción. Ahí nombramos a Mama Sipaqa, que me preguntaste Vicky. Se las canto:

Uma oka tamor khane ${ }^{16}$

Esmoraka yaskay manta ${ }^{17}$

y ha quí has venido forastera

y ha quí has venido forastera

con qué destino forastera

* Kai manta se entiende ¿no?

* Algo de Esmoraka, quizá del pueblo de Esmuraca, en Bolivia.

* Wanusta mama sipaqa

iyaybayay, chirinchoron, khalten, khalten

wañusta mamasipaqa

iyaybayay, chirinchoron

khalten, khalten

aloskita mendosita

unuta mama sipaqa

yyaybayay

* ¿Está bien sacado?

JC. Sí, está bien sacado, el único aquí está repetido el wañusta, ese no tendría que ser repetido, desde el wañusta, después sigue unuta. Eso está repetido. Eso sí que se repite todo, todos juntos, pero ahí esa frasecita no, yo a lo mejor lo dije dos veces y por eso sale repitida.

Este párrafo y el siguiente no se entienden con toda claridad en la grabación.

17 Esta letra se canta en Toconce y Ayquina, donde se menciona claramente la localidad de Esmoraca, en Bolivia.

18 Se refiere a Julián Colamar Recuerda. Visiones de Caspana, libro publicado por Miranda (1997).
* Sí, debe ser eso, porque lo saqué tal cual lo escuché y lo escribí.

JC. Entonces esa, esa partecita que wañusta mama sipaqa eso está bien, de ahí después dice todo lo otro, después dice, de ahí viene unuta mama sipaka. Ese de ahí, sigue casi igual que el otro.

* Pero los saqué, ¿las palabras están bien sacadas?

JC. Sí, están bien sacadas, sí.

* Ahora, tratar de traducir.

JC. Eso.

* Por ahí entremedio hay palabras que..., eso Khalten, khalten.

JC Khalten, Khalten tienes que buscarle aparte.

* Sí. ¿Eso no podrá ser: canten, canten ... a lo mejor?

JC. No. Khalten, khalten alguna cosa tiene...

* Y primero dice q'alten.

JC. Khalten, dos veces repitan Khalten, khalten. A lo mejor si alcanzamos yo te voy a cantar completo el canto. Entonces usted ahí me la traduces.

* Sería bueno.

JC. A veces se hace por partes entonces como que me olvido. En tanto que yendo parejo entonces...

* Pero es importante que quede escrito porque ahí se conserva y después si a uno se le olvida, mira lo escrito y lo vuelve a recordar. Esa es la ventaja de tenerlo así escrito.

* Claro, teniéndolo escrito tú puedes tantas veces ensañarlo acá.

JC. Eso parece que no le he puesto en el libro $^{18}$.

* No pero así después te va saliendo en otro. En tu libro no aparece.

* Bueno, después en otro, en otro, ahí, por ahí puede salir.

JC. Puede salir, claro.

* Entonces volvemos al dibujo.

JC. Ya.

* ¿Qué faltaría? No es mucho, mira, tenemos: Campo, Sopaipilla ahí; después hay otros lugares que antes decías...

JC. Ya. Sopaipilla aquí, tendría que estar en este Campo, Campo Khaner, ahí está Sopaipilla, en estas Puntas de aquí. Y aquí está, este es Inkawasi 
¿no? De ahí, por aquí, por estas partes ese es Mesón.

* ¡Ah! Está dentro de campo Khaner.

JC. Sí, sí está bien, dentro del Khaner. Ahí está Sopaipilla, dentro de eso está Corral Alto, dentro de eso está el Mesón y de ahí sigue pa'rriba, pa $Q$ 'aublor, ya. Ahora, la huella ${ }^{19}$ está pasando por acá; por ahí está pasando la huella para el Tatio, entremedio del lugar ese, está pasando la huella. Ahí están las Puntas pa’bajo. Ya. De ahí por acá está Corral Alto y de ahí para acá está Mesón. De ahí sigue pa'rriba, ya pa acá pa Corral Largo, quebrada de Corral Largo, después viene Mulurujte. De ahí sigue quebrada de Ayserthume o Quebrada Honda.

\section{* Aquí.}

JC. Sí, ese ya está pa'cá, al lado, cerca de llegar aquí, a $Q$ 'aulor. Este es Qhoyer, la vertiente Qhoyer, ¿no? Qhoyer le decimos siempre, siempre estamos acostumbrados, pero la palabra es Qhoyer. Entonces baja así el agua hasta ahí, de aquí es la vega, esta parte es vega y viene hasta aquí, aquí es Q'aulor, se junta este Q'aulor a la vertiente, toma el agua, de ahí baja pa' acá, se juntan los dos y vienen a Caspana. Entonces aquí está la vega de, todo esto es la vega de Qhoyer de ahí es un campo, un espacio que viene quebrada no más, quebrada, hasta llegar a aquí, aquí se hace esta veguita, hasta ahí. De ahí dentra a la quebrada y se viene y empieza a encontrar los terrenos ya. Eso es.

\section{* Ponle ahí la veguita esa.}

JC. Igual aquí. Ese son las vegas que tiene. De ahí ya bajando entendemos. Por ejemplo aquí Corral Largo, le dicen ahí. Está un corralcito que hay y ese es la Quebrada Corral Largo, entonces una quebrada que pasa por aquí, pasa por este pasa la quebrada y.... llega hasta, este ¿qué dijimos que era?

* Ese dijimos que era el Ojo de Chita.

JC. El Ojo de Ch'ita claro, este llega más o menos, hasta Quebrada, por acá está Quebrada de Mulorujte.

* Mulorojte hacia arriba.

JC. Ahí esta Mulorojte que está cerca de estos cerros Grandes. Y aquí está Ayserthume que va de Superior, para referirse a los caminos para vehículos. aquí y que entra ya acá a Caspana y este sube así, poco así, así y llega para allá, para este cerro. De ahí ya está bajando, de este cerro y ya baja a....

\section{* A Aisertume.}

JC. Ayserthume o Quebrada Honda y hay quebraditas, otras chiquitas que van de aquí, unas así bajan y juntan ahí mismo. Así es. Eso pues. Con esto ya vamos terminando los nombres del campo Khaner; este es el Q'ulmor. Aquí dentra ese, aquí, está Incawasi, ya le puse ahí. Incawasi. De ahí está Ch’ilqor. ¿También lo pusieron?

\section{* Sí, Chilqor, Chilqor.}

JC. Ya aquí está la Quebrada Piedregosa que...

* Esta no hemos puesto.

JC. La Quebrada Piedregosa está aquí, eso. De ahí, después, sale otra quebrada que vienen aquí, unas chiquitas, que van ahí, juntan esas pa' abajo, y esta que viene acá arriba, dentra pa' acá, a esta quebradita que llega aquí y ese es aquí. Que es esto, de aquí sale. Este es.

* ¿Cómo se llamaría, ¿Caspana no?

JC. ¿Como se llamaría esta quebrada anteriormente? No me recuerdo su nombre ya se me ha olvidado de esa quebrada. Actualmente le decimos la quebrada del Plan tuníkula. Sí, actual quebrada del Plan tuníkula. Ese es esta quebrada pa' acá. Y ahí está la quebrada Piedregosa, te dije ¿no es cierto? Ya, esta es la Loma Grande que va, ese camino que baja por ahí en las lomas, ese va a terminar hasta el río casi, pa' abajo, a Pila, hasta ahí termina.

* Esa Loma Grande. Es como una lengüeta.

JC. Es como una lengua así grande pero ancha así.

* $\quad$ Es el espacio que queda aquí.

JC. Sí. Eso.

* $\quad$ Eso es Loma Grande.

JC. Loma Grande sí, después de... . No. Este es otra lomita, perdón, ésta es Loma Grande que baja, aquí lado este, entonces este va rejuntando. ¿Éste será río, ¿no? Este es el río Caspana. Entonces este es el río que baja a juntarse aquí ¿ve? Y este es el Loma Grande que baja, este es el Loma Grande.

* ¿Así mismo se llama el río?

JC. No el Loma Grande es el campo, este es Ch'ilqor, la quebrada de Ch'ilqor, ese y este es Loma Grande. Aquí Ch'ilqor, hay una aguadita también, que sale por ahí, más o menos, sigue aguadita y se junta ahí, vuelta. Esto se llama Ch'ilqor Chico y Ch'ilqor Grande. 
¡Ah! el campo mismo.

JC. Sí, esto sigue la Loma Grande pa' abajo y ahora, Khibal. ¿No está puesto?

* Sí, aquí está la aguadita de Khibal.

JC. Eso. Aguadita de Khibal.

* Este sería. Este campo de aquí, sería campo y este campo también y este de aquí es una...

JC. Ese es Ch'ilqor, desde allá y todo ese que sé es Loma Grande, por eso es larga. Loma le decimos a un espacio grande que está tendido, el lomo.

* ¡Ah ya! Ahí es campo Chilqor Grande y campo Chilqor Chico.

* iEsa loma no tiene nombre quichua?

JC. No, Loma Grande, Loma Chica. Quichua no, no sé, yo lo he conocido así.

* Y aquí esto era Sopaipilla.

JC. Sí. Eso.

* Este es un caminito.

JC. Sí ese es la huella que va pa'1 Tatio, por ahí pasa.

* La huella de vehículos.

JC. Sí. Antes no había huella pu. Ahora hay huella.

* ¿ ¿Y este de aquí era Corral Alto?

JC. Corral Harto.

* Corral Alto.

JC. Corral Harto.

* Harto, harto.

JC. Mm.

* Y este de acá era Corral Largo.

JC. Corral Largo y antigua Quebrada de Corral Largo. Este es el mismo te estoy diciendo. Se llama Quebrada del Corral Largo. Y este es vega, veguita. Este es Mesón, Mesón es ese.

* Ya está. ¿Y Aisert'ume dónde vendría a estar?

JC. Este pues. Está.

* Esta parte.

JC. Esta quebrada, esta quebrada es Ayserthume, sí, estas las dos quebraditas se juntan ahí y desembocan aquí a Caspana. Estos son Ayserthume o Quebrada Honda.

* Y Peñaujero ¿dónde vendría a estar?

JC. Peñaujero viene a estar por aquí.

* O sea, desde la aguadita.

JC. Este aquí en la aguadita arriba, aquí en el alto. Por aquí está Peñaujero, toda esta partecita pegado a este, al cerro Sipaqa. Ahí está pegadita.
Yo le pongo puntiagudito porque así es, puntiagudito. Ese ahí está, todo este es Peñaujero. * $\quad$ Entonces este es Peñaujero. Y este de aquí es el Sipaka. Ya. Bueno, todo lo alto uno sube sabe que es pajonal. ¿Verdad?

JC. Sí, todos esos allá son pajonales.

* ¿Y los Filos?

JC. Aquí está por ejemplo. Este que te decía Ch'anal, por acá está Ch'anal, esta partecita. Ahí está en esta quebrada aquí en este ladito está Ch'anal. Son unos Ch'anales, entonces usted anotó Ch'anal ahí.

* Sí tengo.

JC. Sí, sí, Ch'anal hay para este lado no más, ya pa' $C h$ 'ita pa'l otro lado hay otro $C h$ 'anal, pero ese es más grande pero ya pa' Ch'ita, pa'l otro lado de la quebrada, del otro lado, por ahí está.

* Hay sectores de chanales entonces.

JC. Sí, sí, y esta partecita es Ch'anal.

* ¿Y las hoyadas ${ }^{20}$ también están en cualquier parte?

JC. Hoyadas, sí. Hay hoyadas, por ejemplo, aquí mismo en éste, terminando en este Peñaujero, ahí bajando, adentro, ahí está unas hoyadas, así grande, ahí pasa la huella pa'l Tatio. A eso le llamamos Hoyada, a todo eso.

* Hoyada.

JC. Hoyada y así hay otras partes también pa' Ch'ita, pa' abajo, pa' el lado de Incawasi, por ahí pa' allá atrás hay hoyadas, así que entonces, todo que sea parejo abajo así, lo llaman hoyadas.

* Y allá hará frío, se sentará el frío. Y ¿qué más tienes tú aquí? Lomas que ya está claro también. Son esas lengüitas planas. Y también el Filo, sería el...

JC. El Filo es, por ejemplo, teníamos nosotros en esto, que Filos que aquí de las vertientes ese que usted ve. Ese filo con cerros ese de aquí de las vertientes de agua de $K^{\prime}$ aulor de Qhoyer y Q'aulor, están son de arriba del Filo.

* Lo que uno ve así.

JC. Claro. y aquí queda otra partecita también aquí ¿ve? Esta parte, esta parte que viene por acá más o menos, igual haciéndolo otros Filos. Entonces, ese le llaman así, ese que son como cerritos, como lomitas, entonces le llamamos Filos. Entonces viene de aquí el agua de manantial, el manan-

Hoyada. "Terreno bajo que no se descubre hasta estar cerca de él”. (RAE, 1992, II: 1127). 
tial está para acá, al lado de éste, está por aquí el manantial más o menos, al lado de Talikuna baja. Entonces, de ahí, por aquí está Manantial, una partecita así está Manantial, es una agüita. Pero es caer, es lo mismo. En la misma quebrada está eso.

* Claro, o sea, siempre los Filos serían la parte como altita de los cerros.

JC. Esos son los filos, por eso son el Filo Chico, el Filo Alto, son esos cerros que están allá arriba del alto del Ojo de Qaulor, de Qhoyer. Ese decimos es el Filo Alto. Se decía, se denominaba el Filo Alto, fuimos a la llareta, fuimos a encontrarnos en el Filo Alto. El Filo Chico es este. Porque pa' este lado no hay, este no hay. Para acá hay Lomas, aquí Loma alto, aquí también esta pa'l lado de Qhoyer, de Qhoyer este pa' allá es Loma Alto. Y por aquí está más o menos, Purifikan.

\section{* Purifika.}

JC. Mm, Purifikan, ese debe estar en kunsa, Purifikan.

* $\quad$ Ese sería como quebrada.

JC. Sí ese es una quebrada y es aguadita. Tiene agüita ahí.

* Quebrada y aguadita ¿eso es más pa' el lado del Tatio?

JC. Pa'l lado de Río Grande y el alto allá. Sí. En este Alto, este Filo así que va pa' allá, todo eso de allá pasa.

* Ya, ese pa' Río Grande. Ya. Y las vegas están claras, las chacras también, todo eso está claro. ¿Y acá?

JC. Este Ch'ilqor También tiene veguita. Esto de por acá comienza veguita, así, sigue veguita y sigue veguita, sigue.

* ¡Ah!, es bonita esa veguita.

JC. Sigue y sigue esa veguita y hasta por ahí llega la veguita...

* Muy larga.

JC. Larguita, angostita pero es veguita y ahí comen los animales, toman agua los burros, las llamas, a veces está muy lindo estar ahí, tranquilo...

* Sí pues, o sea, en el fondo lo que más hay aquí, es veguitas y aguadas.

JC. Veguitas chicas y aguaditas, todo eso. Ahora, gracias a Dios con el CONADE tenemos todo, todo un mapa hecho con todos los nombres.

* Qué bueno. Si yo supe que lo estaban haciendo los jóvenes, la Panchita y el Ernesto ¿no?
JC. Sí, así que está ahí hecho todo nuestro territorio de nosotros ya. Pero no está el nombre. Por ejemplo esta Chita, está Q'oller, está Qaublor así, no está como está escribiendo nosotros acá, el caballero que sabe el como escribir eso.

* Claro, no está correcto su nombre como es escrito

JC. No está correcto ese nombre porque la señorita no lo entiende de estas nombres y la juventud le dieron[dijeron] eso, sobre todo los dirigentes de la Comunidad Indígena, entonces son jóvenes que dieron Chita, dieron $Q$ 'oller incluso la aguada esta, esta, esta aguada dice, debemos ponerla aquí, esta Quebrada Chica, aquí viene, dijimos Caspana, de por aquí viene la Quebrada Chica, Quebrada Chica y junta por acá...

* Y se llama así.

JC. Soqhor se llama esa quebrada, porque ese es Soqhor y nosotros actualmente le decimos Quebrada Chica, anteriormente se llamaba Soqhor. * Sokos.

JC. Soqhor, con S, Z, no sé cómo, Soqhor así se llamaba la quebrada esa anteriormente, todos decían vamos a S'okos, y ahora no, ahora es Quebrada Chica.

* Zok'os, ¿lo digo bien?

JC. Sí, Sok'os y el otro que se llama también Chols'ana.

* Cholsana.

JC. Ch'olsana.

* Cholsana.

JC. Ch'olsana [SE RIE]. No sale.

* No me sale, este es difícil, tú te ríes mucho de mí. Yo trato pero... Y eso, ¿dónde estaba Cholsana?

JC. Ch'olsana está por aquí, es Caspana y Ch'olsana es esta partecita, aquí es Ch'olsana, en el lado del río también, por ahí hay chacras, son predios que tenemos ahora, ahora.

* ¿Le dicen todavía así o?..

JC. Ya no.

* ¿O tiene nombre castellano ahora?

JC No. Ahora no, le dicen solamente, allá abajo el Peral o allá abajo, eso no más, terreno abajo, nada más, no le denominan el nombre porque no lo sabimos. Yo tampoco no le voy a decir entonces la gente me dice como va a ser tan feo el nombre y ahí quedan pues. Yo no les puedo explicar que significado tiene. Por eso me gustaría eso de 
saber, entonces yo les digo ¡a lo mejor es un buen nombre!

* $\quad$ Puede ser un lindo nombre y tener un lindo significado.

JC. Eso pues. Eso nos falta entender. Por eso nosotros como no sabemos no hablamos, ya le voy a decir otras cosas al Gilberto.

\section{* Sí, dile no más.}

JC. Ya. Veamos. Terminemos esto para...[corte]

* Ya. Esto del dibujo parece que está super bien y clarito. Para continuar, quisiera preguntarte sobre el uso de algunas plantas acá, para completar el trabajo anterior y por otra parte, nombres que escuchamos en Atacama. Todo lo traje escrito. Por ejemplo: el loire, se usa, es remedio para empacho dicen, pero, ¿cómo se usa pa' los empachos?

JC. ¿Quién te dijo que era pa' el empacho? * No, aquí no. En Atacama.

JC. No sé, yo no lo sé.

* No sabes. Después el Kachiyuyo, el kachiyuyo ¿no se usa para comer? En la casa, porque en Toconce lo usaban para comer, en los guisos, hacían guiso.

JC. No, nosotros no lo usamos.

* Ya, después, ese nombre loire es de bien de aquí ¿ah? no hay en otra parte. Sería lindo saber qué significa. Igual, la ortega se usa pa' los carnavales ¿no?

JC. No.

* No la usan acá, ya, acá usan para hacer la Llikta el yuyo ¿verdad?

JC. El yuyo sí, pa'l ch'ili. Ch'ili se decía.

* Pa'l chili.

JC. Porque ahora la gente pronuncia chile. No. Ch'ili es el nombre.

* ¡Ah! ustedes le dicen chile, no Llikta.

JC. Eso lo dicen en Toconce, pa'l norte, lo dicen pa' Bolivia pa' eso le dicen eso, no sé si será en quichua, yo no sé en qué idioma estará, será en kunsa, será en aymara, no sé.

* En Caspana. Esto es mucho más rápido que el dibujo que era lo difícil.

* ¿Cómo le dicen en otras partes los que dijiste?

* Llikta. Llikta.

JC. Pero yo creo que comprenden ahí, la llikta es más suave mientras que el ch'ili es mucho más fuerte, ese sale del yuyo.

* Sí porque en Toconce lo usaban tostando el techo, sacando el yuyo, la quínoa silvestre po- niéndola en el techo a secar. Luego en unas piedras planas la molían y lo tostaban y después hacían los pancitos.

JC. Así es pues, primero secarlo, después cortarle un poco no más y sale a tostar.

* Así que el chili es el más fuerte.

JC. Eso es más fuerte. Más fuerte y firme, en cambio el otro es más débil, no es tan fuerte la masa que se hace. Mientras que el otro queda duro y bien, bien picante, fuerte llega a doler la lengua también y ellos se acostumbran y comen como vicio, anteriormente, la gente.

* Con la hoja [de coca]

JC. Con la hoja .

* Y, por ejemplo, en Talabre usan algunas plantas para "limpiar" 21 a las personas cuando alguien fallece y algunas veces también usan guano de algún animalito. Quisiera saber qué plantas usan acá para las costumbres de difuntos, para limpiar, para chuya ${ }^{22}$. Algo de eso que nos contaras.

JC. Bueno, para eso, la gente acá, nosotros, siempre hemos usado la tolilla. Yo creo que se está usando en todas partes la tolilla, que es un monte de la tola y, también, junto con eso va la pluma de parina. Se llama el chuko. Todo eso va junto, amarrados con una tira de hilo en dos colores, banco y negro que se llama lloqhe. Eso es para limpiar. Y aparte de eso, se tiene la harina de sicha ${ }^{23}$, su "semilla" es molida, entonces le dicen chuya a eso. Otros le ponen también el guano del amo.

\section{* Claro, del ratoncito.}

JC. Claro. Pero no es ratón. Es parecido al ratón, pariente. El guano de amo lo ponen ahí, molido. Es para los pies. Lo hacen poner en el pie izquierdo ahí uno lo mantiene y después ya vienen con la tola y todo eso que tienen preparado. Con eso lo "limpian", le sacan todo eso, cuando pasan la pitira le dan un poquito de contra, son las tres "contras": "la contra blanca, la contra amarilla y la contra negra". Esas contras son molidas; la gente se las pone en la boca. Cuando "lo limpian todo lo

21 Rito de purificación.

22 El vocablo es de uso exclusivamente ceremonial y alude a rito y ofrenda.

23 La sicha, es un engrosamiento radical de algunos arbustos, provocado por una planta parásita (Ombrophyton subterraneum), principalmente en sustratos arenosos y que se producen, en especial, en época de lluvias en las tierras altas del Norte de Chile (Aldunate et al., 1981). 
que tiene, entonces uno escupe en la tola Así, con eso significa que es una tola, lo que estaba acostumbrado con uno que ha vivido, que ha hablado algunas veces.

* Entonces es que al limpiarte, sale de ti o de la persona que no ha muerto, toda relación con el difunto.

JC. Sale eso, entonces se dice: "Eso que salga todo". Eso, lo que uno ha tenido con la persona [fallecida], lo que ha conversado, lo que ha hablado. Entonces, ahí se despide, eso es para borrar su intención que él hacía con nosotros, lo que conversaban y todas esas cosas y se olvida toda esa historia y él se olvida[el difunto], y nosotros también.

* También. ¿Y de qué son los contras?

JC. Vienen de Bolivia.

* ¡Ah! Las compran allá.

JC. Las compramos. Vienen de Bolivia.

* ¿YY por qué son tres contras?

JC. Son tres contras, porque la "contra blanca", eso significa para la tierra que es, o para el alma que va eso. Y la "contra amarilla" es como "pago" [ofrenda] que uno hace. Es tal como se hace el linki, el qhore linki, entonces, ese que llaman el Pago, como plata, como oro que le llaman. Y el negro es el duelo pues.

* iY entonces, el qhorelinki es de metal?

JC. No. Ese es el otro. Yo estoy comparando con ese. Se hace igual, pero ese es otro. La contra no. La "contra" es pues, las dos iguales.

* ¿No son de plantitas?

JC. Posiblemente que sean de planta porque tienen hoyito en el medio. Ellos le traen para acá. Nosotros no lo conocemos así.

*. ¿Como semillas son?

JC. Como semillas, claro. De esos colores, blanco y amarillo y negro.

* Y paja sikuya, ¿no usan?

JC. Esa la paja sikuya, eso no lo dije. Esa es la paja sikuya siempre, pero aquí no le llaman sikuya. * ¿Cómo le llaman?

JC. Paja no más. Paja, por ejemplo, la paja que come la viscacha, los conejos, la paja viscachera le llaman. Más que nada la gente la conoce por paja viscachera, pero se llama la paja sikuya. Antes le decían sikuya.

* Porque la tolilla. ¿Es esa que en otras partes llaman tola del alma o almatola?

JC. Es el mismo. Tola del alma, almatola es igual. Almatola están diciendo en quichua, ¿no? Porque la quichua siempre pronuncia el castella- no que usamos nosotros de atrás para adelante, una cosa así. Por ejemplo, no dicen Tola de Alma. Almatola dicen y es lo mismo.

* Volviendo a la "limpia", después, ¿no se ponen acá, un tiempo esas plantitas en el pecho y no solamente en el pie izquierdo?

JC. No, si esa plantita tiene que tenerla uno, entonces uno se limpia, se limpia todo, todo, todo lo que uno quiera, todo depende de su fe de cada uno. Nosotros nos hacemos cariño, nos encariñamos. Entonces eso que salga, todo lo que ha participado conmigo, por eso uno se saca todo [del difunto]. Esa es la gente mayor. La gente mayor, por ejemplo, ellos creen más, mientras que la juventud, ellos le hacen por acá, por allá y listo. Porque ellos no lo saben y no buscan todavía el significado, mientras que nosotros, ya más. Decimos por ejemplo: Yo tengo mi amigo, mi familiar o mi madre, yo me limpio bastante con ellos para que se salga todo, se olvide de mí[el difunto] y yo me olvide de ellos, así.

* Y la sicha ¿es de brea o de otra planta o de cualquiera para ese pago?

JC. Denante lo dije mal. La sicha es después.

* A ver. Después del pie izquierdo donde está el guanito del ratón amo, ¿verdad? Y el atadito que es para "limpiar" el cuerpo, para limpiarse uno entero hecho con la paja sikuya y la almatola y las plumas de parina, chuko, y se amarra todo con un hilito que está trenzado... .

JC. O está torcido y que se llama lloqhe. Le llamaban anteriormente aquí, la palabra lloqhe, es dos colores.

* Y va torcido a la izquierda... .

JC. Va todo a la izquierda.

* Todo porque es para el alma.

JC. Alma. Sí, toda el alma

* Entonces hasta ahí. ¿Después la sicha?

JC. Sí. Al final la sicha. Sean las finales después para ya cuando se deja todo, eso es para dejar chuya que le llaman. Después que han limpiado todo, entonces se deja chuya.

* Y esa chuya es cuando está todo limpio entonces.

JC. Todo está listo, todo eso. Sobre todo para dejar la ropa guardándole [del difunto] para el próximo año ${ }^{24}$, ahí se deja con eso ya, chuyando.

Parte del ciclo de ceremonias y ritos asociados a la muerte en el área centro sur andina. Se realiza siempre transcurrido exactamente un año de la defunción (Aldunate, Berenguer \& Castro, 1982). 
¿Y se chuya con la harinita de sicha?

JC. La blanca primero. Primero la blanca y después la sicha [chuya de sicha]. Anq'añoq'a se llama la sicha. Es palabra quichua.

* Entonces, la palabra sicha ¿no sería quichua?

JC. La palabra sicha no es quechua. Anq'añoq'a es la quichua. La sicha yo creo que es más bien castellano o cunsa, sería sicha.

* Ankañoka parece que escuchamos en el norte también, a los aymara.

JC. Por qué Anq'añoq'a. Hay veces que la palabra aymara juntan casi igual, iguales. Algunas, no todas.

\section{* ¿La pronunciación, es Anqhañoka?}

JC. Anq'añoq'a.

* Oye don Julián: ¿Y la sicha para esa ceremonia de difuntos tiene que ser una ankañoka de cualquier planta o de una planta en especial?

JC. Mira, en esto se usa más que nada la chilka o de la brea, porque la chulla es eso, para hacer todo lo bueno que hay que hacer. Por ejemplo, para el ganado, para la salud; para eso se usa de monte, de tola, eso casi no hay allá en Qaulor, en Qhoyer, porque tantos años que no ha llovido. Entonces se trae más que nada de Bolivia. Le traíamos nosotros. Le compramos eso. Algunos que sabimos bien, la gente joven no saben, entonces usan lo de aquí; porque de cualquier parte lo usan igual. Nosotros no, los antiguos ya sabemos que no. Sobre todo mi señora. Conoce bien, pero ella no te va a decir esto.

* No pues. Como hay varias plantitas que hacen sicha, la idea era saber si para limpiarse del difunto, la sicha era de una planta especial.

JC. Claro pues. La brea y la chilka sí son para eso. De allá del monte, también, produce el monte el loire que decimos nosotros, la planta. Ese también produce sicha. También produce la Tikára pero no lo usamos para esto. La tika, ¿qué es la tika?

* ¿La flor?

JC. Claro, la flor.

* Oye Don Julián, y después, cuando vas a guardar la ropa, porque en algunas partes la queman la ropa otras cosas del difunto, pero cuando se hace el "cabo de año" ¿ahí sacan la ropa del lugar donde se guardó después de chuyarla, o como lo hacen?
JC. Sí. Eso siempre le tienen manteniendo durante el año, sobre todo los dolientes, de acuerdo a la promesa que tengan ellos. Porque el duelo es una promesa durante el año. ¿No es cierto? Se comprometen ellos a acompañarlo, entonces es una promesa de ellos y de acuerdo a esa promesa que ellos tienen, durante el año en la casa que tienen encerrada [las pertenencias del difunto], mensualmente o semanalmente le prenden velas.

* Y la koa, ¿la usan en esa ocasión?

JC. La koa es más importante para otras cosas, más bien para todo, para el bien, para la salud. Más bien el incienso.

* ¿ ¿Y el incienso es de la resina de la yareta?

JC. El incienso no lo sé de qué es, porque también viene de Bolivia. Sí. Eso anteriormente lo usaban aquí y nosotros seguimos esa costumbre, esa tradición.

* La koa entonces es para la vida.

JC. Eso. Para la pacha, para los lugares, para todo eso.

* Para pagar todo bienestar.

JC. Todo eso sí y no para difuntos, que de alguna manera lo supiera yo.

* Y en todo esto, ¿hay alguna palabra que usted considere que es kunsa? Porque estos nombres que ha dicho son quechua ¿no? Y algunos aymara. ¿No se usa alguno que a usted le parece que es kunsa, que pudiera ser kunsa?

JC. K'itira ${ }^{25}$, Pitirar sale en cunsa, o sea en aymara o quichua. Tirar, Tira, ese tal vez. Eso yo no sé, pero es que a lo mejor no me doy cuenta. Pitira, porque eso no hemos terminado. Cuando hablábamos de cuando uno se limpia con el almatola y el amarro ese, entonces después de eso también va la Pitara que se hace. La Pitira significa hilos, hilados, a la izquierda y derecha. Entonces ese es el lloqhe, en el que se pone blanco y negro. Y después, esto da puro blanco. Eso es hilado. Todo a la derecha. No. A la izquierda.

* Enteramente a la izquierda.

JC. Entonces, después usted, le vas a juntar. No se te enrolla. No se te enrolla, está aparte. Siem-

La palabra original pudo ser Iterar, y de ahí transformarse en pitirar, o k'itirar. En castellano, "Iterar" es "Repetir" (RAE, 1992, II: 1193), lo que puede tener sentido con la reiteración de este acto ritual. 
pre está aparte, no se te enrolla. Entonces, y ese es el significado con eso, $k^{\prime}$ itirar, es decir que te va a hacer la Pitira, que limpie todo lo malo que ha quedado, su pensamiento, sus palabras[del difunto], que ha quedado en las personas que hemos hablado con el difunto. Eso, eso es la Pitira [o k'itira].

\section{* ¿Porque corta?}

JC. Corta. Corta arriba, corta en el cuerpo, corta abajo en todas partes la corta. Una vez que termine de Pitirar,[o K'itirar] da la vuelta el puñado del hilo, entonces ahí hay que escupir con la "contra”. Entonces eso, significa que salió todo.

\section{* Ahí estás "limpio".}

JC. Con eso queda limpio y más de eso, a las finales como te digo ya le hacen la chuya, pa' dejarle en chuya sus cosas.

* Toda su ropa, todo lo que fue de la persona. Y ahí cierran la pieza y ahí en la chuya sí, es que está con la harinita de sicha blanca ...

JC. No. De sicha no más. La harina blanca es de sicha, no sicha blanca. Es harina blanca de maíz, ese sé primero. Primero eso y enseguida la chuya. * ¿ ¿Y para "el cabo de año", usan alguna planta?

JC. No, casi ya no se usa ninguna. No se usa de eso nada ya. Nada más que todo se hace el velatorio, ya está listo todo eso. Y lo que sí hacen los waki $^{26}$. Siempre. Se hacen los wake para poder despacharle todo lo que había. Ya con eso despachan todo eso. Entonces se sacan el duelo para quemarlo todo eso. Entonces va el waquecito. El wake, el significado que tiene es las juntas de las comidas que uno participa a ellos. Ese es una y la otra parte del harina blanca con la quinoa que a eso se comparte a los abuelos a la derecha y a la izquierda a las almas.

* Claro. Las almas serían las más nuevas.

JC. Claro.

* ¿Y los abuelos, los antepasados?

JC. Los más antepasados sí. Porque ellos fueron los primeros que llegaron por aquí, que tuvieron que ellos empezar aquí el cultivo. Entonces por eso hay que cuidarse de ellos también. Y eso lo hacen con la quínoa[los rituales]. ofrenda ("pago") y agradece a las divinidades, a las almas y a las "antigüedades" (abuelos, anteabuelos y rey Inka). La palabra en aymara significa "Parte, porción, precio" (Bertonio, II: 148; Castro et al. 1994: 107).
* ¿Con quinoa rosada y blanca?

JC. Cualquiera de las quínoas. Que sea quínoa. La cosa es que sea quínoa.

* ¿ ¿Y en chuyeros de barrito o en koberos? ${ }^{27}$

JC. En chuyeros no más. Algunas veces otros lo hacen. Porque ahora ya, los cantaritos ya no están existiendo, porque no hay la fabricación como en Toconce, tú sabes. Sí están ahí, todavía lo están fabricando pero es muy sencillo, pero, como te diré, anteriormente eran firmes, ahora los hacen muy débil [de greda].

* $\quad$ No está el abuelo Nato[Natividad Berna Ansa, alfarero de Toconce].

JC. No está. Y el mismo los está[ba] haciendo mal ya. En sus tiempos, cuando era joven hacía bien, después ya más "fulero" como podríamos decir. Bueno, disculpa, como es para negocio. Lindo, bonito están todo eso, pero es lamentable que en duración no, no tiene. Por eso yo prefiero, le estoy encargando a la Leo que me hiciera conseguida del sur, jarritos así chiquitos, cantaritos así para el wake, que salen firmes. Yo me encontré en Valparaíso, en una feria [de artesanos], no recuerdo, el ' 87 fue. Un amigo de la feria, entre feriantes, convidaba un jarrito así chiquitito. Y el dijo: "No, si este es firme, ¡miren!" Le tiró y no se quebró. De esos tarros de dos litros, de dos kilos, de eso están usando ahora.

* Ya. Pero, ¿ igual es con las dos harinitas? JC. Igual con las harinitas.

* Y también para "Todos Santos", cuando se pone mucha comida para las almas y están usando los claveles para saludar a la mesa de difuntos. $¿ \mathrm{O}$ usan cualquier otra flor?

JC. ¿Para el agua bendita dice usted?

* Sí.

JC. Mira, cualquier otra flor, pero que sea florcita. Algunas veces podría ser de árbol la ramita también. Que haiga con qué poner la agüita. Eso es importante. Eso solamente para eso. Pero

Se trata de vasijas hechas tradicionalmente de greda, ambas de uso exclusivamente ceremonial. El kobero tiene dos asas horizontales y se usa particularmente para sahumerio, con incienso y koa Santiago (Fabiana bryoides). El chuyero, es un jarro con un asa lateral (Varela 1992). En el contexto de "cabo de año" en Toconce, se dispone en la mesa ritual, un chuyero a la izquierda que representa al difunto y otro a la derecha del oficiante, que simboliza las almas. Sirven de recipiente para contener vino, harinas de maíz y quínoa y hojas de coca. 
los antiguos siempre usaban la florcita y no se entendía el significado. Pero no pues, en cambio se está comprendiendo bastante eso ahora y trata de buscar eso que la flor es la vida y entonces, qué haya entre la vida y la muerte.

* Tú sabes. Yo pensé que quizá los colores de las flores eran importantes y había visto que a los "angelitos", a los guagüitos, a muchos chicos difuntos lo hacían con el clavel. Ahora sé que lo importante aquí es que haya una ramita fresca entonces.

JC. Fresca, claro. Lo importante es que haya con qué compartir la agüita. Eso es importante en cuanto a la $\mathrm{cruz}^{28}$. Sí. A la crucita[crucecita] sí. Eso cambia. Tiene que ser. Para el adulto es negro y para el "angelito" ya puede ser blanquito o rojito. Así lo hace, o sea, rosadito. Más que, la gente más lo hacen blanco, blanquito. Sí.

* Blanco. También he visto que hacen el arco con hojas verdes, el arco donde se ponen las escaleras, los pancitos, todo eso ${ }^{29}$.

JC. Sí. Eso usan mucho aquí en Caspana, del árbol, árbol.

\section{* ¿Y fruta?}

JC. También. Eso más que nada para el adorno, porque tenga el adorno. Sobre todo aquí en Caspana la gente que, por ejemplo, yo tengo mis plantas, plantaciones, y por qué no me pueden poner un arco de mis plantas[diría el difunto]. Eso he pensado siempre, la gente conoce aquí.

* Y para todos Santos, ¿también se usan las harinitas para las almas y para los anteabuelos y los abuelos?

JC. Se usan para las almas nuevas de hasta tres años. Después ya no.

* ¿Pero si hay waki después, en los años siguientes?

En los ciclos de ceremonias vinculadas con la muerte, el primer acto de saludo al ingresar a la pieza en donde yace el difunto, o el bulto que lo representa en las ceremonias posteriores, y para noviembre ("Todos Santos"), es dirigirse a su altar, mojar la flor o rama fresca en el agua bendita y hacer la cruz asperjando al bulto y su mesa. Solo después de este acto se saluda a los presentes y se pasa a tomar asiento (Castro V. MS., 1991).

29 En estos ciclos, la mesa de difuntos también está compuesta por un arco de ramas de árbol, adornada con flores y frutos. Delante de ella, en una especie de altar, y asociado a una escalera también de masa, se
JC. De la comida no más. Sólo de la comida. Siempre hay, siempre tiene que haber. Un caso. Que yo tengo mi mesa en ofrenda, mesa ofrendada, no tengo visita ${ }^{30}$, pero entonces[igual]yo estoy[he] dispuesto todo. Entonces tengo que compartirlo y ponerle apartito para ellos. Aparte de eso, de que le puse aparte las comidas, las golosinas, todo que le he puesto aparte, que he puesto para la visita, de ahí tengo que sacarle y juntarle y eso lo voy a quemar ${ }^{31}$. Y así lo hace la gente aquí, pero cuando va la visita no. Ahí uno lo entrega a ellos, ellos comparten con sus manos ahí. Si no dan, entonces nosotros nos encargamos de compartirlo. Y cuando va la visita no pues, nosotros lo convidamos a ellos.

* ¿ ¿Y porqué tú Don Julián decías del loire, "cuando se hacen floramentos se mueven las chuyas solamente con loire"?

JC. Claro. Que es la leña, el monte, entonces la sicha es para el ganado también, por ejemplo, cuando ése produce[para que se reproduzca el ganado].

* ¿Ahí es cuando usan esa sicha de la léjia o loire?

JC. Esa. O también de la tola amarilla. Si esa hay en Q'aulor, en Ch'ita, en Qhoiyer. ¿Ahí te salió la cunsa?

* A ver. ¿Cómo son esas palabras?

JC. Ch'ita, K'aulor y Qhoyer.

* Chita, Kablor y K'oller.

JC. Ahí no lo sé qué significado tienen.

* Oye ¿y el monte chana es lo mismo que la chana, o no? Son dos plantas distintas.

JC. La ch'ana es igual que ésta, están diciendo chana ustedes, pero es ch'ana el nombre. El nombre verdadero es ch'ana, ch'anal, no chana, ahí cambea. Yo digo. Igual que quito dice ahora la gente. Qhitu es el nombre. Qhitu es en kunsa, no sé como dicen ¿sabe usted?

disponen panes dulces hechos especialmente para la ocasión. Panes redondos grandes llevan las iniciales en negro de el o los fallecidos. Otros son miniaturas con formas de animales preferentemente (Mercado et al., 1997; Miranda, 1998).

30 Es fundamental tener abundancia de comida y bebida. La gente del pueblo, de las comunidades vecinas $\mathrm{y}$, eventualmente, forasteros van de visita casa por casa durante estas ceremonias.

31 Uno de los ritos fundamentales en estas ceremonias es la quema ritual. Una buena combustión de los elementos de la ofrenda, asegura que las almas recibirán estos alimentos. 
Eso tenemos que investigar nosotros.

JC. Qhitu nosotros ya hemos encontrado de acuerdo de lo que dice, Qhitu, la parte más superior, más alta, y aquí nosotros tenemos donde viene el agua más alta del canal, ese se llama Qhitu * ¡Ah! entonces, en Toconce también hay un Quitu y en San Pedro también.

JC. Claro, porque es más alta, más arriba que todos los demás.

* $\quad$ Parece que eso fuera quechua.

JC. No, eso no, kunsa.

* ¿ ¿Y dónde aquí, o sea por dónde estaría Quitu acá, bueno, tú sabes que yo no sé pronunciar ¿dónde estaría?

JC. Caspana ¿no es cierto? Qhitu está por aquí pu. En este alto, pongámosle que este sea el canal de arriba. Aquí viene otro canal matriz y pongámosle que por ahí que viene, sale otro canalcito, ahí está Qhitu. Ese va por ahí atrás al Plan tunícula, todo eso es Qhitu, ese canal. Ese es el canal matriz que viene por aquí y ahí viene la siembra, todo esto. Ahí está Qhitu. Por eso es que pure es el agua en kunsa ¿no es cierto?

* Puri.

JC. Entonces allá dicen Purefican, fikan es helao en kunsa. En quichua no sé.

\section{* ¿Y Puritama?}

JC. Tama. Tama, es caliente. Por eso en Puritama el agua es caliente. Tama, ese tama es caliente. Puri es agua. Tama es caliente.

* Lo contrario de Purifica.

JC. Contrario es igual. Entonces es helao y ahí...[caliente]

* Purifikan.

JC. Purifik'an, fik'an.

* Fiq'an, eso sería helado.

JC. Helado. Frío. Así.

* Puritama, agua caliente.

JC. Puritama es agua caliente, tama es caliente.

* Porque helado en quechua es chiri.

JC. Chiri sí, se me olvidan las palabras.

* Y bonito es.

JC. Parece que es diferente la idioma. Ya. ¿Qué más te falta para terminar eso?

* Quería saber si ese monte chana es lo mismo que la ch'ana.

JC. Que la ch'ana, claro.

* Es la misma planta chana.

JC. Es la misma planta. Todo ese es espinoso, es crecido.
* ¿ ¿Y no lo usan acá para hacer herramientas o algo así?

JC. No, la ch'ana no, no se usa, solamente para el fuego más que nada, eso lo usan la ch'ana y algunas veces por ejemplo, pa' poner como ramas arriba de la estancia ahí lo necesitamos, lo usamos. Ch'ana, porque es larga, así, algunas son largas entonces, le ponemos ramas en la estancia. * Después, ya esto está listo. La qoba también ya sabemos que se usa para la vida, para la vida, para el Señor, para la Santa Tierra, todo eso. Después el motokoro...

JC. El motokoro bueno, es un producto que nadie lo usa para nada, solamente que anteriormente, lo usamos nosotros, porque no había aquí frutos. No había, por ejemplo, la pera, ni la manzana, ni la tuna. Entonces, ¿que hacíamos nosotros? Los niños, donde había eso cuando llovía, cavábamos y sacábamos unos botoncitos del suelo y comíamos, ¡ ese es dulce!

* Papa dulce.

JC. Claro, ese es todo lo que sé. Es bueno pa' comer.

* ¿ ¿Y es lo mismo que la papa de los abuelos? ¿O es otra la papa de los abuelos? Dicen que hay una papita que comían los antiguos, también chiquitita. ¿Es la misma planta?

JC. No, es otra. Debe ser eso que venía una papa, una papita blanca que nosotros todavía lo usamos eso. Ahora se desapareció acá, ya no hay. * ¿Y la muina, o algo así?

JC. La múina, el nombre es múina, ahora dicen muñamuña. Múina es el nombre, múina, entre paréntesis póngale muña.

* Como la muñamuña.

JC. Múina le decía la gente aquí. ¿Ese, lo sabís para qué es bueno eso?

* ¿Es medicinal? Pero no sé pa’ qué.

JC. Medicina, eso es bueno pa' el estómago, pa' el dolor de guatita, es pa' todas esas cuestiones nos hace bien a nosotros. Toma la gente. Igual el qhore, qhore ¿sabe ese usted qué es lo que es ese qhore?

* Qori eso es yerba, planta.

JC. Sí, pero q'ore ¿qué significado tendrá q'ore?

* ¿En quichua?

JC. En quichua debe ser pero yo no sé...

* Es planta.

JC. Planta no más, qhore. Que no sé... Igual que qhiri, eso dice gente anteriormente y no pues, 
la rika rika en castellano, el otro la candela le dicen al qhiri.

* Candela, debe ser caliente.

JC. Eso, eso, pero en ese caso en castellano. Qhiri y ahí nosotros, será en quichua, será en qhiri, será en aymara o será en kunsa, no sé, pero eso se decía qhiri, qhore, así eran los nombres, como tikara.

* $\quad$ Es que en este caso pueden ser palabras antiguas del quechua que ahora ya no, no las usan. Entonces por eso nosotros, después, tenemos que ver en los diccionarios antiguos y tratar de encontrar estas palabras.

JC. A lo menos está en kunsa.

* Si no parecen en ninguna parte, quiere decir que son del kunsa pues.

* Claro, y el estudio que estamos haciendo los tres ahora, esta conversación, justamente nos sirve para que nosotros busquemos la mayor cantidad de significados. Ya cuando esté escrito, venga el trabajo acá, ya. Qué sé yo, dirá, motokoro, es alimenticia y su nombre puede provenir de tal lengua, puede significar tal cosa y eso es lo que va a llegar.

* Y nosotros después tenemos que conversar otra vez para ver si pegan los significados que uno ha encontrado.

* Claro, porque puede ser que a uno le suene como que está muy bien, pero no es así, entonces hay que volver a revisar. Así es que la muina se usa solamente medicinal y no se usa para otros fines así como pa' los pagos, no. Después la virakocha.

JC. La viraqocha. Ese es el ñible, entre paréntesis póngale ñible, ñible dicen.

* Claro, en el sur le dicen ñilhue, también debe ser esa. Una como finita que tiene un tallito así, una florcita como que se sopla.

JC. Sí, algunos amarillos, otros blanquitos, esos son.

* Y esa plantita ¿se usa para té?

JC. No, para el resfrío no más, pa'l resfriado. Sobre todo para las guaguas se usaba antes eso, la gente le daba ese, cuando estaba resfriadito le daba el matecito.

* En matecito. O sea, esa planta no sustituye a ninguna planta, no se usa para nada más. Sólo medicinal.

JC. No, no, por lo menos yo lo conozco para eso.
* Ya, qué bueno, porque no sabía yo que era la misma. Bien, eso era mi parte que yo te quería consultar de lo que tenía escrito. Ya está más o menos clarito lo de los filos, lo de las aguadas que son distintas de las vegas. Después que las chacras, las chacras se llaman chacras y no terrazas y que hay una parte que se llama tablón, en la chacra misma.

JC. Tablón, tablones, la chacra. Ese tablón, el otro tablón, los dos tablones decimos si hay dos. Por ejemplo, el canal baja por el medio pero a un lado va regando este, y va regando este, entonces ese lo llamamos dos tablones en mi pedazo de terreno, en chacra mía, entonces eso [significa] que son dos lados, aunque no esté terminado, está la mitad, el otro lado está completo, entonces se dice, tablón.

* Y Peñaujero hay uno solo, un solo lugar.

JC. Ese es el único que nombra a veces, se oigo nombrar por acá, otro no.

* Ya. Eso quería saber de estas plantas. Teníamos una lista de antiguos nombres de plantas pero no sé pues si tienes tiempo, pero Gilberto, a lo mejor, te quiere preguntar algo más, o tú a él. * Bueno, ¿él quiere decir algo ¿no?

JC. Ah, bueno yo quería decir, en primer lugar pa' terminar, yo no tengo la seguridad que don Gilberto algún día vaya a tener los significados de los nombres de los terrenos, de los predios que se dice actualmente, pero antes se decía terreno. Ya te dije Soq'os, te dije Chol'sana y ahora te voy a decir este. Q'ilbar. Ahí tiene usted, Q'ilbar, lo otro, Toq'o.

* Toqo,

JC. No, Toqo no, Toq'o, ¿Ya? La otra es Khakharte

* Q'aq'arte.

JC. Khakharte.

* ¿ ¿Y ese de aquí ¿dónde está en el dibujo? No está.

JC. Están ahí dentro, todo eso están aquí dentro.

* ¡Ah!, porque son de las chacras.

JC. Claro, todo son de las chacras. Cada lugar tenía su nombre. Claro, tenía su nombre. Siloqhitor ya más o menos lo sé, Siloqhitu. Siloqhitu.

* ¿Y silo significa algo?

JC. Eso no sé. El qhito lo sé ya por lo menos.

* ¿Y nunca has escuchado que era, por ejemplo, Kolkaqito? 
JC. Qhitu como te decía, en kunsa es más alto. Silo ahí no sé. Yo digo así, como ti dice, el terreno, el canal más arriba, dice qhitu y más abajo usted, mira el otro, entonces algo que es más abajo o algo, entonces tiene que ser silo, no es qhitu también porque siempre está más arriba, un poco más arriba que el canal matriz, ya. Ahora el otro parte es S'ulte.

\section{* Sulte.}

JC. Sult'en, Sult'e. Sult'i o Sult'in algunos dicen Sult'in. Y ahora la gente dice Sulte no más.

\section{* Se comieron la N.}

JC. Claro, Sulte. Y ahora lo otro es Ch'uruta. Fik'an, ya estamos encontrando más.

\section{* Fik'an.}

JC. Lajte.

\section{* Ah! Lajten.}

JC. Lajtin. Tamto. Mm... Qhalqhay, qhalqay. Qhalqhay en quichua parece ser, qhalqhay conversemos, dialoguemos, algo así.

JC. Qhalqhay.

* Es que o bien son palabras antiguas, antiguas, que ya no se usan ahora...

JC. Yo le pregunté a uno que vino de Bolivia, me dijo que era conversar. Porque hay un lugar donde hacemos un descanso para la limpia del canal, entonces hay gente antigua que incentiva a la juventud de las costumbres, de la tradición que teníamos y que estos deben hacer eso. Eso es una conversa que tienen ahí con la juventud. Entonces eso se llama, todo eso se llama Qhalqhay.

* ¡Ah! mira, todo eso tiene que ver con significado pa' ustedes, bien definido; a ver, por ahí se puede sacar también.

JC. Entonces yo pregunté eso, entonces me dijeron que en quichua sale, es dialogar, conversar o dialogar, así una cosa así.

* Pero eso en quichua actualmente es rimakuy.

JC. ¿Conversar?

* Claro, entonces por eso, o es una palabra antigua que ya no se usa o bien, una palabra que se ha usado en estos lugares no más y que no quedó tampoco escrita ¿no?

JC. Eso, a lo mejor está en kunsa también.

* Puede ser.

JC. Ya, a ver, la otra, Qholaire, Qholaire.

* Qholaire, esto tiene cara de kunza porque tiene la misma terminación de Socaire.
* Socaire. Había un pato que se llamaba soko, también, pero me parece que en quichua...

* ¿Soqo?

JC. Qholaire parece que algo es sonido de agua, en kunsa, es sonido del agua, parece, no estoy seguro. Ustedes, lo van a ver.

* Eso hay que averiguar.

JC. Banerqhollo, Banerqhollo.

* Banerq'ollo.

JC. Banerqhollo. Ninas. Thono.

* Mira, sabe hartas palabras sueltas, Thono.

JC. Tamser.

* Tamser.

JC. Tamser. Otra es Puriqh'olay, Puriqholay. * Puriqholay.

JC. Eso sería en cuanto a los nombres de los terrenos, no tengo más y ahora tendría otras palabras de esto, de conocer los lugares, por ejemplo, khatu.

* Khato, khatu.

JC. Qhatu para nosotros debe estar en kunsa, no sé, pero para nosotros es un lugar que tiene que es roca abajo y es extendido así. Entonces decimos khatu, decía antes la gente. Ahí ese, khatu.

* O sea, es un lugar extendido pero que tiene una roca base.

JC. Tiene roca abajo. Entonces es Khatu. Chi'ltau, chi'ltau.

* Chi'ltao.

JC. Chi'ltau. Que ese era, para nosotros, era una cosa como atascada, una cosa así, una cosa que está bastante metida, una cosa metida en una cosa chica y le ajustaba pues, entonces se llama chi'ltao.

* Muy apretado, como una cuña.

JC. Muy apretado, igual que chikiu, chikiu, también igual.

* Es como metido a presión.

JC. Chilkiu es como a presión, el chialtao es así, en un hoyo que tenís, por ejemplo la olla, un jarro, tienen hoyito, entonces uno le pone un trapito, entonces ese se llama chiltar.

* ¡Ah!, es apretado.

JC. Con, ya sea con cualquiera otra cosa, con trapo, con lana con, entonces es chiltar. Ese debe estar en kunsa.

* Tiene cara.

JC. El ch'ikiu no pues, ese es, como le digo es metido, bien apretado ch'ikiu. Ch'ikiu.

* Y no chilquiu. 
JC. El ch'iltao es uno, el otro es chikiu. Me olvido sí, hay varias más pero me olvido. Qhayna * Qhaina.

JC. Qhayna.

* ¿Qué quiere decir eso más o menos?

JC. No sé pues, acerca de ese no sé. Ese no sé, estaría cerca de ese como el qhato, una cosa así. Qhayna. Por ahí puede ser, yo no sé cómo se pronuncia. Qhatu sí, lo sés2.

* Y por ejemplo cuando los antiguos leían el cielo, los nombres de lo que leían en el cielo.

JC. ¿Los nombres que habían en el cielo?

* Claro, como la estrella grande, el Lucero por ejemplo.

JC. Eso no. Usan leer las Cabrillas.

* Y lo usan en castellano.

JC. En castellano siempre.

* Nunca dijeron yacana por ejemplo.

JC. No, nada, a lo mejor los antiguos sabían hablar. Pero cuando yo conocí, solamente las estrellas, el Lucero, las Cabrillas, el Río, el Suri eso sí. El arco, eso siempre se hablaba eso, pero no en otro idioma.

* Claro, pero más conservaron nombres de lugares, para transitar.

JC. Claro, eso, porque es muy importante para poder distinguir de un lugar a otro, donde estaba yendo, dónde estaban las personas, a donde va ir, a dónde vamos a mandar nosotros. Ahora por ejemplo, la Viviana le dijimos que vaya a encontrarnos en Sulki, porque nosotros estamos en Sulki, entonces ella sabe más o menos donde venir y si no, dónde estaría yendo. Entonces pa' eso conservan los nombres de los lugares.

* Claro, es lo que más se conserva.

JC. Entonces, nosotros así ya sabíamos donde vamos a ir o nuestra madre sabía que nosotros donde fuimos, así. Igual que los caminos, los lugares, por ejemplo. Me voy a Qhoyer entonces yo sé que ellos saben que yo estoy yendo pa'llá a buscar los animales. Me voy a Ch'ita, me voy a Qaulor, entonces igual. Me voy pa' Sopaipilla, o pa' campo Khaner. Me voy ya ¿y qué parte? A Corral Alto, Mesón por ahí . Ya.

* Claro, eso era importante pa' conservar los nombres.

En esta parte de la conversación, le preguntamos nombres de las partes del cuerpo y como se dirían en alguna lengua nativa. Don Julián respondió que conocía estos nombres solo en castellano.
JC. Como quien dice, la comunicación. Comunicarnos en qué lugar estamos nosotros. Entonces ya. Por ejemplo, ellos no sabían nuestros lugares, si fue al campo y toca que hay una cosa de emergencia, como ahora último pasó, que falleció mi hermano y yo andaba por el Tatio, por este alto, por estos filos, por ahí andaba buscando los animales y no me encontraron pues. Entonces, nadie sabía en dónde estaba yo porque yo no había avisado porque yo me fui a Kaublor donde fui, en la vega esa noche. Al otro día salí, anduve por acá, estas partes y el compañero que había no conocía ese, entonces llegó se bajó, llegó a la estancia y yo buscaba a él pu', entonces él no sabía y él tampoco, y entonces, ¿yo dónde estaba? Como no conocía los lugares no podía decirme dónde me quedé yo pu'. La gente toda me tenían perdido, yo andaba perdido. Yo no, estaba ahí. Entonces, por eso nosotros, mi señora dijo, ella se fue a Tatio y después de Tatio se habrá bajado seguramente por el Cerro Negro o se había bajado por el cerro Huacho, se habrá ido pa'l Ojo Qaulor o bien se fue al lado de Qholyer, el Cerro Negro, por ahí entonces, ella sabe. Si ahora estaba ahí, entonces ella habría dicho que tal parte está, pero como el compañero no sabía, no conocía, no lo pudo decir dónde. Entonces, por estos lugares nosotros decimos tienen nombrao, ya para este lado es otra parte. Así se conoce. Por ejemplo la Qharqha.

* Qharqha.

JC. Claro, la Qharqha o el Filo Chico, que te decía yo, que es Khaner.

* $\quad$ El Filo Chico, me dijiste, este es un Filo Chico.

JC. Sí, entonces de ahí pa acá está la qharqha que son unas quebraditas chiquitas, angostitas así, unas quebraditas, quebraditas, entonces se llaman todos esos peñascos, qharqha, entonces ellos pueden decir esta palabra, se fue pa la qharqha pa'l lado de Talikuna, entonces por ahí tiene ese lado se fue al Loma Alto, tenemos también por ahí.

* Hay otros lugares que no has nombrado Don Julián, como por ejemplo nos has nombrado el Kurte.

JC. Khurte parece que no lo hemos anotado. Aquí esta Talikuna y Khurte, por aquí. Y dentra junto con este (curso de agua) y se van. Esta es una quebradita que viene, que así.

* Hay un Filito Chico, y viene el Qhurte. 
JC. Sí. De Las Puntas. De Las Puntas que van así para allá. Esas Puntas son. Puntas le llamamos. Entonces aquí está la meseta arriba y sale una quebradita, sale de ahí; esta es veguita también. ¡Bueno! Todo vega hasta encontrar el Caspana (Río). Después se encuentra con el Salado que viene de Toconce.

* ¿ ¿ Y qué otros nombres de los lugares que transitan te gustaría saber lo que significan?

JC. Te he estado nombrando. Ticara por ejemplo el camino que va a Tatio. Si se va por este lado, llega a Thono, de ahí después llegan a las Ojotas, de ahí llegan al Filo Chico, de ahí al Filo Alto y de ahí llegan al Tatio. Igual para ir a Ch'ita, trastomamos el Alto y de ahí llegamos a Corral Alto, o llegamos a Mesón, allí estamos cerca ya. Y con eso ya llegamos a Chita altiro. Igual para ir para Qhaublor, primero llegamos a Corral Largo, quebrada Mulurujte, de ahí a quebrada de Ayserthume y ya estamos sí en Qaulor ya. Para ir a Qhoyer, yendo por Ch'ita llegamos a Corral Alto, de ahí a Ch'ita, salimos de Ch'ita al Alto y ya estamos en Qhoyer ya.

* Todos los nombre conocidos por ustedes. Propios.

JC. Claro. Igual para ir a todas partes sabemos nombrar. Lo mismo cuando vamos a Toconce. De Khurte llegamos a Pila. De Pila llegamos a Chaparqholo y por último de ahí sales y llegamos al Salado y ahí estamos ya en el territorio de Toconce, estamos llegando. Punta Negra, llegamos a la quebrada de Khatos. Ya lo sabe la Victoria.

* ¿ ¿Y usted sabe qué quieren decir los nombres de Caspana y Toconce?

JC. Ckaspana por ejemplo, han dicho que es un lugar hondonado . O "hijos de la hondonada". De esos dos tengo conocimiento.

* ¿Pero tiene sentido? ¿Habrá sido así?

JC. Yo creo porque estamos en la quebrada. Puede ser que sea eso. Porque en otras partes le han puesto también Qhaspana y yo no estoy de

Don Julián está bien informado al respecto. El vocablo Ckaspana, en kunsa, significa "hijo de la hondanada" (Vaisse et al. Op. cit: 17). Capana en aymara se traduce como "enclaves dispersos a lo largo de vertientes" (Saignes 1986: 9), lo que también tiene sentido en virtud del antiguo patrón estanciero de la localidad (Castro, 1997). acuerdo con eso. Qhaspana no sé que será3 ${ }^{33}$. Vicky ¿tú me contaste de los Colamares?

* Te conté que ya había Colamares en Caspana en el siglo XVII; ya existía Caspana como pueblo y en Cobija, que quedaba en la costa de Antofagasta, también había Colamares. Y subían. Había Colamares aquí y allá en Cobija, pero parece que era la gente de acá que bajaba desde aquí al Puerto de La Mar.

JC. Ya. ¿Me das un papelito? Voy a anotar. ¡Eso! Esos. Igual para ellos. Pa' Río Grande, pasar por todas esas partes, Ch'ita, Qhoyer ya con eso estaban pasando, el Purifican, ya estamos llegando pa'l lado de Río Grande, territorio de Río Grande. Ellos igual nos conocen, para venirse por tal parte. Escríbemelo tú. Así es pues. Y esto, me gustaría preguntar. Y las finalidades de esto que estamos hablando. ¿Qué va a pasar más adelante? ¿Qué fin tiene?

* Esto es puro conocimiento. Queremos escribir sobre el conocimiento del paisaje de los caspaneños y el uso de las plantas por los caspaneños y escribirlo así para devolverlo a la comunidad y además para que se sepa que existe una ciencia indígena, que es tan valiosa como la ciencia universitaria. Entonces por ejemplo, va a venir escrito la planta, el motoqoro. Va a venir su nombre científico acá, que los botánicos le dan un nombre universal que es Hoffmansegia eromophilla, que es complicado para los que no somos botánicos, pero uno aprende. Al lado va a decir el nombre mutuquro, que la llaman acá, su uso y qué dicen los caspaneños sobre esta planta. Después por ejemplo, la muina y cuál es su nombre científico, Satureja parvifolia y después su uso por la gente de Caspana.

JC. Ya. Ahora el retrato del mutuquru, como tiene que ir, como lo conocen ustedes el retrato.

* Hay fotos. Pero eso también depende de la plata que haya. Porque si hay plata y hacer un librito y poner las fotos en color, se hace así. Y si no, no se podría hacer con fotos.

JC. Pero Vicky, poner en blanco el dibujo de la planta por lo menos. Si no, como lo van a conocer.

* Tienes razón. Hay que intentar el dibujo. A lo mejor, al principio es sin mucha foto ni dibujo para que no se demore tanto en salir como publicación. Y después lo hace con dibujo y foto. Ya puede demostrar que hay un conocimiento valio- 
so y mostrarlo a interesados con la idea de un librito con fotos a color y dibujos. Me gustaría mucho; sería lo más lindo, para que aprendan los niños. Se necesita dedicación de nosotros y luego conseguir platas para la imprenta que es muy caro en color. Pero hay que partir de algún modo, ir paso a paso. Primero es escribir y publicar, para conservar este conocimiento. Después ir a conversar para obtener recursos, contando lo importante que sería para los niños del pueblo tener este librito; conseguir para que lo puedan tener todas las familias de la comunidad. Como el libro que hice para Toconce y Ayquina. La idea es partir primero con una publicación y después ver cómo se puede alcanzar la otra meta.

JC. Lo otro que te quería preguntar, de esa otra plantita que tú conoces.

* Le decían Jatamasa, hace una papita que se come.

JC. Yo te voy a dibujar una que se come su papita. Otra palabra es $Q$ 'ome. No sé qué significado tiene, pero $Q$ 'ome le decimos nosotros a esa planta espinuda. Quisco le dicen otros. Q'ome nosotros. Pero no sé en qué idioma será. Atalte $?^{34}$

¿Y has escuchado alguna vez la palabra

JC. Atalte. Alabalte ${ }^{35}$ decimos. Que es bienvenido en cunsa. ¡Bienvenido, bienvenidos! Decían antes los veteranos, alabados, en la Limpia del Canal.

* ¿ ¿ Y has escuchado la palabra Básal?

JC. Básal sí. Es un monte Básal. Con flores guindas. Ese es Básal. Y una palabra quechua que se usa aquí para decir sapo es Jamp'atu.

\section{* ¿Y Chápir?}

JC. Cháper. Anda cerca de Ch'aparqholo, ahí debe juntarse una palabra más. Otra palabra es chaba. Cuando algo no está cocido, por ejemplo, el haba o la papa cuando la echamos a la cazuela, nosotros decimos chaba.

* Así te acordaste de otra palabra.

En este momento, consultamos a Don Julián sobre su conocimiento sobre varios nombres de plantas registradas en el Salar de Atacama, como: kabra mikuna, káfle, kámen, kauchal, chókel, entre otras. En todos los casos respondió no conocerlas, salvo las que él asocia aquí.
JC. Sí . Me estoy acordando de otra palabra más. Y también t’oqo, para nosotros corto de vista, no ve bien. Así decimos T'oqo. En Ayquina sabían decir mucho eso. Por cualquier cosa como broma o como reto así, le decían T'oqo (se ríe Don Julián con este recuerdo). K'intairi, yo no sé, eso será en Cunsa, $K$ 'intaire, yo no sé. Tal como estoy yo, todo despedazado, sin dientes, le decía $K$ 'intaire. Yo estoy $K$ 'intaire decía la gente cuando estaba así. Yo no sé en qué idioma será K'intaire.

\section{* ¿Y likia?}

JC. No, lliclla. ¿Qué significará esta palabra? * Bueno, es algo parecido al aguayo.

JC. No es igual. El aguayo es moderno, tejido a máquina. La lliclla, no pues. Es antigua.

* Sí, la de los abuelos hecha a telar.

JC. El jiru, decían a la paja brava. Y K'aspau, decíamos. Significaba algo chamuscado, que estaba medio quemado. Khincha. Debe estar en quechua. Por ejemplo, que yo en este momento esté aquí o llegue algún pajarito aquí y que tenga mal espíritu. Que llegue este pajarito y me avise diciendo de que "este día va a estar mal para Ud", que vas a saber una noticia mala o cosa así. Entonces este pajarito, es khincha que está llegando aquí. Así también se decía al burro, al llamo. Cuando bufa el burro, viéndole a uno también es k'incha, porque seguramente anda otro espíritu en Quincha. Pues eso decían. K'incha. A nosotros también, a las personas. Si alguno hablaba una cosa así, entonces uno decía, es K'incha.

* Entonces es casi de mal agüero.

JC. Claro. Es como cuando el pajarito viene. Yo siempre uso esas palabras quechua. Un día allá en la iglesia había entrado un pájaro. Entonces dije: "¿De dónde salió este K’incha?, dije”. Entonces la Nelly (su hija) me dijo: “¿Por qué le dices así?” Y yo le explico. Y ella sabe.

* Pero entonces, en el caso del Quincha, ¿también puede ser una persona, un pajarito, el llamo, el burro?

JC. O el perro.

* El perro.

JC. El perro sí. Porque llora toda la noche o cava el perro afuera de la casa. Entonces nosotros sabemos que un amigo, un familiar, falleció. Entonces decimos: “Ahí está el $K^{\prime}$ incha, pasando ya. K'incha o brujo, asî". Pero es el mismo.

* $\quad$ Es el mismo. 
JC. Es el mismo el significado que sacamos nosotros. Otra palabra que recuerdo es qhausulor. Y qhaiba, me acuerdo ese nombre del monte.

* ¿Es una pajita?

JC. Sí. Es una pajita.

* ¿Es como el esporal?

JC. Claro. El animal lo come, pero en la siembra hay que sacarle. T'akni también. Los antiguos decían. Y para nosotros igual, le decíamos a la compuerta del agua del canal.

* Te has ido acordando. ¿Has escuchado los nombres de Séber, Sitor o Suntur $?^{36}$

JC. No. Tampoco. K'iruna sí.

* Hay un lugar con ese nombre, una quebrada Kiruna. ¿Y tenía significado para ti?

JC. No. El lugar no más, pero no el significado. Y Khaner, tampoco sé qué significará. Khaner, Qhulmor... Ya lo tienes anotado. T'uri también. Allá pa'l lado de Río Grande hay T'urikapu.. Aquí no. T'uri no más.

* ¿Y Keltur?

JC. No.

* ¿Kelekelte?

JC. Tampoco.

* Y Béter?

JC. Un lugar en San Pedro de Atacama.

* ¿Y Capchaka?

JC. No. Ch'akach'aka sí. Otros le dicen el "Mata ratón". Tiene espinitas chicas, entonces se pegan y hay que sacarles.

* ¿cómo las de la tuna?

JC. Claro, casi como las de la tuna, pero es como que agarra. La tuna no pues; te clava. La otra no. Agarra. Es buena para la vejiga, para el mal de orines.

* Don Julián ¿por qué hay tantas palabras que terminan en "or", como Sequitor y Solcor?

JC. Yo no lo sé. Las usamos y deben tener un significado preciso. Otra palabra: "antes la gente le decía al chingol [chincol], chulludo, puede ser por su sombrerito. Por el Chullu, todo lo que se ponían en la cabeza.

* Por el Chullu [gorro] de lana.

JC. Claro, por el chullu que se ponía la gente en la cabeza; entonces al pajarito le decían chulludo. Gente. Igual que el otro el que que canta, ch'oto. Y a la hormiga le decían Ch'inkhabre. Ch'inkhabre. Una hormiga bien grande, café o negrita. Negra. La gente le dice Ch'inkhabre

* $\quad$ Ese es un nombre bien novedoso.

JC. Otros le decían también a las personas, como apodo así, Ch'anka. No sé qué significaría. Ya está pues. Así ustedes trabajan con estos nombres para que no se pierdan. Para que vaya saliendo lo mismo en todas partes y no se vaya cambiando.

* Sí. Está muy bueno todo lo que nos has enseñado. Y al perro, ¿siempre le dijeron perro, no más?

JC. Aquí sí. En Toconce lo conocen por allqo. Quechua también.

* ¿Y Kéber, has escuchado esa palabra?

JC. En el canto sale esa palabra, qhéber. Es importante que no se pierda la pronunciación. Ya. Yo me voy. Muchas gracias, perdonen.

* Ya. Muchas gracias y perdona tú.

$$
* * * * * *
$$

En abril de 1998 viajamos desde San Pedro de Atacama a Caspana, un viernes 4 a mediodía, y trabajamos con Don Julián esa tarde, todo el sábado y el domingo, en la tarde, hasta la noche. Nos despedimos el lunes en la mañana. Ninguno de nosotros, ni tanta otra gente que lo conocía y apreciaba, pudo pensar en que no lo volveríamos a ver a la vuelta del año. Incluso antes, en nuestro caso. Lo habíamos invitado oficialmente al Taller de Ciencia Indígena, que realizamos en enero de 1999, para que participara y en donde le entregaríamos un video, que incluía parte de sus enseñanzas, dibujando el paisaje de Caspana. Don Julián era un maestro. Quería enseñar y quería siempre aprender cosas nuevas. Falleció entre la Navidad y el Año Nuevo, en diciembre de 1998. De algún modo, algo de sus palabras y sentires están presentes en este trabajo.

Abril 1999. 